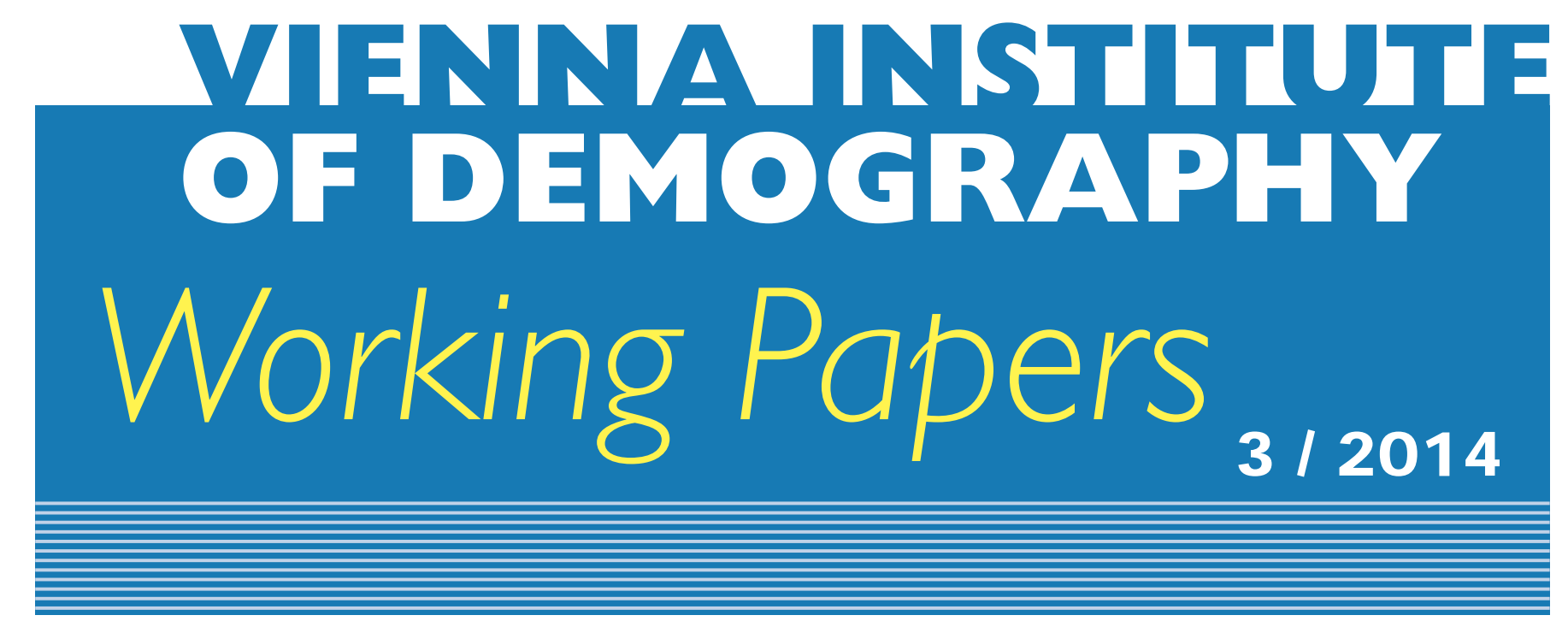

Tomáš Sobotka and Éva Beaujouan

\title{
Two is Best? The Persistence of a Two-child Family Ideal in Europe
}

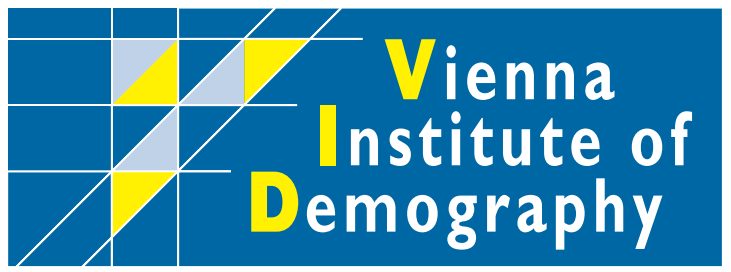

Vienna Institute of Demography Austrian Academy of Sciences

Wohllebengasse I 2-14 A-1040 Vienna $\cdot$ Austria

E-Mail:vid@oeaw.ac.at

Website: www.oeaw.ac.at/vid

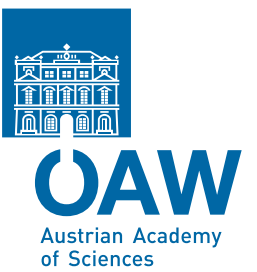

of Sciences 


\begin{abstract}
How persistent and universal has the two child family ideal been in Europe during the last three decades? We analyse responses of women of reproductive age from 168 surveys conducted in 37 countries in 1979-2012. A two-child ideal has become nearly universal among women in all parts of Europe. Countries that used to display higher ideal family size have converged over time towards a two-child model. Six out of ten women in Europe consider two children as ideal and this proportion is very similar in different regions. The mean ideal family size has become relatively closely clustered around 2.2 in most countries. Gradual shifts can be documented towards more women expressing an ideal of having one child (and, quite rarely, having no children) and a parallel decline in an ideal of three or more children. An increasing number of European countries saw their mean ideal family size falling to relatively low level around 1.952.15. But with an exception of one survey for eastern Germany and a few additional surveys not included in our study due to high nonresponse, none of the analysed surveys suggests a decline of mean ideal family size to levels considerably below replacement, i.e., below 1.9 children per woman. Data for countries outside Europe suggest a global spread of two-child preferences, also in many countries where the fertility transition is still in progress.
\end{abstract}

\title{
Keywords
}

Fertility ideals, ideal family size, fertility preferences, below-replacement fertility, Europe.

\section{Authors}

Tomáš Sobotka, Wittgenstein Centre for Demography and Global Human Capital (IIASA, VID/ÖAW, WU), Vienna Institute of Demography/Austrian Academy of Sciences. Email: tomas.sobotka@,oeaw.ac.at

Éva Beaujouan, Wittgenstein Centre for Demography and Global Human Capital (IIASA, VID/ÖAW, WU), Vienna Institute of Demography/Austrian Academy of Sciences. Email: eva.beaujouan@,oeaw.ac.at

\section{Acknowledgements}

This research was funded by the European Research Council under the European Union's Seventh Framework Programme (FP7/2007-2013) / ERC Grant agreement $n^{\circ} 284238$ (EURREP project).

Data for Switzerland are calculated from the Swiss Household Panel (SHP), which is based at the Swiss Centre of Expertise in the Social Sciences FORS (project financed by the Swiss National Science Foundation). Many thanks to Kryštof Zeman who provided help with the analysis of the Swiss Household Panel Data (SHP) surveys. 


\title{
Two is Best? The Persistence of a Two-child Family Ideal in Europe
}

\author{
Tomáš Sobotka and Éva Beaujouan
}

\section{Introduction}

Completed fertility rates in most of the highly developed countries fell below two children per woman already among the women born in the 1960s (Frejka and Sobotka 2004; Myrskylä et al 2013), supporting the view that fertility transition does not abruptly come to an end when fertility reaches a replacement-level threshold (Demeny 1997). At the same time, surveys of ideal and intended family size conducted in the 1980s and 1990s in low-fertility countries suggested that family size ideals as well as intentions had surprisingly stabilised around the replacement-level and became firmly centred on having two children. Hagewen and Morgan's (2005: 510) analysis of data for the United States concluded that "there is a remarkably pervasive desire (and supporting norms) for a family size of two children". Repeated cross-sectional Eurobarometer surveys conducted in all the European Union countries also suggested that family size of two still clearly remains a dominant ideal (Testa 2007, 2012). As Coleman (1999) observed "the pervasive endorsement across so many societies of the unique value of being a parent is impressive, as is the durability of ideal family sizes over two children in almost all advanced societies." This stability has contributed to a general decline in demographers' interest in the concept of ideal family size and has prompted some researchers to question the usefulness of studying fertility ideals and preferences, especially when making inferences about the likely future changes in family size (Simons 1978, Demeny 2003).

Some studies suggest, however, that the dominance of a two-child family ideal may eventually erode. There seems to be no intrinsic reason why individuals deciding about their family size should embrace replacement-level ideal of having two children (Bongaarts 2002). An extended experience of very low fertility would thus be unlikely to persist indefinitely without being accompanied by a corresponding change in family size ideals (Coleman 1999; Testa and Grilli 2006; Goldstein, Lutz and Testa 2003). This mechanism is part of the 'Low Fertility Trap' hypothesis (Lutz, Skirbekk and Testa 2006), which suggests that declining fertility rates lead to a spiral of falling numbers of births, rapid population aging, diminishing economic opportunities for younger generations and, eventually, to fewer encounters with children and declining family size ideals. Cultural changes may also contribute to the eventual erosion of a two-child family ideal: As societal norms related to family, living arrangements and gender roles become more permissive over time and across cohorts (Inglehart 1990, Lesthaeghe 1995), women and men should feel free to express unusual family size ideals. For instance, Merz and Liefbroer (2012) found a close connection between approval of voluntary childlessness and country's advancement in characteristic family and fertility changes associated with the Second demographic transition (Lesthaeghe 1995). However, van de Kaa (2001) found that women with "postmaterialist" value orientation, who are at the forefront of this transition, express similar or even higher family size ideals than the more traditionally-oriented women with "materialist" values. While people may become more tolerant of non-traditional behaviour, the high value placed on experiencing parenthood and having children may not necessarily disappear. 
In this paper we revisit data on ideal family size in Europe and provide a systematic analysis of their trends since the late 1970s, especially focusing on the possible erosion of two-child family ideals. Specifically, we address the following questions:

- How persistent and universal has the two child family ideal been in Europe during the last three decades?

- Is there evidence of emerging preference for small family size (zero or one child) in European countries with long history of sub-replacement fertility?

To address these questions, we analyse surveys conducted in 1979-2012 in 37 European countries with population above 1 million (data for eastern and western Germany are analysed separately). ${ }^{1}$ We focus on the responses of women of reproductive age (15-49) regarding their ideal family size. First we discuss the motivation for studying trends in ideal family size in Europe, the recent literature, and available data. After analysing time trends in ideal family size across all surveys, we discuss regional developments and the evidence for selected countries, with a special focus on Austria, eastern Germany, western Germany, and Switzerland. We also explore whether observed declines in mean ideal family size tend to slow down or reverse when they reach a low level. In addition, we discuss whether the countries experiencing an early decline in fertility well below replacement levels or a fall in fertility to very low levels subsequently saw a fall in ideal family size to subreplacement levels. The concluding discussion focuses on the reasons why a two-child ideal continues dominating in all parts of Europe.

\section{The Motivation for Studying Fertility Ideals}

Questions on the ideal family size have been asked first in a 1936 Gallup poll in the United States (Blake 1966). Since then it has appeared in different forms in hundreds of surveys globally. But it has also repeatedly attracted criticism for its perceived shortcomings, including the bewildering variety of questions on ideal number of children and yet more possible interpretations of these questions, encompassing also the distinct concepts of personal/individual, societal, group-specific and situational ideals (see a discussion in Ware 1974 and Philipov and Bernardi 2011). In addition, the term "ideal family size" may not include the choice of childlessness in the minds of many respondents, inhibiting them from mentioning zero as an ideal number of children (Blake 1974). Some researchers have questioned the validity of the concept of reproductive ideals: Hauser (1967: 404) considers the question meaningless, suggesting that since fertility ideals are closely correlated with completed family size, the "ideal tends to be what has actually occurred." Ryder and Westoff (1969, quoted in Ware 1974: 7) concluded their comparison of intended, expected, desired and ideal family size in the United States with a clearly negative assessment for the ideal family size, seeing it as "the least profitable variable to explore further" and positing that it "lacks face validity, is relatively unreliable, and it has small variance." Early research has also repeatedly questioned the

\footnotetext{
${ }^{1}$ This separation of datasets for eastern and western Germany is based not only on the fact that they formed two separate countries until 1990, but especially on the evidence of the severity of eastern German fertility decline in the early 1990s, and the distinctiveness of family and fertility patterns in these two areas which has persisted after the reunification (Kreyenfeld 2003, Goldstein, Lutz and Testa 2003, Goldstein and Kreyenfeld 2011, Sobotka 2011).
} 
usefulness of asking numerical questions about ideals in the context of high-fertility societies with little contraceptive use and limited concept of fertility as a planned and purposeful behaviour (Ware 1974). Over time, studies have highlighted the failure of questions on ideal family size to predict actual fertility behaviour. In the European context of low fertility, attention has been repeatedly paid to the perceived "gap" between ideal and actual family size (e.g. Testa 2012), which suggests either that respondents might be unrealistic about their fertility preferences or that ideals are perhaps too abstract and removed from real decision-making. As Demeny (2003) eloquently claims, fertility preferences may turn out to resemble a title of Günter Grass' novel, Kopfgeburten - births that increasingly occur only in the minds of would-beparents.

Some of these criticisms are clearly valid. The concept of ideal family size remains rather ambiguous and open to a multitude of interpretations (Blake 1966); there is no consensus among demographers about the preferred way(s) of asking about fertility ideals (Philipov and Bernardi 2011). But some of these perceived shortcomings are either subjective and might even be interpreted as the strengths of the measure (low variance and stability of ideals over time), or are caused by an inappropriate use of ideals for purposes for which they are not suited. Ideals are clearly not well suited for predicting fertility levels and their interchangeable use with intentions or desires, found in some of the past research papers, is misleading (Trent 1980). Past research also shows that ideals may change rapidly in times of swift cultural changes and thus can give useful signals about shifting societal norms and images about "desirable" family size. Such a shift was well documented by Blake (1974) for the United States between the mid-1960s and 1972, when ideal family size fell especially among those below age 25 and a two-child ideal became most common.

Furthermore, ideals, preferences, desires and intentions are often considered as key determinants of reproductive decision-making process (Philipov and Bernardi 2011) and behaviour (Schoen et al. 1999). They also constitute a useful measure of fertility motivation (Miller 2011) and, in comparison to other covariates, short term intentions give reasonably good predictions of subsequent fertility (see review in Ní Bhrolcháin and Beaujouan, 2011). Ideals and intentions are relatively "soft" concepts as they are open to uncertainty, doubt and revisions (e.g. Quesnel-Vallée and Morgan 2003), but nevertheless form a basic layer in the chain leading to the decision to have a child. Ideals, differently from intentions, reflect well more general societal pronatalist or antinatalist norms (Trent 1980). Family size ideals, especially personal ones, can also be seen as reflecting the number of children people would like to have if they lived under "ideal conditions" and faced no constraints such as poor health, infertility, not having a suitable partner, demanding job, precarious economic situation or inefficient contraception (Philipov and Bernardi 2011). Under this assumption, change over time in ideals could be seen as reflecting the air du temps, in particular the changing attitudes towards family, childbearing and the value of children in society.

\section{Trends in Fertility Ideals: Shifting To Subreplacement Levels?}

While an extensive body of literature in the last two decades has been devoted to studying shortterm fertility intentions, their determinants and their realisation in low-fertility countries, there 
has been comparatively little attention paid to aggregate-level fertility preferences. In particular the research on fertility ideals has fallen out of fashion and the question has been removed from a number of recent international surveys (Philipov and Bernardi 2011). This is perhaps due to the widespread notion that family size ideals are stable and that they do not matter much for reproductive decisions. Consequently, little global evidence of the ongoing trends in fertility ideals has been collected.

Viewed from the "low fertility trap" perspective, tentative evidence suggests that ideal family size has fallen below the replacement level in several low-fertility settings. Goldstein, Lutz and Testa (2003) suggested that Austria and Germany might be the first countries experiencing such a shift. Their analysis of Eurobarometer data from 2001 indicated that the mean ideal family size in these two countries has dipped to 1.6-1.7 children per woman. They expect that a similar decline is likely to take place in other low-fertility countries as well. Testa and Grilli (2006) reported a close link between the actual family size among older generations (women aged 40-60) and ideal family size of younger women aged 20-39 in Europe. Outside Europe, a shift towards one-child preferences has been reported for younger and higher-educated women in urban China (Ding and Hesketh 2006), where the mean ideal family size fell well below two children (Merli and Morgan 2011, Basten and Gu Baochang 2013). It remains unclear, however, to what extent this might be due to an internalisation of the restrictive government policies promoting one-child families during the last three decades (Nie and Wyman 2005).

\section{Data}

We used data from several cross-sectional multicountry surveys conducted since the 1970s: The World Value Survey (WVS) ${ }^{2}$, the European Values Study (EVS) ${ }^{3}$, the International Social Survey (ISSP) ${ }^{4}$ and the Eurobarometer surveys ${ }^{5}$. We also analysed complementary datasets for selected countries, specifically, the tabulated data from the Demographic and Health Surveys (DHS) in Albania and Ukraine ${ }^{6}$, data from several family surveys conducted in France ${ }^{7}$, Swiss Household Panel Survey (SHP) ${ }^{8}$, and the Generations and Gender Project surveys in Austria. ${ }^{9}$ Additionally, a discussion of trends in ideal family size in non-European countries is based

\footnotetext{
${ }^{2}$ WORLD VALUES SURVEY 1981-2008 OFFICIAL AGGREGATE v.20090901, 2009. World Values Survey Association (www.worldvaluessurvey.org). Aggregate File Producer: ASEP/JDS, Madrid

${ }^{3}$ European Values Study 1981-2008, Longitudinal Data File ZA4804. Spanish data files ZA4451 and ZA4487. GESIS Data Archive, Cologne.

${ }^{4}$ ISSP Research Group, International Social Survey Programme (ISSP): 1988 ZA1700, 1994 ZA620. Distributor: GESIS Cologne Germany

${ }^{5}$ European Commission, Brussels: Eurobarometer 11, 56.2, 65.1; TNS OPINION \& SOCIAL, Brussels (Producer); GESIS, Cologne (Publisher): ZA1036, ZA3627, ZA4505.

${ }^{6}$ ICF International, 2012. MEASURE DHS STATcompiler - http://www.statcompiler.com - data downloaded April 172013.

${ }^{7}$ INED, Enquêtes conjoncture 1955, 1967, 1976, 1982, 1987; INED, Enquête intentions de fécondité 1998; INEDINSERM, Enquête Fecond 2010.

${ }^{8}$ Swiss Household Panel Surveys (SHP). waves 2002 and 2005.

${ }^{9}$ Austrian Generation and Gender surveys, wave 1 (2009) and wave 2 (2013), Statistics Austria,Vienna Institute of Demography.
} 
mainly on the DHS and RHS (Reproductive Health Survey) data, despite their question wording which differed considerably from the other surveys analysed here (see questions below and footnote 12).

To obtain a reasonable sample size we included all women of reproductive age, broadly defined as 15-49 years. We might have selected a younger and narrower group of respondents, but that would have limited the sample size in most surveys to uncomfortably small numbers. ${ }^{10}$

The question on ideal family size differed in each group of surveys. In the multi-country surveys analysed here the question was as follows: ${ }^{11}$

WVS and EVS: "What do you think is the ideal size of a family - how many children, if any?" ISSP: "All in all, what do you think is the ideal number of children for a family to have?"

Eurobarometer (1979): "In (country name) today, what do you think, is the ideal number of children for a family?"

Eurobarometer (1990): "In (your country) today, what do you think, the ideal number of children is, for a family like yours or the one you might have?"

Eurobarometer (2001, 2006, and 2011): "Generally speaking, what do you think is the ideal number of children for a family?"

DHS, RHS: (a) For childless women: "If you could chose exactly the number of children to have in your whole life, how many would that be?". ${ }^{12}$

(b) For women with surviving children: "If you could go back to the time you did not have any children and could choose exactly the number of children to have in your whole life, how many would that be?"

In the questionnaires, the "Don't know" option was not explicitly included in the WVS, EVS and ISSP surveys, but it was added in the Eurobarometer surveys, which also included in 2001-11 the response option "There is no ideal number, it depends". The distinction between missing responses and "don't know" answers was often not available in the datasets. In the 1979 Eurobarometer survey, nonresponse in the questionnaires was coded " 0 ", the same way as an ideal of having no children. After investigating the subsequent surveys from the $1980 \mathrm{~s}$, we adjusted these data by considering all these responses as either missing or "do not know"

\footnotetext{
${ }^{10}$ It might be argued that by selecting a wide age range for our analyses we would miss the opportunity to detect shifts in ideal family size among young adults, who could be the early adopters of low family size ideals. However, the available literature does not suggest any important shift among the young respondents. A detailed analysis of the data from the 2011 Eurobarometer survey by Testa (2012) actually shows that mean general ideal family sizeis higher in the age group 15-24 than in age groups 25-39 and 40-54 in a large majority of countries, which is also illustrated by the results for all the EU countries combined (mean ideal family size of 2.27, 2.11 and 2.13 in these respective age groups) (Table A2.1 in Testa 2012).

${ }^{11}$ Exact question wording in individual-country surveys for Austria, France and Switzerland is available from the authors upon request.

${ }^{12}$ The question does not closely match the questions asked in other surveys, although it is consistently interpreted as "ideal family size" in DHS reports as well as online tabulations provided by MeasureDHS Statcompiler. In our study we refer in broader term to "fertility preferences" when analyzing DHS and RHS data. In the European comparisons we use the DHS only for one survey in two countries (Albania and Ukraine), and the results are closely aligned with the results of the other surveys. The DHS has an advantage of a large sample size in comparison with the other surveys available. We also use this survey in a discussion of non-European countries alongside with WVS and ISSP surveys for Australia, Canada, Japan, and South Korea.
} 
answers, i.e. assuming that no respondents were choosing a zero-child ideal family size. Indeed in the 1980s, the share of respondents in different surveys choosing an ideal family size of zero was negligible, reaching highest values as low as $1.1-1.3 \%$ in Austria, Belgium and the Netherlands in 1988 (ISSP survey).

In all the surveys and for each country, we checked the proportion of respondents who did not give a numerical answer to the question on ideals or whose responses were missing (see overview table in Appendix 1). This number was surprisingly high (up to 30\%) in a number of surveys, especially in some of the Eurobarometer surveys 2001, 2006 and 2011. After looking at the general proportion of unspecified values in all the surveys, we chose a threshold of $18 \%$, above which the survey was not included for further analysis. ${ }^{13}$

Indeed, for any given country the surveys with a high proportion of missing or nonnumerical responses often showed values of ideals deviating most from the other surveys. Furthermore, the sample size in the analysed WVS, EVS, ISSP and EB surveys was already small, typically between 200 and 500 women of reproductive age (fewer in smaller countries). Nonresponse and missing values further diminished the sample usable for our computations. To obtain comparable results relatively little affected by the differences in the share of respondents giving non-numerical answers, we computed two alternative sets of indicators of ideal family size; 1) as reported in each survey, and 2) adjusted for non-response and non-numerical responses, i.e., providing a distribution of ideal family size only among the respondents specifying their ideal number of children (excluding the range responses). Most of our analyses present these adjusted results.

Finally, we excluded available datasets for countries with population below 1 million (Cyprus, Iceland, Luxembourg, Malta and Montenegro) and Northern Ireland as only a few surveys were available, and each was based on small number of female respondents aged 15-49 ranging from 82 to 194 except for the two surveys available for Iceland and the 2001 Montenegro WVS survey. Altogether 168 surveys for 37 countries and regions, out of the total 203 datasets considered, met our selection criteria and were selected for our analyses of changes from 1979 to 2012 (see the list of all considered, included and excluded surveys in Appendix 1).

The analysis of time series of reproductive ideals constituted a good check of the accuracy of results for different countries, which were typically based on small samples. Partly in order to compensate for the small sample size in most surveys, we conducted additional regional analyses, grouping the data for broader geographical regions that also reflect major differences in fertility patterns across Europe (Sobotka 2013). This helped us eliminating fluctuations in the data that might have been caused by a small sample size or changes in non-response. We used the following regional groupings:

\footnotetext{
${ }^{13}$ The high share of respondents choosing the answer "There is no ideal number" in some of the Eurobarometer surveys provides a signal about the possible erosion of a notion that there might be a common ideal family size. This issue is worth analysing deeper, but as it is not captured in the other surveys, we do not analyse these responses and treat them merely as "statistical noise" that may affect the aggregate results. Moreover, in many countries there is little consistency between the share of missing and non-numerical responses across different Eurobarometer surveys (see Appendix 1), which makes it difficult to pursue a substantive interpretation in terms of uncertainty being systematically higher or lower in specific countries.
} 
- Western and Northern Europe: Belgium, Denmark, Finland, France, Netherlands, Norway, Sweden, United Kingdom. ${ }^{14}$

- Southern Europe: Greece, Italy, Portugal, and Spain.

- “German-speaking countries": Austria, eastern and western-Germany, Switzerland.

- Central Europe: Croatia, Czech Republic, Estonia, Hungary, Latvia, Lithuania, Poland, Slovakia, Slovenia.

- Eastern and South-eastern Europe: Albania, Belarus, Bulgaria, Macedonia, Moldova, Romania, Russian Federation, Serbia, and Ukraine.

\section{Results}

\subsection{Changes in Ideal Family Size in Europe since 1979: All Surveys Combined}

We first inspect changes in ideal family size and the share of women expressing a two-child ideal across Europe, computing selected key indicators for the pool of all analysed surveys combined in the period 1979-2012. Potentially, this analysis can be biased by the changing composition of countries and surveys analysed in different periods, including multiple surveys analysed in one period for some countries (see overview of all surveys by country in Appendix 1). To improve comparability of data over time and obtain a reasonable number of surveys for each period we grouped the surveys into six periods that do not cover equal time intervals, but are rather centred on the years of the important multicountry surveys analysed here.

Despite uneven country and survey coverage Table 1 gives a concise picture of the changes over time. First, it shows a gradual decline in the average value of mean ideal family size (MIFS) by about 0.1 in a decade: The average ideal family size in the analysed surveys dropped from 2.53 in $1979-83$ to 2.21 in $2008-11$. The median of ideal family size across all surveys declined slower and from a lower initial value of 2.38 in 1979-83 to 2.19 in 2008-11. At the same time, the orientation towards a two-child family ideal has slightly strengthened. In the surveys conducted since 1993, around $60 \%$ of respondents expressed a two-child ideal when the data were adjusted for nonresponse and non-numerical answers, up from $55 \%$ in the $1980 \mathrm{~s}$. More important, the share of surveys where a majority of respondents express a two-child ideal has climbed over time, from $58 \%$ in 1979-83 to three quarters in the 1990 s and the early $2000 \mathrm{~s}$ and to $85 \%$ in 2008-11. Only in two out of 109 surveys conducted since 1993 the most frequent ideal differed from two: In Norway in 1996 (WVS survey) and in Finland in 2006 (EB survey) the share of women stating a three-child ideal slightly surpassed that with the two-child ideal. While a two-child ideal firmly prevails today all over Europe, the gradual decline in mean ideal family size was fuelled by a declining share of women with an ideal of three or more children, accompanied by a slower increase in the share of women expressing a sub-replacement ideal of

\footnotetext{
${ }^{14}$ We did not include data for Ireland in this regional comparison. The surveys consistently displayed considerably higher fertility ideals in Ireland than in the other countries in this region but were only available for the earlier period until 1994. This affected the regional comparison of trends after 1994 when no survey was available for Ireland (the EB 2001-11 surveys for Ireland showed a high share of non-numerical responses between 23 and $30 \%$ and, in accordance with our selection rule, were not included in the analyses).
} 
zero or one child only. Across all surveys, this share has more than doubled from 5\% in 1979-83 to $11 \%$ in $2008-11$ when adjusting for non-response.

Table 1: Summary results for European countries; all selected surveys combined, by period, women aged 15-49

\begin{tabular}{|c|c|c|c|c|c|c|c|c|c|c|}
\hline \multirow[b]{2}{*}{ Period } & \multirow[b]{2}{*}{$\begin{array}{c}\# \\
\text { surveys }\end{array}$} & \multirow[b]{2}{*}{$\begin{array}{c}\# \\
\text { countries }\end{array}$} & \multirow[b]{2}{*}{$\begin{array}{l}\text { Average } \\
\text { MIFS }\end{array}$} & \multirow[b]{2}{*}{$\begin{array}{c}\text { Median } \\
\text { MIFS }\end{array}$} & \multirow[b]{2}{*}{$\begin{array}{l}\text { Std. dev. } \\
\text { MIFS }\end{array}$} & \multirow[b]{2}{*}{$\begin{array}{c}\text { Surveys } \\
\text { with > } \\
50 \% \\
\text { stating 2- } \\
\text { child } \\
\text { ideal (\%) }\end{array}$} & \multirow[b]{2}{*}{$\begin{array}{c}\text { Mean } \\
\text { share } \\
\text { with 2- } \\
\text { child } \\
\text { ideal (\%) }\end{array}$} & \multicolumn{3}{|c|}{ Adjusted for non-response } \\
\hline & & & & & & & & $\begin{array}{c}\text { Mean } \\
\text { share } \\
\text { with ideal } \\
0+1(\%)\end{array}$ & $\begin{array}{c}\text { Mean } \\
\text { share } \\
\text { with ideal } \\
2(\%)\end{array}$ & $\begin{array}{c}\text { Mean } \\
\text { share } \\
\text { with ideal } \\
3+(\%)\end{array}$ \\
\hline $1979-83$ & 19 & 11 & 2.53 & 2.38 & 0.44 & 58 & 51 & 5 & 55 & 40 \\
\hline 1987-91 & 38 & 27 & 2.45 & 2.42 & 0.26 & 63 & 54 & 5 & 56 & 38 \\
\hline 1993-97 & 36 & 27 & 2.35 & 2.38 & 0.23 & 78 & 58 & 7 & 60 & 33 \\
\hline $1998-2002$ & 25 & 19 & 2.34 & 2.36 & 0.20 & 76 & 55 & 7 & 59 & 33 \\
\hline 2005-07 & 23 & 23 & 2.25 & 2.22 & 0.19 & 78 & 57 & 9 & 62 & 29 \\
\hline 2008-11 & 27 & 24 & 2.21 & 2.19 & 0.19 & 85 & 56 & 11 & 61 & 28 \\
\hline
\end{tabular}

Figures 1 and 2 allow a more detailed look at the variation of changes in ideal family size. The decline in the variance of mean ideal family size in different surveys and countries (Table 1) has been driven especially by a diminishing number of countries with high ideal family size. This is also illustrated by the rapidly declining level of the highest-reported MIFS in each analysed period, from 3.88 in 1979-83 (Ireland in EVS in 1981) to 2.54 in 2008-11 (Albania in DHS, 2008-9). ${ }^{15}$ By contrast, the minimum reported MIFS almost suggests that there is a lowerfloor to the decline in ideal family size, as it was remarkably stable and close to 2.0 in all the analysed surveys and periods except in 1998-2002 (Figure 1). Since the mid-1990s a majority of surveys shows a MIFS in the range of 2.0-2.5, with a slightly declining tendency.

There was a clear trend towards more uniformity in a two-child ideal (2CI) across different surveys, as illustrated also by a strong rise in the minimum share of respondents with a two-child ideal from $17 \%$ in the earliest period (Ireland in 1981) to $43 \%$ in the latest period (Finland in 2011). A majority of the surveys conducted in 2008-11 fall into the narrow range of 50 to $60 \%$ of respondents expressing a two-child ideal (Figure 2), suggesting a remarkable convergence across Europe.

\footnotetext{
15 The contrast between the earlier and later period is partly affected by excluding the 2001-11 Eurobarometer surveys for Ireland from our analyses due to the high share of non-response and non-numerical responses. If we included these data, the maximum MIFS value would remain somewhat higher and would decline to 2.70 in 2008 11.
} 
Figure 1: Mean ideal family size in Europe, summary results for all selected surveys by period, women aged 15-49

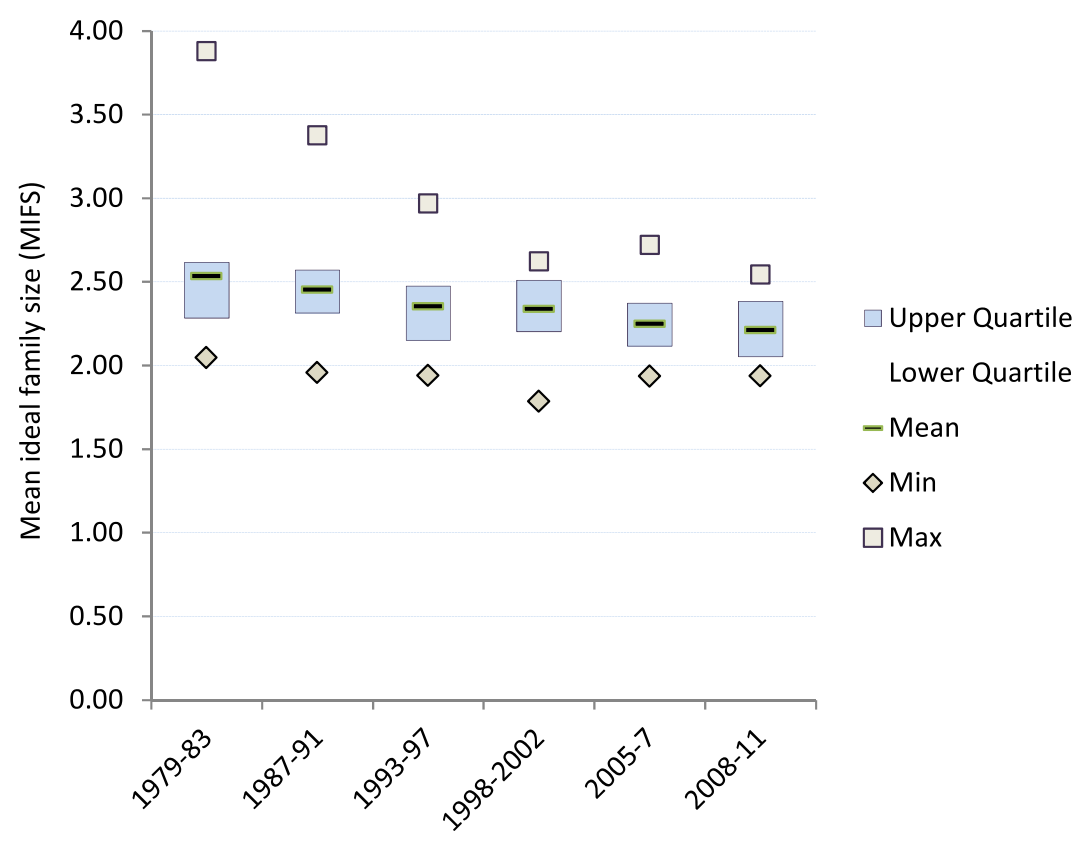

Figure 2: Percent respondents with an ideal of two children, summary results for all selected surveys in Europe by period, women aged 15-49

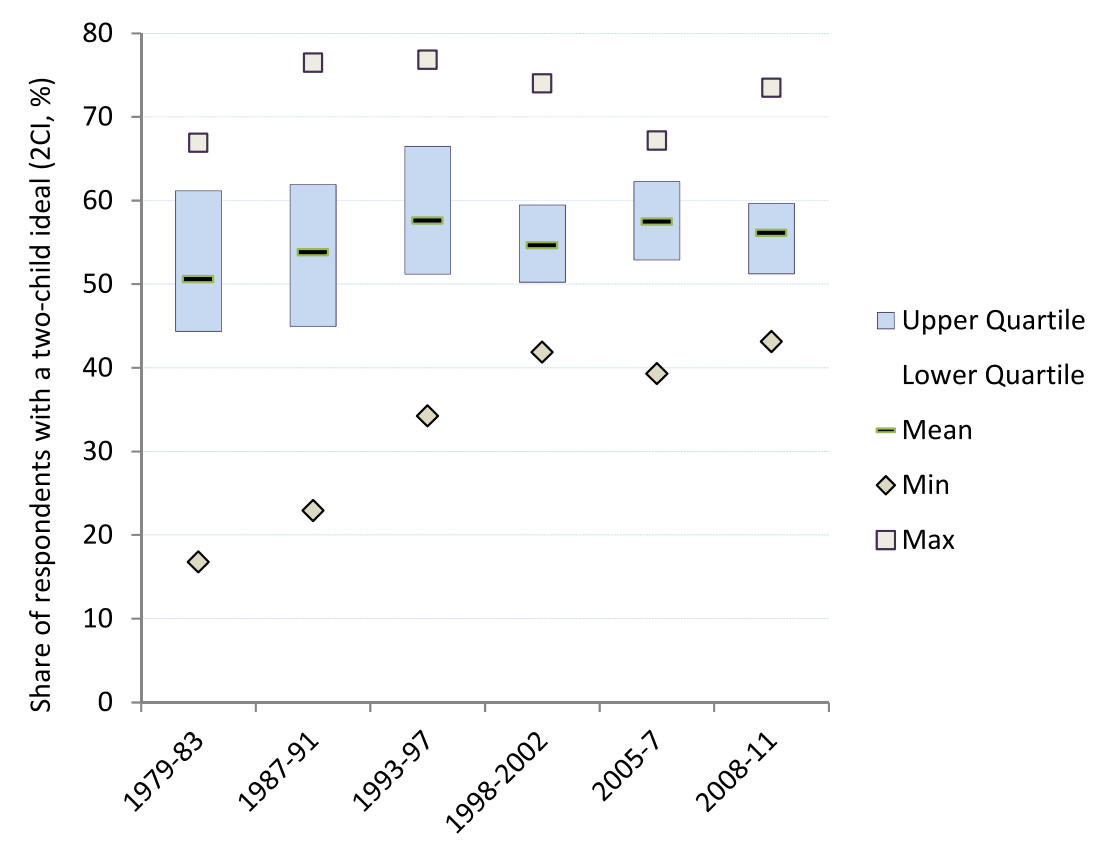




\subsection{Comparison of Major Regions}

Did the trends in ideal family size, evidenced in the analysis of all surveys combined, progress in different parts of Europe in a similar fashion? Our analysis in Figures 3 and 4, complemented by Appendix 2, focuses on broad time periods since the late 1980s - except for Western \& Northern Europe - in order to increase the number of surveys in each region and make the regional data more comparable over time. The data depict remarkable similarities between regions, especially regarding the ideal of having two children. By the late 1980s, and most probably earlier, this had become a clearly dominant family ideal in all the broad regions studied, with as many as two thirds of respondents in the German-speaking countries in favour of two-child families. None of the regions studied shows any sign of an erosion of the two child ideal between the late 1980s and 2006-11; in fact only minor changes can be seen over time. In the most recent period, the adjusted average share of respondents embracing a two-child ideal surpasses 6 out of 10 in all parts of Europe except Western \& Northern Europe, where the share has been slightly lower during the whole analysed period.

In contrast with this stability in two-child ideal, subtle shifts and regional differences can be seen in trends in mean ideal family size as well as in the ideals of larger family size (three or more children) and smaller family size (none or one child). Gradual declines in the MIFS can be observed in Central, Southern, South-eastern and Eastern Europe, with only Western \& Northern Europe and German-speaking countries showing general stability. The average value for Eastern Europe in 2006-11 reaches a low of 2.0, followed by Southern Europe and German-speaking countries with the average of 2.1 .

Recently, the spread of one-child ideal has been rather pronounced in Southern, Eastern and South-eastern Europe, where it may soon surpass the ideal of having three or more children, unless they both stabilise at a similar level. Data for Southern Europe allow a finer distinction of trends after 2001. A faster shift towards a stronger preference of very small family size began already in 2001-6, although the rise of one-child ideal accelerated between 2006 and 2011, when its preference jumped from 10 to $15 \%$ (see also the next section). At the same time, even in this region a two-child ideal remains dominant and four times as frequent as an ideal of having zero or one child only. 
Figure 3: Changes in ideal family size (mean and distribution) in broader European regions (average values across all surveys in a given period; data adjusted for non-response and for nonnumerical responses)
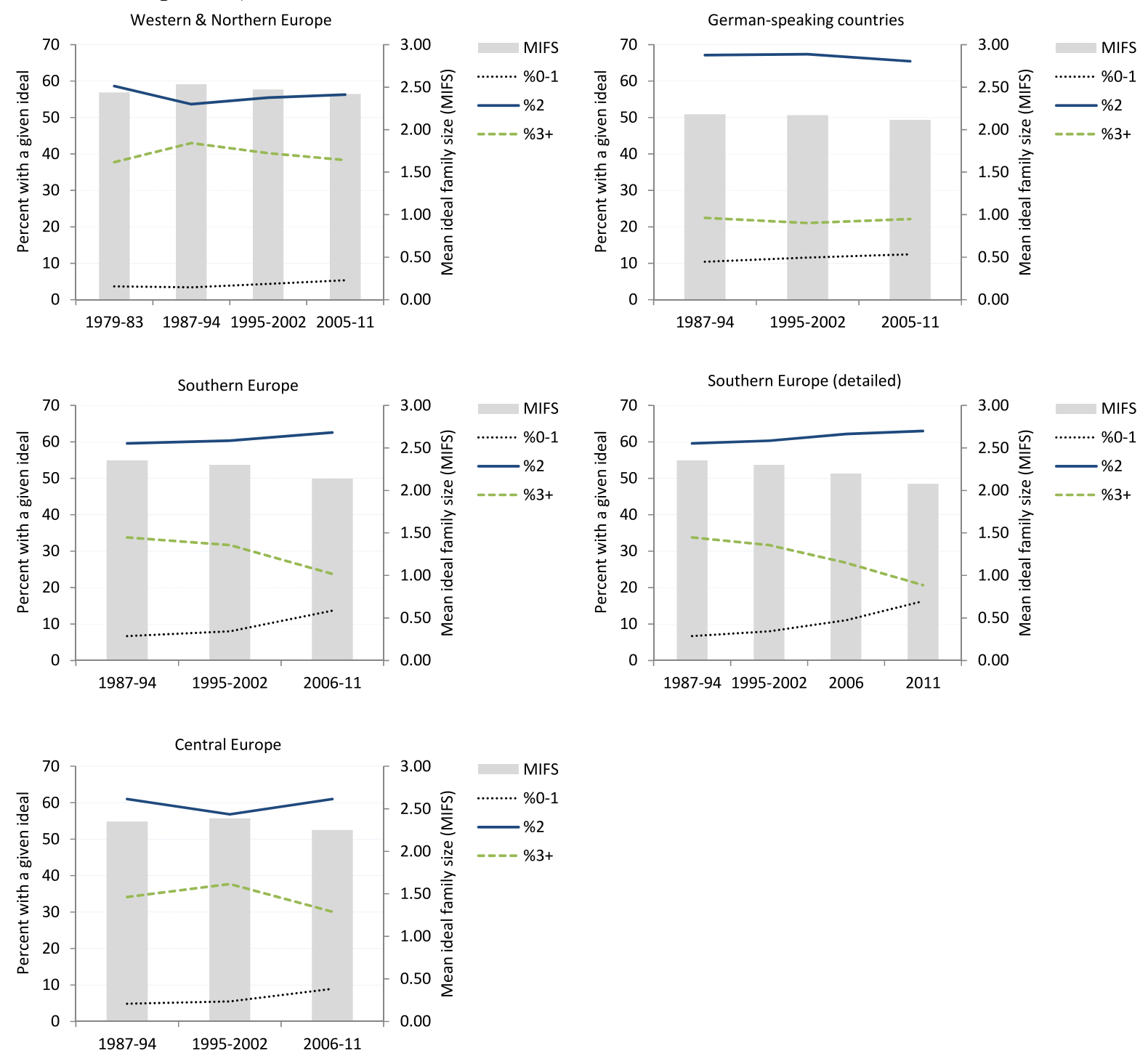
Figure 4: Mean ideal family size and the share of women with a two-child ideal in broader European regions (average values across all surveys in a given period; data adjusted for nonresponse and for non-numerical responses)
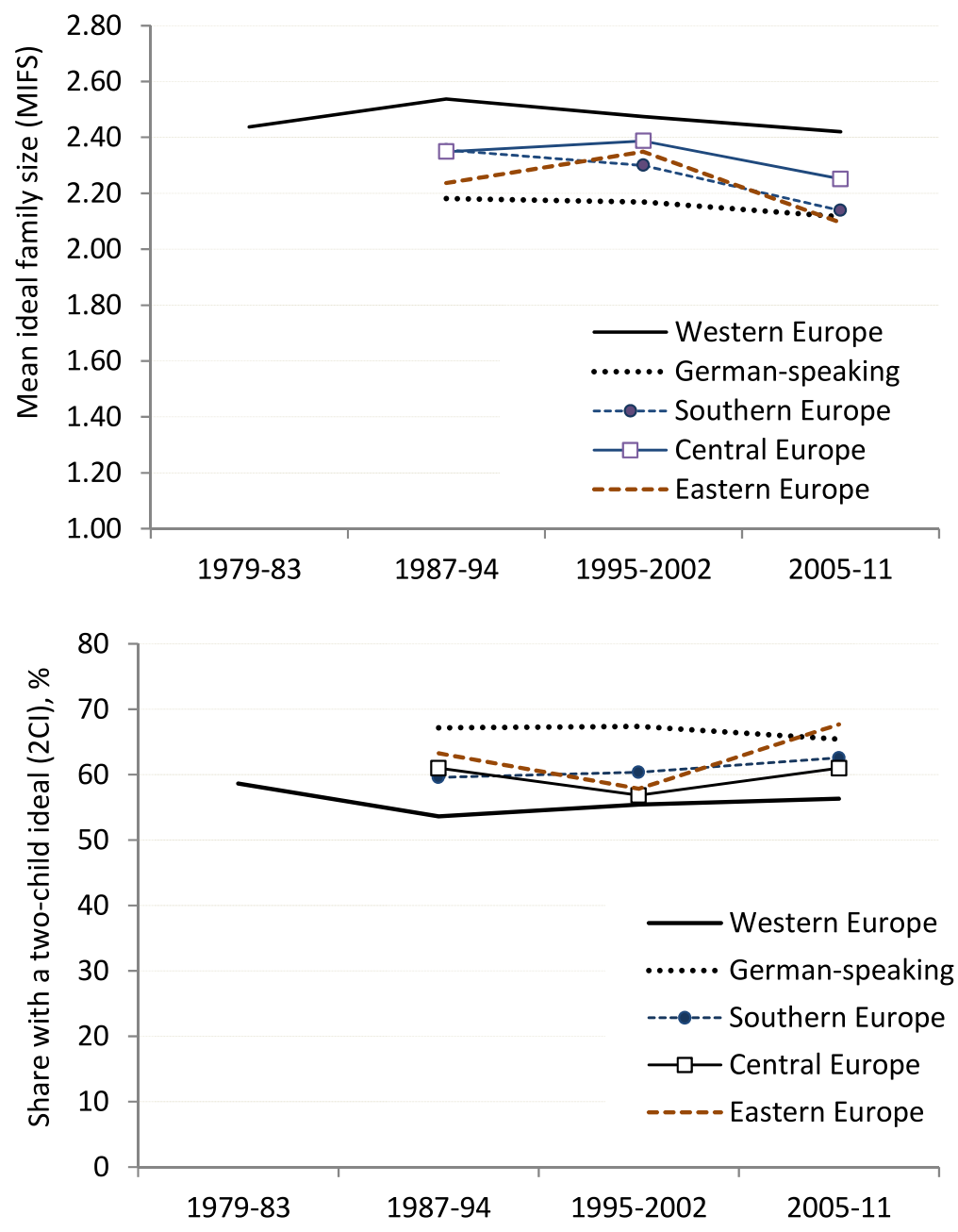

\subsection{Trends in Selected Countries}

To gain deeper understanding of regional trends in reproductive ideals, we illustrate changes in ideal family size in selected countries with a longer time series of available data (Figure 5). We focus especially on the largest European countries and on providing contrasting examples for each region. Data for the three German-speaking countries are discussed separately in the next section. We do not discuss trends in the countries in Eastern and South-eastern Europe, for which we lack longer time series of comparable data.

France and Sweden are two countries representing well the higher end of the European range of ideal family sizes. These countries have a stable model of "two or three" family size preference: The slightly predominant ideal of two children coexists with the high share of women expressing an ideal of three children, whereas the ideal of one or no child remains rare. 
Corresponding to that, the mean ideal family size approaches 2.5 . In France, where we have compiled a longer time series spanning from 1955, the two-child ideal started prevailing continuously over the "three or more" option only in the 1990s. In Belgium, the ideal of two dominates more strongly and a slight increase in the share of women with an ideal of zero or one can be observed.

The Southern European countries share a trend towards a low MIFS around 2.0, a fast decline in the share of women with a larger family ideal and a concurrent rise in the preference for a small family size. In Portugal and Italy, the share of women with a zero or one-child ideal has already surpassed that with the preference for a family of three or larger. The rather sharp decline in family size ideals between 2006 and 2011 in Portugal and Greece (not shown here) is suggestive of the possible negative influence of the long-standing economic recession (Testa 2012), similar to the evidence on the likely negative effect of the recession on fertility intentions in Greece (Testa and Basten 2013). However, only the next survey can confirm our speculations.

In Central Europe, Czech Republic had a very strong orientation towards a two-child ideal already in 1990, with only one in five women at that time having an ideal of three or more children. By 2011, this has further eroded and the one-child ideal has become more prevalent, with the adjusted share of 19\%, pushing the MIFS to the lowest level in Europe (1.93). In Hungary, a gradual shift towards more women with a small family ideal is also observed, but not (yet) depicting a cross-over with the share of women expressing a larger ideal. Slovenia, despite having similarly low fertility as the Czech Republic and Hungary, shows yet another pattern, characterised by stable distribution of ideal family size and a very low share of women with an ideal of zero or one, which does not increase over time.

Figure 5: Changes in ideal family size in selected European countries, women aged 15-49 (data adjusted for non-response)
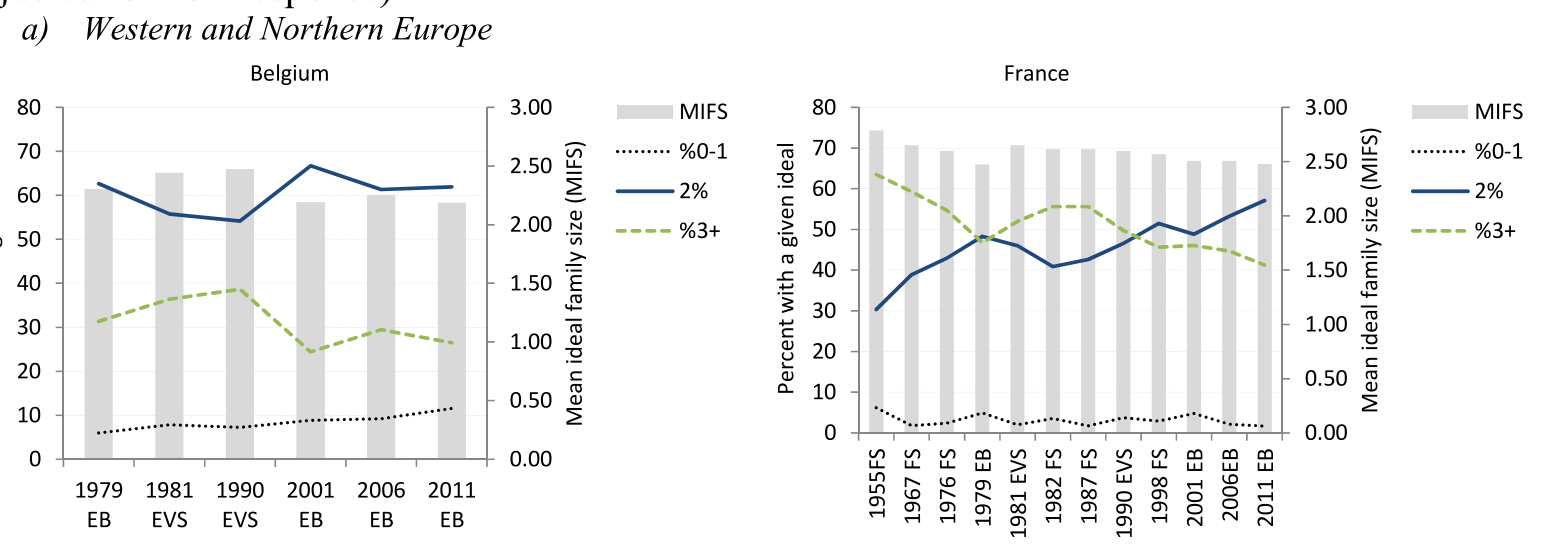


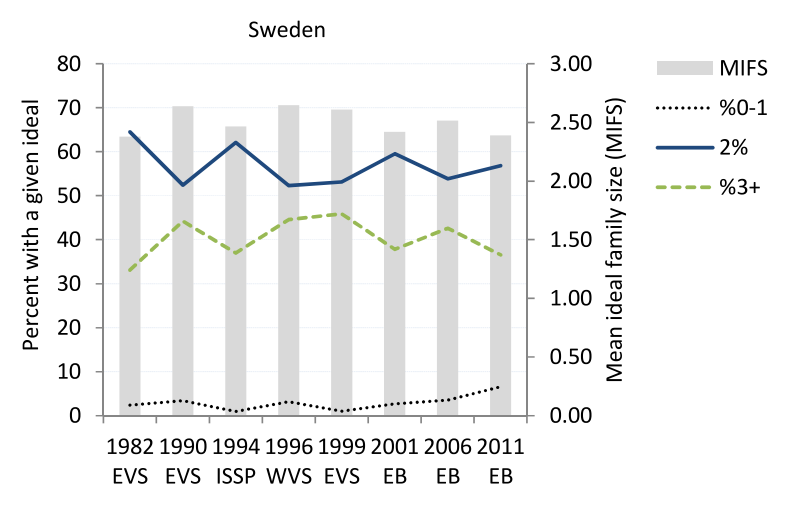

\section{b) Southern Europe}
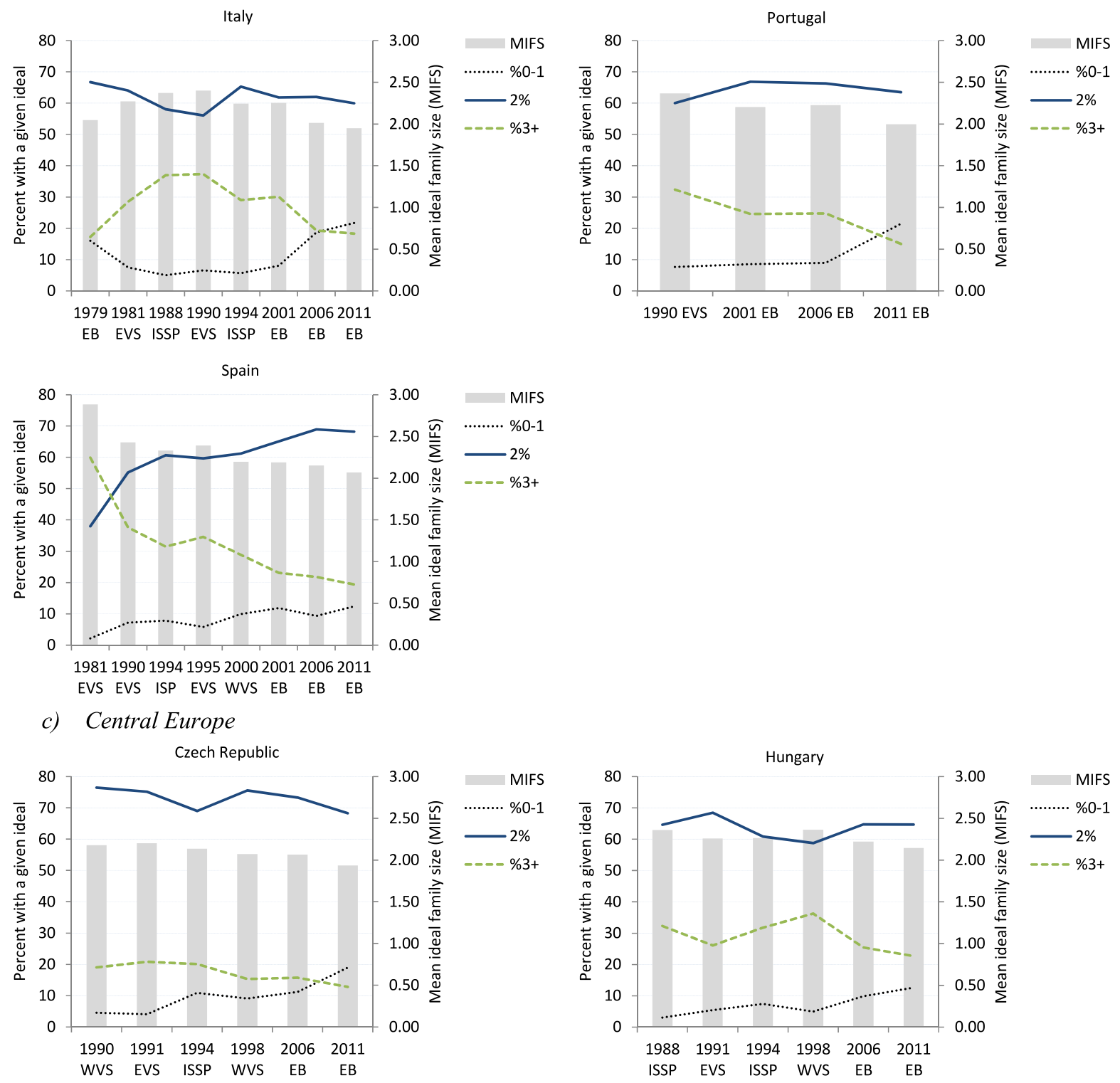


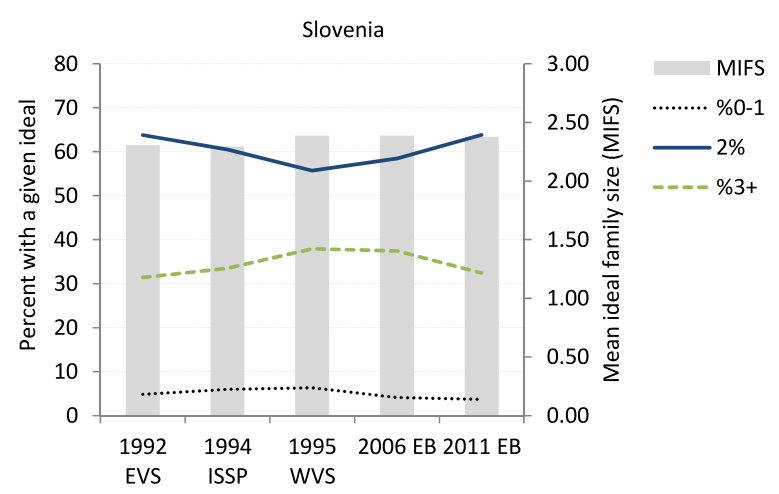

\subsection{Ideal Family Size in Austria, Germany, and Switzerland}

We were able to reconstruct trends in family size ideals in all the three predominantly Germanspeaking countries of Europe, looking separately at eastern and western Germany. These countries share a long history of low fertility (Sobotka 2011). With the exception of two surveys that do not align well with longer-time trends, the Austrian 1994 ISSP survey and the 2001 EB survey in eastern Germany, the time series for Austria and Germany show remarkable stability in fertility ideals, especially in western Germany (Figure 5). This is best illustrated by comparing the earliest and the latest survey conducted in 1979 and 2011. Both surveys show identical MIFS for western Germany of 2.10 and an identical share of respondents with a two-child ideal of 67 $\%$ when adjusted for non-response and non-numerical responses. There are no noticeable shifts in the distribution of larger- or small-family size ideals. The available literature indicates that women and men in western Germany have fully embraced a two-child family ideal at least two decades earlier: A 1957 survey of married women and men aged 15-45 showed that $45 \%$ had an ideal of two children, with the MIFS reaching $2.58^{16}$ (Freedman et al. 1959, Table 2). Also a comparison of eastern German 1990 EVS data with the 2011 EB data reveals striking continuity, with the MIFS "changing" from 1.96 to 1.98. The data for Austria suggest a decline in MIFS (2.30 in the 1998 ISSP survey vs. 1.98 in the 2011 Eurobarometer survey and 2.20 in the 2012 GGP survey) going hand in hand with a gradual increase in the share of women having an ideal of one or no children. In Switzerland we observe a gradual shift to a lower family size ideal, with a notable decline in the ideal of having three or more children, contributing to the rising popularity of a two-child ideal. Unlike in Austria and Germany, the ideal of having one or no children remains marginal in Switzerland.

Our results do not lend support to the earlier widely discussed findings of Goldstein, Lutz and Testa (2003) that younger cohorts of women in Austria and Germany have, after experiencing decades of low fertility, started expressing fertility ideals well below the replacement threshold. What is the main reason for the lack of supporting evidence in our study? First, we analyse general ideal family size, whereas Goldstein, Lutz and Testa looked at personal ideals, which have been in Austria slightly lower than the general ideals. Second, we excluded the 2001 EB surveys for Austria and western Germany which did not conform to our selection

\footnotetext{
${ }^{16}$ If the survey included also unmarried men and women - as has become a common practice a few decades laterthe mean ideal family size would probably be lower as some of those who were unmarried arguably formed a select group with a lower family size ideals.
} 
criteria due to the high share of non-response and of respondents that stated that "there is no ideal family size," altogether $19 \%$ in western Germany and $23 \%$ in Austria. These surveys reported very low ideals (see Appendix 1) that were not replicated in subsequent surveys in these countries, as shown in our analyses as well as in additional surveys analysed by Philipov and Bernardi (2011: 503, Table 1). One of the surveys analysed by the authors, the $2001 \mathrm{~EB}$ in eastern Germany, is included in Figure 6, but it constitutes an interruption in otherwise relatively stable time series. In our whole dataset, this survey showed the lowest value of MIFS at 1.78, way below the next lowest value of 1.93 reached in Romania in 2006 and in the Czech Republic in 2011, which adds to our suspicion that the 2001 EB survey in eastern Germany might suffer methodological problems, such as having a sample selection not well representative of east German population. ${ }^{17}$

Figure 6: Changes in ideal family size in Austria, eastern and western Germany and Switzerland, women aged 15-49 (data adjusted for non-response)
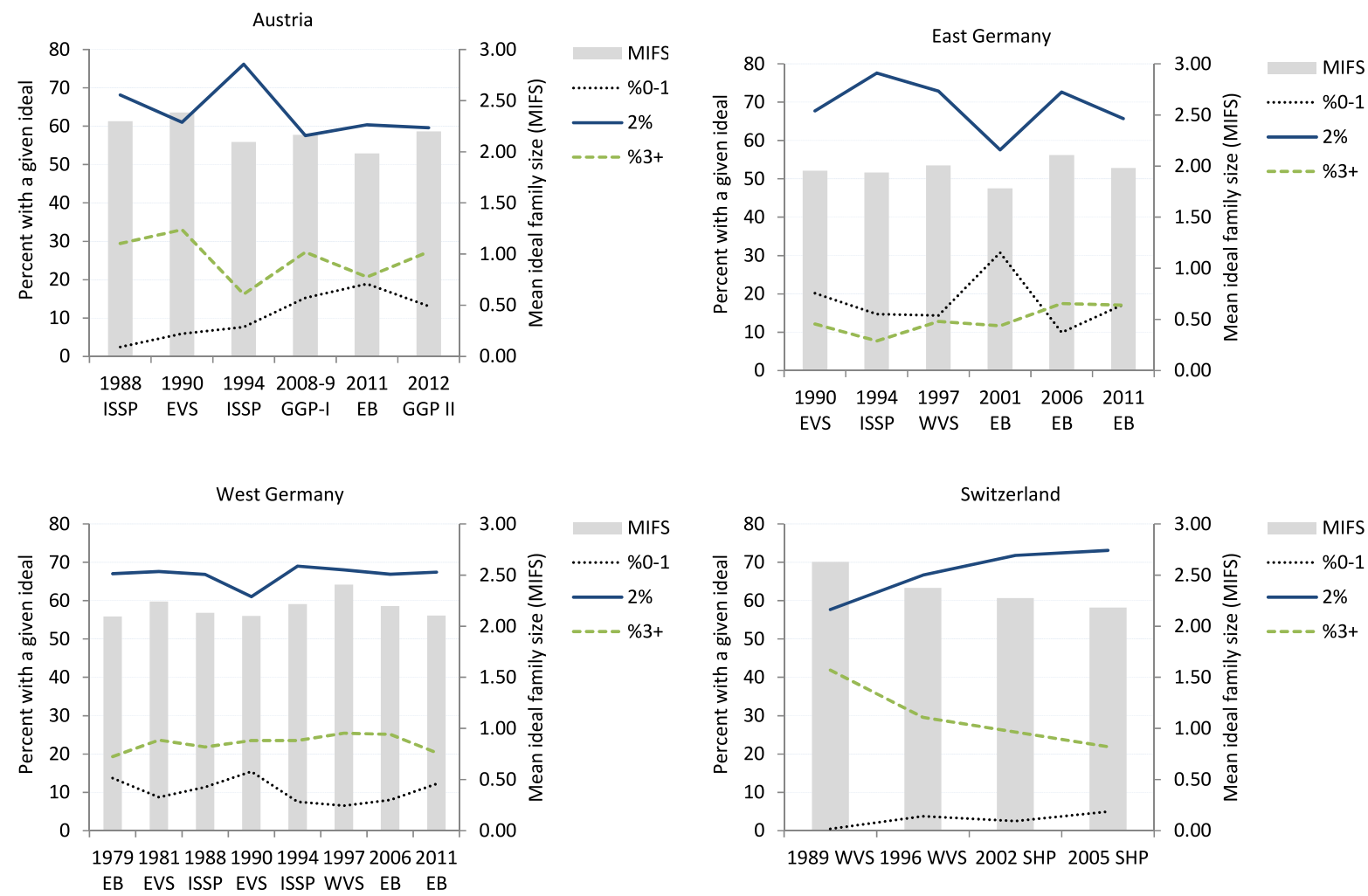

\subsection{Does a Decline in Mean Ideal Family Size Slow down when it reaches Low Levels?}

Our analyses suggest that the mean ideal family size around two constitutes a low threshold which, so far, has not been consistently crossed in Europe - except for a few one-off surveys and

\footnotetext{
17 The study by Philipov and Bernardi (2011: 503, Table 2) compared additional datasets for eastern Germany and reported a similarly low mean family size ideal of 1.70 in another survey, the 1992 FFS.
} 
some variation around this value. This is remarkable both because the long history of very low fertility in a number of countries suggests that ideals could eventually follow the fertility trends observed earlier (Lutz, Skirbekk and Testa 2006) and because there is no pertinent reason to believe that ideals should follow the homeostatic logic of the "replacement level of fertility" model and stop falling when reaching the levels around replacement.

To investigate this in a more systematic fashion, we analysed changes in mean ideal family size depending on the initial MIFS level. Specifically, we selected for each country all pairs of consecutive surveys that took place within a period of up to ten years and analysed the changes in MIFS from one survey to the next. To standardise the results, we computed the annual change in MIFS between the year of the initial survey and the subsequent one. The results displayed in Figure 7a are by definition affected by the fact that we combined different surveys with not fully comparable questions, sample sizes, non-response options and other features. This should increase the noise in our time series as well as instability in the analysed results. This concern aside, our analysis suggests indeed that there is a relationship between the initial MIFS level and its subsequent change: The lower the initial MIFS level, the weaker its subsequent decline. A crossover even occurs when the MIFS falls below 2.3 children: When a survey shows a MIFS below this threshold, it is more likely to increase rather than decline in the next period. This effect is not very strong, but nevertheless suggests a frequent broad stabilisation of mean ideal family size once it reaches a low level close to the replacement. We also found a similar relationship for the two-child family ideal with the stabilising level at around $60 \%$. Above that level, the share of respondents with a two-child ideal is more likely to fall than to rise in the next survey (Figure 7b).

Figure 7a: Average annual change in the mean ideal family size (MIFS) between two consecutive surveys, conditional on the initial MIFS value; 127 pairs of surveys in Europe, 19792011

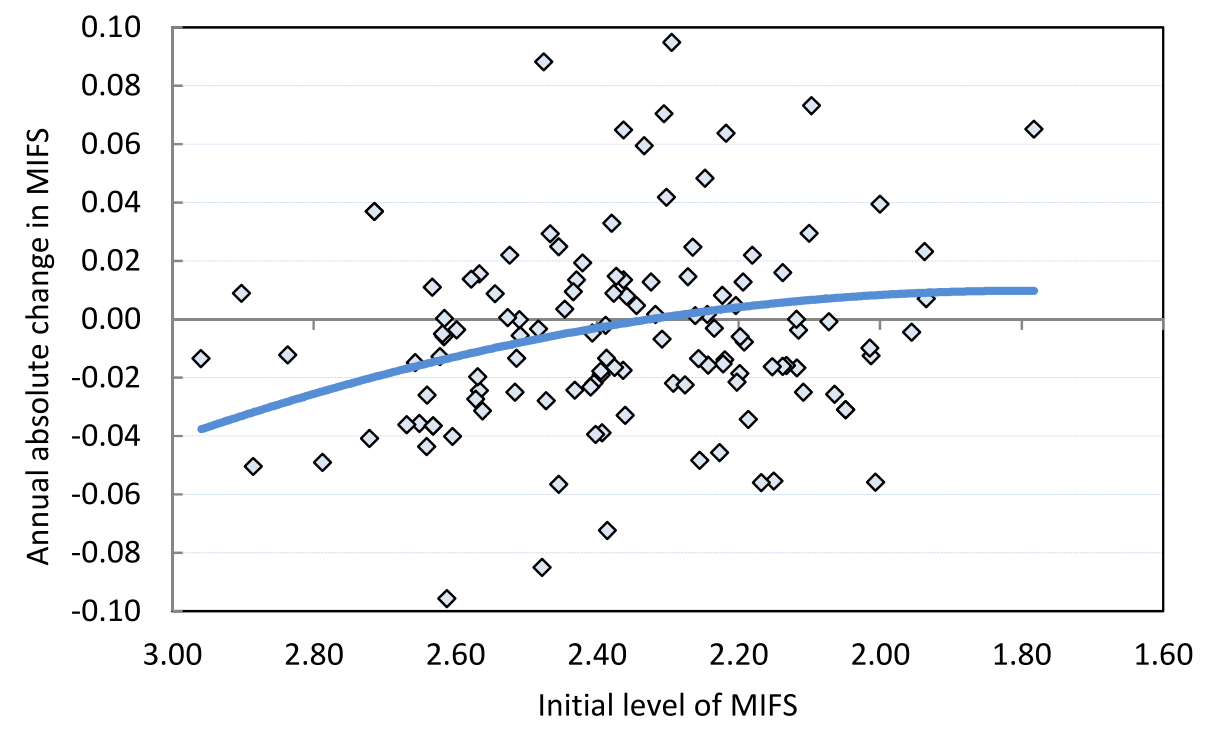


Figure 7b: Average annual change in the share of women aged 15-49 reporting a two-child family ideal (2CI) between two consecutive surveys, conditional on the initial 2CI value; 131 pairs of surveys in Europe, 1979-2011

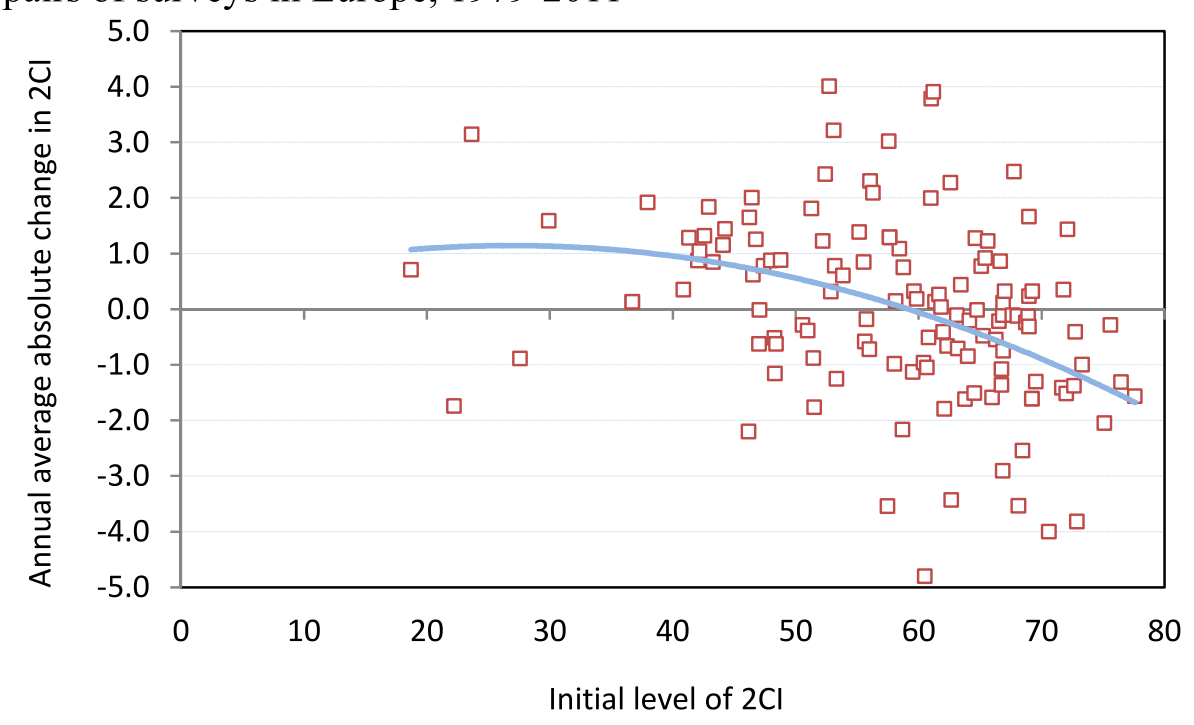

Notes: For the initial MIFS level only the data with an initial MIFS at or below 3.0 were selected (this resulted in the withdrawal of four data pairs). The level of $2 \mathrm{CI}$ is adjusted for non-response and non-numerical responses. The trendline in both graphs is a second-order polynomial curve supplied by MS Excel package.

\subsection{The Links between Subreplacement Fertility and Ideal Family Size}

If the changes in ideal family size tend to follow, at least partly, the changes in fertility behaviour as hypothesised by Lutz, Skirbekk and Testa (2006), two predictions related to its possible decline to levels significantly below replacement can be made:

- 1) The earlier a country experiences a decline in fertility to very low levels, the more likely it is to see a shift to MIFS below replacement;

- 2) The deeper fertility falls in a country, the more likely this country is to experience a shift to MIFS below replacement.

We address these predictions by ranking European countries by the timing and intensity of their fertility declines to low levels and analysing their most recent MIFS levels. To avoid tempo and parity composition distortions present in the most conventional measure of fertility, the period total fertility rate (Sobotka and Lutz 2011), we use completed cohort fertility rate (CFR). Table 2 looks at the European countries that experienced an early decline of CFR below 1.8 children per woman, selecting all countries experiencing such declines by the 1963 cohort. There appears to be no systematic relation between the early spread of low fertility and recent ideal family size. Three countries with earliest spread of low cohort fertility, western Germany, Austria, and Switzerland, retain comparatively higher MIFS at 2.1-2.3 than many countries with later cohort fertility declines, including Italy, eastern Germany and Spain.

However, when we rank countries with lowest fertility levels, as measured by their estimated cohort fertility rate among the women born in mid-1970s, a tentative link emerges between the 
magnitude of cohort fertility decline and MIFS level (Table 3). Specifically, all countries except Greece with a CFR below 1.6 children per woman share a low MIFS in the narrow range 1.952.11 . $^{18}$ However, even in these countries ideal family size still remains very close to the replacement threshold.

Table 2: European countries which experienced an early decline of completed fertility below 1.8 by cohort when fertility fell below this level and most recent MIFS level

\begin{tabular}{l|c|cc} 
& $\begin{array}{c}\text { First cohort with } \\
\text { a CFR }<1.8\end{array}$ & Year & Value \\
\hline Western Germany & 1944 & 2011 & 2.10 \\
Switzerland & 1950 & 2005 & 2.18 \\
Austria & 1954 & 2012 & 2.20 \\
Italy & 1956 & 2011 & 1.95 \\
Eastern Germany & 1960 & 2011 & 1.98 \\
Spain & 1960 & 2011 & 2.07 \\
Russia & 1961 & 1995 & 2.15 \\
Belarus & 1962 & 1996 & 2.11 \\
Ukraine & 1962 & 2007 & 1.97 \\
Lithuania & 1962 & 2011 & 2.22 \\
Slovenia & 1963 & 2011 & 2.38 \\
\hline
\end{tabular}

Notes: Data not shown for Luxembourg, where the CFR fell below 1.8 already in the 1947 cohort, but later rebounded above this threshold in the 1960s cohorts (the MIFS for Luxembourg was 2.26 in the 2011 EB survey). Sources: MIFS data are based on the most recent surveys listed in Appendix 1. Data on completed fertility are based on Council of Europe (2006) yearbook.

\footnotetext{
${ }^{18}$ Despite finding some correspondence between fertility level and ideal family size among the countries with the lowest cohort fertility in Europe, relatively low MIFS levels are also found in some countries with a higher cohort fertility rate. For instance, the country with a lowest MIFS of 1.93 in the 2011 Eurobarometer survey, the Czech Republic, has comparatively high CFR estimated at 1.77-78 for the 1974-75 cohorts (Prioux et al. 2013).
} 
Table 3: European countries with lowest completed cohort fertility among women born in 197475 and most recent MIFS level

\begin{tabular}{|c|c|c|c|}
\hline & $\begin{array}{c}\text { CFR } \\
\text { (Cohort } \\
1974-75)\end{array}$ & Iost rec & Value \\
\hline Spain & $1.37-1.41$ & 2011 & 2.07 \\
\hline Italy & $1.42-45$ & 2011 & 1.95 \\
\hline Ukraine & $1.51^{*}$ & 2007 & 1.97 \\
\hline Eastern Germany & 1.55 & 2011 & 2.10 \\
\hline Romania & 1.55 & 2011 & 1.97 \\
\hline Bulgaria & 1.56 & 2011 & 2.03 \\
\hline Western Germany & 1.57 & 2011 & 1.98 \\
\hline Greece & $1.55-58$ & 2011 & 2.29 \\
\hline Portugal & $1.57-58$ & 2011 & 2.00 \\
\hline Belarus & $1.58^{*}$ & 1996 & 2.11 \\
\hline Poland & $1.61-62$ & 2011 & 2.15 \\
\hline Russia & 1.62 & 1995 & 2.15 \\
\hline Austria & $1.63-64$ & 2012 & 2.20 \\
\hline Switzerland & $1.63-65$ & 2005 & 2.18 \\
\hline Slovenia & $1.66-67$ & 2011 & 2.38 \\
\hline
\end{tabular}

Notes: * Data pertain to the 1972 cohort;

Sources: MIFS data are based on the most recent surveys listed in Appendix 1. Data on completed cohort fertility are partly projected and for most countries based on the computations by Prioux et al. 2013: 537, Table A7 for the 1974-75 cohort (trend projection), Data for Russia, eastern and western Germany are for the 1975 cohort and were computed by Myrskylä et al. 2013 (Table 2). Data for Belarus and Ukraine pertain to the 1972 cohort and are based on the forthcoming European Demographic Data Sheet 2014 (VID 2014; computations by Kryštof Zeman).

\subsection{How Prominent are Two-Child Ideals outside Europe?}

Is the ideal of having two children equally popular outside Europe? The evidence for nonEuropean countries with a long history of low fertility is indeed similar to that for Europe: Having two children has become a dominant ideal decades ago and it remains widely adhered to.

According to the series of Gallup polls dating back to 1936, the United States is close to the "two or three" children ideal, exhibited in Europe in France and in the Nordic countries. The two-child ideal rose quickly in prominence in the US during the socially turbulent times of the late 1960s-early 1970s: Between 1966 and 1973 the share of respondents saying that two children are ideal jumped from 18 to $46 \%$ (Livingston and Cohn 2010), and oscillated between 46 and $57 \%$ thereafter. Hagewen and Morgan's (2005) study, based on the considerably larger CPS and GSS surveys, shows similar results with close to a half of women of reproductive ages embracing a two-child ideal and with a mean ideal family around 2.4 in the 1990 s and the early 2000s. 
Data for Australia and Canada from the ISSP and WVS surveys in 1995-2000 (our computations, data for countries outside Europe not listed in Appendix 1) show around a half of women aged 15-49 having an ideal of two children, with a MIFS at 2.4-2.6. Very similar values are found in the 2001 WVS survey for South Korea. In Japan, the WVS surveys in 1995-2005 show equal shares of women with two- and three-child ideal, around $40 \%$. The repeated waves of the Japanese National Fertility Survey indicate stable mean ideal family size among married women, dropping slightly from 2.6 in 1977 to 2.4 in 2010, while Japanese period total fertility rate has fallen to very low levels below 1.5 since the early 1990s (NIPSSR 2011a). ${ }^{19}$ In Taiwan, surveys of fertility preferences among married women indicate a continuous increase in the preference for having two children between 1970 and 2002, reaching $66 \%$ in the latest survey (Chang 2006: 13, Table 11).

We conducted additional analyses for countries in advanced stages of fertility transition, using the Demographic Health Survey (DHS) and Reproductive Health Survey (RHS) tabulations available in MeasureDHS Statcompiler (ICF International 2012). Specifically, we looked at the change in the preferred number of children among women of reproductive age in 18 countries of Latin America and the Caribbean, South Asia, South-east Asia, and in Turkey, Morocco and Namibia, where surveys were conducted both around 1990 and 2008 (for exact question wording see the Data section). ${ }^{20}$ Figure 8 shows a considerable shift towards a preference for two children; the average share of women desiring two children across the 18 countries jumped from 36 to $46 \%$, with an interquartile range of 40 to $53 \%$ in the latter period. The number of countries where more than $40 \%$ of women expressed a 2-child preference rose from 4 to 13 (Figure 9); in Bangladesh, Colombia, India, Nepal, Peru, and Turkey over half of women preferred two children. The mean desired family size declined in all analysed countries except Turkey and by around 2008 fell below 2.6 in 8 out of the 18 countries studied including Bangladesh, Bolivia, India, Nepal, and Peru.

\footnotetext{
${ }^{19}$ Never-married women were only asked about their desired number of children in case they planned to marry later in life. Among those aged 18-34 a two-child orientation clearly dominated, with a mean desired number of children showing a small decline from 2.3 to 2.1 between 1982 and 2010 (NIPSSR 2011b: p. 18, Table 3.2).

${ }^{20}$ Data for the following countries and surveys were analysed: Bangladesh DHS 1993-94 and 2007; Bolivia DHS 1989 and 1998; Colombia DHS 1990 and 2010; Dominican Republic DHS 1991 and 2007; Ecuador DHS 1987 and RHS 2004; Egypt DHS 1988 and 2008; Guatemala DHS 1987 and RHS 2008-9; Haiti DHS 1994-95 and 2005-6; India DHS 1992-3 and 2005-6; Indonesia DHS 1991 and 2007; Morocco DHS 1992 and 2003-4; Namibia DHS 1992 and 2006-7 ; Nepal DHS 1996 and 2011; Paraguay DHS 1990 and RHS 2008; Peru DHS 1991-2 and 2007-8; Philippines DHS 1993 and 2008; Sri Lanka DHS 1987 and 2006-7 (only ever-married women included in the latter survey); Turkey DHS 1993 and 2008 (only ever-married women included in the latter survey). We applied the same selection criteria as for European datasets, therefore did not include the data for Jordan and Pakistan, where a high share of women provided no or non-numerical responses (31 and $61 \%$, respectively) in the surveys that took place around 1990.
} 
Figure 8: Percentage of women aged 15-49 with a desired family size of two around 1990 and 2008; summary results from DHS and RHS surveys in 18 countries in advanced stage of fertility transition as compared with the ideal family size in European countries (data from Figure 2)

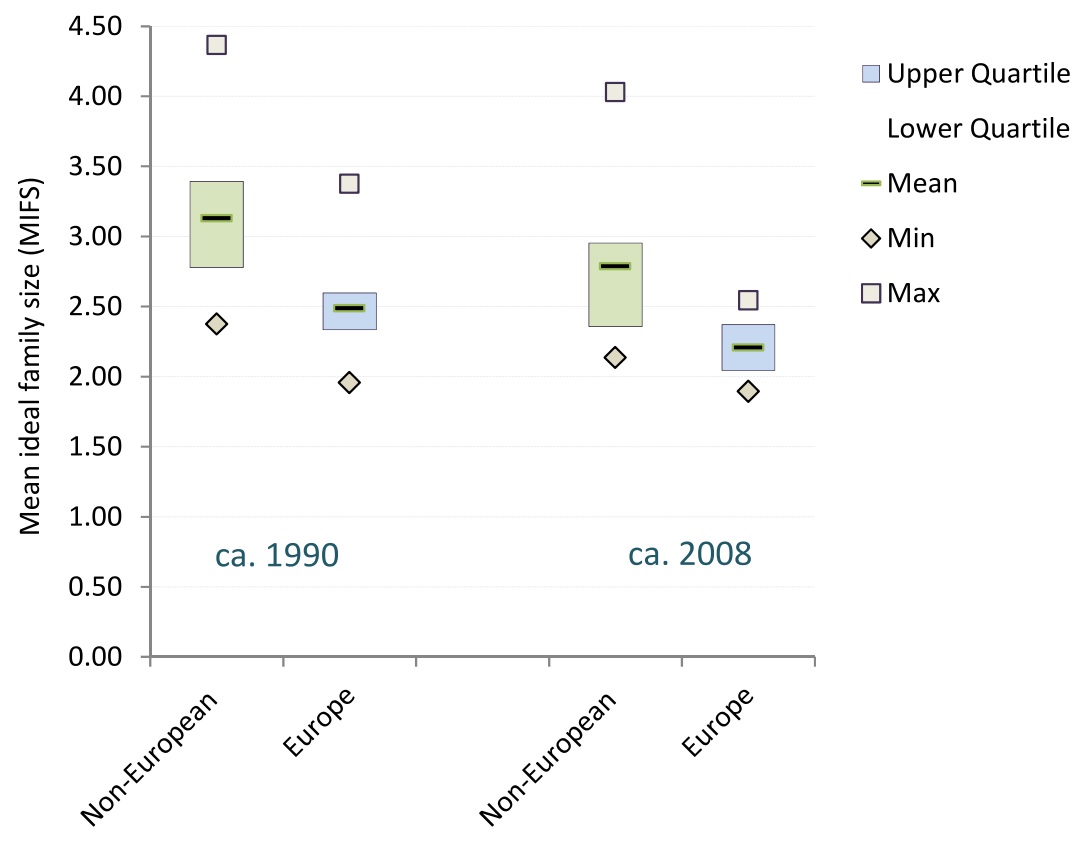

Figure 9: Share of women aged 15-49 desiring a two-child family around 1990 and 2008; summary results from DHS and RHS surveys in 18 countries in advanced stage of fertility transition

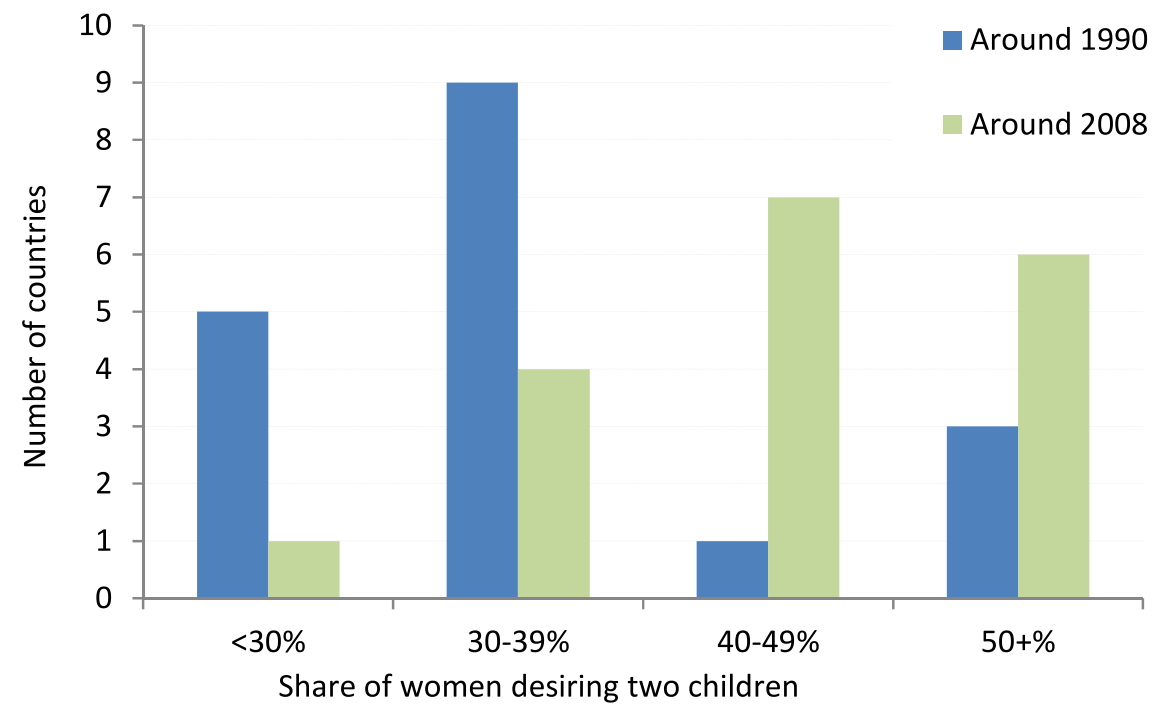




\section{Concluding Discussion}

\subsection{Main Findings}

In the last decades a two-child ideal has become nearly universal among women in Europe, as countries that used to display higher ideal family size have converged over time towards a twochild model. Six out of ten women in Europe consider two children as ideal and this proportion is very similar in different regions, irrespective of their fertility patterns and levels. Similarly, the mean ideal family size has become relatively closely clustered around 2.2 in most countries. Gradual shifts can be documented towards more women expressing an ideal of families with one child (and, quite rarely, no children), which goes hand in hand with the decline in an ideal of three or more children. These trends are regionally differentiated and have been more pronounced in Southern Europe (possibly in part due to the recent economic recession), Eastern and South-eastern Europe. However, there are no signs that women in any of the analysed European countries are moving away from a two-child ideal and embracing massively an ideal of having only one child, as has been evidenced in urban China (Basten and Gu Baochang 2013).

An increasing number of European countries - especially those which have reached a low level of completed fertility around 1.6 or lower-saw their mean ideal family size falling to relatively low level around 1.95-2.15. But with an exception of one survey for eastern Germany and a few additional surveys not included here due to high nonresponse, none of the analysed surveys suggests a decline of mean ideal family size to levels considerably below replacement, i.e., below 1.9 children per woman. Indeed, once a relatively low ideal family size below 2.3 is achieved, the next survey is more likely to show a slight increase rather than a further decline in MIFS. The evidence on the stability of reproductive ideals at around-replacement levels is most surprising for Austria, western Germany and Switzerland, which share an early fertility decline to levels well below replacement. Women in western Germany born in the mid-1950s reached a low completed fertility around 1.6, yet their daughters born in the 1980s continue expressing considerably higher ideals averaging around the population replacement level of 2.1. This evidence is at odds with earlier reports on fertility ideals in Austria and Germany falling to the very low levels of 1.6-1.7 (Goldstein, Lutz and Testa 2003), which might have been partly affected by high non-response, low sample size or other data-related issues in the 2001 Eurobarometer survey (see also Philipov and Bernardi 2011: 502, fn 4).

We have not analysed fertility ideals for men, but available studies indicate that they come very close to those of women in most countries (see Testa 2012: 57, Table A.2.1 for the 2011 Eurobarometer survey ). Furthermore, the findings presented here align closely with our earlier analyses of intended family size of young women and men aged 25-29 in European countries participating in the Family and Fertility Surveys (FFS) in the 1990s and Generation and Gender Program (GGP) surveys in the 2000s. In both surveys, mean intended family size among young adults was closely clustered around 2.1 in most countries, with the minimum values around 1.9 (Beaujouan, Sobotka, Brzozowska and Neels 2013). Thus the findings on family size ideals presented here can be broadly extended to reproductive intentions at younger ages in Europe: The intention of having two children clearly dominates and there are not many signs yet of a systematic shift of intentions to levels considerably below replacement. Such a shift occurs partly only among women at later reproductive ages, when they are confronted with various 
obstacles and competing preferences that lead to downward revisions of their initially higher reproductive intentions (Iacovou and Tavares 2011, Gray et al. 2013).

The data for countries outside Europe, though often based on somewhat different measures of reproductive preferences in DHS and RHS surveys, suggest a remarkable global spread of two-child orientation also in many countries where the fertility transition is still in progress. A clear two-child preference is detected even in some countries with fertility level remaining well above replacement such as Bolivia (estimated period TFR of 3.2; PRB 2013), but also in countries with "ultra-low" fertility such as South Korea (period TFR hitting a low of 1.08 in 2005).

\subsection{Why an Ideal of Two?}

The spread and the subsequent persistence of a two-child family ideal in Europe are remarkable. Neither long-term experience of below-replacement fertility nor major social and economic upheavals or cultural and technological changes seem to have affected the widespread perception that having two children is ideal, both personally and for the society. The notion that fertility ideals and norms might not stay centred on two or more children forever has been around for long. Coleman (1999) argued that the basic question is "...whether there is any imaginable reason why the average should be two. (...) It is difficult to think of a mechanism, outside the realm of psychological 'instincts', or of biology, how such norms could be permanently protected." But childlessness is often viewed as an "extreme" choice. From the perspective of evolutionary biology and psychology, Foster (2000) argues that humans, and in particular women are biologically predisposed to nurturing behaviour and this "need to nurture" is strong enough to ensure that "women want to bear at least one child, despite the substantial costs of so doing." As parenthood is perceived by most people as a unique, valuable and desired experience, childless people may attain the status of parents and satisfy their "baby longing" by having just one offspring (Rotkirch et al, 2011).

There are many pertinent arguments why having one child might be best from an individual point of view. Parents can allocate more time and resources to interacting with their only child while minimising the negative impact children have on their leisure time, career progression and income. Their resources and attention can concentrate on one child, who does not have to experience conflict and competition with siblings (Mancillas 2006). From the perspective of parents, having one child is the "cheapest way to become a parent" (Jefferies 2001) and it minimalizes not only the economic costs, but also the potential negative impact children have on parents' leisure and employment. Wilson (2013: 1383) suggests that if the demographic transition "is hypothesised as a change from quantity to quality in children, then the logical endpoint is one child, not two." Striessnig and Lutz (2013: 411) argue that "at the individual level it is sufficient to have one child (under low child mortality conditions) if the primary goal is to pass on one's genes and continue to live on in the next generation". Blake (1981), reviewing the contemporary evidence on only children, found that despite widespread negative stereotypes they are intellectually superior, record better educational achievement, tend to count themselves as happy and suffer no obvious character or personality defects or disruptive behaviour when compared with children from larger families. A more recent review by Mancilas (2006) broadly corroborates these findings, citing high achievement and intelligence as "the most 
consistent and strongest advantages of only children" (pp. 270-71). Finally, the first child may substantially increase parents' happiness, while second child increases happiness only a little or not at all (Kohler, Behrman and Skytthe 2005, Myrskylä and Margolis 2012).

We have identified four broader factors that motivate people in contemporary lowfertility settings to view more than one child as an ideal. Besides the last one (fitting the social norm) they do not necessarily provide a rationale for preferring two children rather than, say, three or four, but they do provide a clear case for preferring more than one. Given that parents face high opportunity costs of having children, two children provide an "ideal strategy" to conform to the factors discussed below with the smallest possible effort.

Having one child of each sex provides a strong motivation for preferring two children. Interacting with a boy and with a girl may be perceived as qualitatively distinct experiences linked with different kinds of practical and psychological benefits, enjoyment, stimulation, communication, and play. Having two children is then a minimum needed-under ideal circumstances - to experience an interaction with one kid of each sex. Indeed, research on sex preferences and actual fertility behaviour documents considerable motivation of couples to have at least one child of each sex. This is most clearly illustrated in the studies of fertility behaviour among the parents of two or more children, where "a distinct and stable preference for at least one child of each sex can be observed as a common pattern (...) across many different social, economic and cultural contexts, whether they be located in developing countries or in highly industrialized nations" (Hank 2007).

Single child is viewed as spoiled and suffering. Even in contemporary low-fertility societies there are enduring negative stereotypes about only children who are often perceived as spoiled, self-centred, narcissist, domineering and quarrelsome (Mancillas 2006, Hagewen and Morgan 2005, Blake 1981, Almodovar 1973). Mancilas (2006: 268) traces these stereotypes to the psychologist G. Stanley Hall who claimed in his 1898 study that "being an only child is a disease in itself". The "onlies" are also expected to suffer from their status, experiencing loneliness, anxiety and deprivation. Although most of these stereotypes are unfounded (Blake 1981, Mancillas 2006), they create a negative perception of parents who have only one child as being selfish. Jefferies (2001: 4) cites British and Australian studies as well as a UK online forum that show that providing a companionship for the first child is an important reason why parents desire a second one.

Two children as an insurance strategy. In high-mortality societies individuals had a strong motivation to "produce" many offspring to achieve a high chance that at least one survives to adulthood and will be able to reproduce. This motivation for having more than one child has dramatically diminished as almost all children now survive to middle age. But more subtle "insurance strategy" to have more than one child may still be at work. If one child does not meet parental expectations because it is troublesome, difficult, hyperactive, or scoring badly at school, and, later in life, drops from school, experiences poor health, abuses drugs, turns violent, or moves far away and severs his or her ties with parents, having another child dramatically improves the chances that at least some of the parents' expectations and desires related to their children will be met. In many societies, children still serve as main providers of 
care for their ailing parents and having two children strongly increases the likelihood the parents will have someone to care about them when they get old.

Fitting the social norm. In Europe and many countries outside Europe, having two children has become a norm widely shared across generations and social groups. Since this norm is so widespread, most people know about it. Individuals uncertain about their preferences may state, for convenience, that their ideal family size is two-as they know this conforms to general expectations. Moreover, many people may receive cues from their parents, other relatives, friends, peers and colleagues, perpetuating the notion that two children are ideal. Recent comments posted by the readers of a blog entry "From one child to two" by Aimee Phan (2013) attest to that. Reader 479 writes: "As a parent of an only child, I get negative comments all the time", while DMV74 states "I must say I'm sick of the constant bash against only children (...) I've NEVER heard anyone say anything negative about couples having a second child. My baby is only 6 months old and all we get is when are we planning for the second one." In addition, people responding the question on "societal ideal" may also answer it having in mind a common sense (and broadly correct) perception that in order for the population to replace itself each couple needs to have (at least) two children.

Finally, some respondents expressing a two-child ideal may be influenced by their current family size and the size of their family of origin. An online survey focused on fertility ideals revealed that the respondents with children had difficulties stating their ideals "retrospectively" without being affected by their current family status (Hin et al. 2011: 147, fn 9). At younger ages, respondents may base their preferences on the size of their family of origin (Régnier-Loilier 2006, Hayford 2009), which now frequently means two children.

Clearly, these are pertinent explanations for the persistence of two-child ideals. But since these ideals are partly based on misconceptions (negative stereotypes about only children) or on perceived social norms that may eventually erode, the current remarkable and near-universal dominance of the two-child ideal in Europe may not prevail in all parts of the continent. The two-child norm may also erode via the changes in family forms, especially stepfamilies, which contribute to the spread of other living arrangements than the "stereotypical" married couple with two biological children. Although the earlier predictions of the imminent spread of subreplacement ideals have not yet materialised, subtle shifts towards a higher share of women with one child ideal are observed in many countries. They provide a signal about the potential for a future spread of one child ideals in Europe. Whether this will indeed take place is an open question. 


\section{References}

Almodovar, Jean-Pierre. 1973. "Existe-t-il un "syndrome de l'enfant unique "?". Enfance 26(3): 235-249.

Basten, Stuart and Baochang Gu. 2013. "National and regional trends in ideal family size in China". Paper presented at the IUSSP International Population Conference, Busan, Korea, 26-31 August 2013. Accessed in November 2013 at $<$ http://www.iussp.org/sites/default/files/event_call_for_papers/GU $\% 20$ and $\% 20$ Basten $\% 2$ 0Long\%20Abstract.pdf $>$

Blake, Judith. 1966. "Ideal family size among white Americans: A quarter of a century's evidence." Demography 3(1): 154-173.

Blake, Judith. 1974. "Can we believe recent data on birth expectations in the United States?". Demography 11(1): 25-44.

Blake, Judith. 1981. "The only child in America: Prejudice versus performance." Population and Development Review 7(1): 43-54.

Bongaarts, John. 2002. "The end of the fertility transition in the developed world". Population and Development Review 28 (3): 419-443.

Chang, Ming-Cheng. 2006. "Taiwan's transition from high fertility to lowest low levels." Asian Journal of Health and Information Sciences 1(1): 1-15.

Coleman, David A. 1999. "Reproduction and survival in an unknown world". NIDI Hofstee Lecture Series 5, NIDI, The Hague.

Demeny, Paul. 2003. "Population policy dilemmas in Europe at the dawn of the twenty-first century". Population and Development Review 29 (1): 1-28.

Ding, Qu Jian and Therese Hesketh. 2006. "Family size, fertility preferences, and sex ratio in China in the era of the one child family policy: results from national family planning and reproductive health survey." $B M J, 333(7564): 371-373$.

Foster, Caroline. 2000. "The limits to low fertility: A biosocial approach". Population and Development Review 26 (2): 209-234.

Frejka, Tomas and Tomáš Sobotka. 2008. "Fertility in Europe: diverse, delayed, and below replacement." Demographic Research, Special collection 7, 19(3): 15-46.

Goldstein, Joshua R. and Michaela Kreyenfeld. 2011. "Has East Germany overtaken West Germany? Recent trends in order-specific fertility." Population and Development Review 37(3): 453-472.

Goldstein, Joshua R., Wolfgang Lutz, and Maria Rita Testa. 2003. "The emergence of subreplacement family size ideals in Europe". Population Research and Policy Review 22 (56): 479-496.

Gray, Edith, Ann Evans and Anna Reimondos. 2013. "Childbearing desires of childless men and women: When are goals adjusted?" Advances in Life Course Research 18(2): 141-149.

Hagewen, Kellie J. and S. Philip Morgan. 2005. "Intended and ideal family size in the United States." Population and Development Review 31(3): 507-527.

Hauser, Philip M. 1967. "Family planning and population programs." A book review article. Demography 4(1): 397-414.

Hayford, Sarah R. 2009. "The evolution of fertility expectations over the life course." Demography 46(4), 765-783. 
Hin, Saskia, Anne Gauthier, Joshua R. Goldstein, and Christoph Bühler. 2011. "Fertility preferences: what measuring second choices teaches us." Vienna Yearbook of Population Research 2011 (9): 131-156.

Iacovou, Maria and Lara Patricio Tavares. 2011. "Yearning, learning and conceding: reasons men and women change their childbearing intentions." Population and Development Review 37(1): 89-123.

ICF International. 2012. MEASURE DHS STATcompiler. Accessed April 17, 2013 at http://www.statcompiler.com.

Inglehart, Ronald. 1990. Culture shift in advanced industrial society. Princeton University Press, Princeton, New Jersey.

Kreyenfeld, Michaela. 2003. "Crisis or adaptation reconsidered: a comparison of East and West German fertility patterns in the first six years after the 'Wende'." European Journal of Population 19(3): 303-329.

Lesthaeghe, Ron. 1995. "The second demographic transition in Western countries: an interpretation". In.: K. O. Mason and A.-M. Jensen (eds.) Gender and family change in industrialized countries. Oxford, Clarendon Press, pp. 17-62.

Livingston, Gretchen and D'Vera Cohn. 2010. The New Demography of American Motherhood. Pew Research Centre, A Social \& Demographic Trends Report, Revised August 19, 2010.

Kohler, Hans-Peter, Jere R. Behrman, and Axel Skytthe. 2005. "Partner + Children = Happiness? The effects of partnerships and fertility on well-being." Population and Development Review 31(3): 407-445.

Merli, M. Giovanna and S. Philip Morgan. 2011. "Below replacement fertility preferences in Shanghai." Population-E 66(3): 519-542.

Merz, Eva M., and Aart C. Liefbroer. 2012. "The attitude toward voluntary childlessness in Europe: Cultural and institutional explanations." Journal of Marriage and Family 74(3): 587-600. Miller 2011

Myrskylä, Mikko and Rachel Margolis. 2012. "Happiness: before and after the kids." MPIDR Working Paper WP-2012-013, Max Planck Institute for Demographic Research, Rostock.

Myrskylä, Mikko, Joshua R. Goldstein, and Yen-Hsin Alice Cheng. 2013. "New cohort fertility forecasts for the developed world: rises, falls, and reversals." Population and Development Review 39(1): 31-56.

Ní Bhrolcháin, Máire and Éva Beaujouan. 2011. "Uncertainty in fertility intentions in Britain, 1979-2007." Vienna Yearbook of Population Research 2011(9): 99-129.

Nie, Yilin and Robert J. Wyman, 2005. "The one-child policy in Shanghai: Acceptance and internalization." Population and Development Review 31(2): 313-336.

NIPSSR. 2011a. The Fourteenth Japanese National Fertility Survey in 2010. Marriage Process and Fertility of Japanese Married Couples. National Institute of Popyulation and Social Security Research, Tokyo.

NIPSSR. 2011b. The Fourteenth Japanese National Fertility Survey in 2010. Attitudes toward Marriage and Family among Japanese Singles. National Institute of Popyulation and Social Security Research, Tokyo.

Philipov, Dimiter and Laura Bernardi. 2011. "Reproductive decisions: concepts and measurement in Austria, Germany and Switzerland." Comparative Population Studies, 36(2-3): 495-530. 
Quesnel-Vallée, Amélie and S. Philip Morgan. 2003. "Missing the target? Correspondence of fertility intentions and behavior in the U.S.". Population Research and Policy Review 22 (5-6): 497-525.

Phan, Aimee. 2013. "From one child to two." Posted 13 October 2013 on The Motherlode blog; accessed 25 March 2014 at <http://parenting.blogs.nytimes.com/2013/10/13/from-onechild-to-two/? _php $=$ true\&_type $=$ blogs\&_r $=0>$

PRB. 2013. World Population data Sheet 2013. Population Reference Bureau, Washington. Accessed 8 April 2014 at http://www.prb.org/Publications/Datasheets/2013/2013-worldpopulation-data-sheet/data-sheet.aspx

Régnier-Loilier, Arnaud. 2006. "Influence of own sibship size on the number of children desired at various times of life. The case of France." Population (English Edition) 61(3): 165-194.

Rotkirch, Anna, Stuart Basten, Heini Väisänen, and Markus Jokela. 2011. "Baby longing and men's reproductive motivation." Vienna Yearbook of Population Research 2011(9): 283306.

Ryder, Norman B. and Charles F. Westoff. 1969. "Relationships among intended expected desired and ideal family size: United States 1965." Population Research, March 1969.

Schoen, Robert, Nam Marie Astone, Young J. Kim, and Constance A. Nathanson. 1999. "Do fertility intentions affect fertility behaviour?" Journal of Marriage and the Family 61(3): 790-799.

Simons, John. 1978. "Illusions about attitudes." In: Population decline in Europe: Implications of a declining stationary population. Edward Arnold Publishers, Council of Europe, pp. 197-214.

Sobotka, Tomáš. 2011. "Fertility in Austria, Germany and Switzerland: is there a common pattern? “ Comparative Population Studies 36(2-3): 263-304.

Sobotka, Tomáš. 2013. "Pathways to Low Fertility: European Perspectives", Expert Paper No. 2013/8, United Nations Department of Economic and Social Affairs, Population Division. URL: $\quad$ http://www.un.org/en/development/desa/population/publications/pdf/expert/20138 Sobotka_Expert-Paper.pdf

Testa, Maria Rita. 2007 "Childbearing preferences and family issues in Europe: evidence from the Eurobarometer 2006 survey." Vienna Yearbook of Population Research 2007(5): 357379.

Testa 2012 - report on EB intentions

Testa, Maria Rita and Stuart Basten. 2013. "Fertility intentions and the 'Great Recession': evidence from the Eurobarometer surveys." Paper presented at Session 177 of the 2013 Annual Meeting of Population Association of America, New Orleans, 11-13 April 2013. Accessed in September 2013 at $<$ http://paa2013.princeton.edu/abstracts/132162>,

Testa, Maria Rita. 2012. "Family sizes in Europe. Evidence firom the 2011 Eurobarometer survey." European Demographic Research Papers 2012, No. 2. Vienna Institute of Demography, Austrian Academy of Sciences. URL: http://www.oeaw.ac.at/vid/download/edrp_2_2012.pdf

Testa, Maria Rita and Leonardo Grilli. 2006. "The influence of childbearing regional contexts on ideal family size in Europe." Population (English edition) 61(1) : 99-127.

Trent, Roger B. 1980. "Evidence bearing on the construct validity of" ideal family size"." Population and Environment 3.3-4 (1980): 309-327."

Van de Kaa, Dirk J. 2001. "Postmodern fertility preferences: From changing value orientation to new behavior". In.: R. A. Bulatao, J. B. Casterline (eds.) Global fertility transition. 
Supplement to Population and Development Review 27, New York, Population Council, pp. 290-338.

VID. 2014. European Demographic Data Sheet. Vienna Institute of Demography and IIASA / Wittgenstein Centre for Denmography and Global Human Capital. Forthcoming in June 2014 at http://www.oeaw.ac.at/vid/datasheet/index.html

Ware, Helen. 1974. "Ideal family size." World Fertility Survey, Occasional Papers No. 13 (October 1974), $28 \mathrm{p}$.

Wilson, Chris. "Thinking about post-transitional demographic regimes: A reflection." Demographic Research 28(46): 1373-1388. 


\section{Appendix 1: Overview of all European datasets considered for the analysis}

\begin{tabular}{|c|c|c|c|c|c|c|c|c|}
\hline Country & Year & Survey & Selected & $\begin{array}{l}N(F \\
\text { aged } \\
15-49) \\
\end{array}$ & $\begin{array}{l}\text { \% miss., } \\
\text { DKN, } \\
\text { other }\end{array}$ & $\begin{array}{l}\text { Mean } \\
\text { ideal FS }\end{array}$ & $\begin{array}{l}\text { \% with 2- } \\
\text { child } \\
\text { ideal }\end{array}$ & $\begin{array}{l}\text { \% 2-child } \\
\text { ideal } \\
\text { (adjusted) }\end{array}$ \\
\hline Albania & 1998 & WVS & $\mathrm{Y}$ & 362 & 8 & 2.36 & 53 & 57 \\
\hline Albania & 2002 & WVS & $\mathrm{Y}$ & 363 & 3 & 2.62 & 42 & 43 \\
\hline Albania & $2008-9$ & DHS & $\mathrm{Y}$ & 7584 & 1 & 2.54 & 48 & 48 \\
\hline Austria & 1988 & ISSP & $\mathrm{Y}$ & 299 & 0 & 2.30 & 68 & 68 \\
\hline Austria & 1990 & EVS & $\mathrm{Y}$ & 496 & 2 & 2.38 & 60 & 61 \\
\hline Austria & 1994 & ISSP & $\mathrm{Y}$ & 299 & 3 & 2.10 & 74 & 76 \\
\hline Austria & 2001 & EB & $\mathrm{N}^{1}$ & 316 & 23 & 1.86 & 45 & 58 \\
\hline Austria & 2006 & EB & $\mathrm{N}^{1}$ & 324 & 32 & 1.73 & 40 & 59 \\
\hline Austria & $2008-9$ & GGP & $\mathrm{Y}$ & 3001 & 0 & 2.17 & 57 & 58 \\
\hline Austria & 2011 & EB & $\mathrm{Y}$ & 329 & 15 & 1.98 & 51 & 60 \\
\hline Austria & 2012 & GGP & $\mathrm{Y}$ & 2808 & 1 & 2.20 & 59 & 60 \\
\hline Belarus & 1990 & EVS & $\mathrm{Y}$ & 418 & 1 & 2.45 & 56 & 56 \\
\hline Belarus & 1996 & WVS & $\mathrm{Y}$ & 743 & 2 & 2.11 & 67 & 69 \\
\hline Belgium & 1979 & $\mathrm{~EB}^{+}$ & $\mathrm{Y}$ & 297 & 4 & 2.30 & 60 & 63 \\
\hline Belgium & 1981 & EVS & $\mathrm{Y}$ & 358 & 17 & 2.45 & 47 & 56 \\
\hline Belgium & 1990 & EVS & $\mathrm{Y}$ & 841 & 9 & 2.48 & 49 & 54 \\
\hline Belgium & 2001 & EB & $\mathrm{Y}$ & 298 & 15 & 2.19 & 57 & 67 \\
\hline Belgium & 2006 & EB & $\mathrm{Y}$ & 296 & 7 & 2.26 & 57 & 61 \\
\hline Belgium & 2011 & EB & $\mathrm{Y}$ & 272 & 6 & 2.19 & 59 & 62 \\
\hline Bulgaria & 1991 & EVS & $\mathrm{Y}$ & 367 & 2 & 2.17 & 68 & 70 \\
\hline Bulgaria & 1994 & ISSP & $\mathrm{Y}$ & 361 & 0 & 2.00 & 66 & 66 \\
\hline Bulgaria & 1997 & WVS & $\mathrm{Y}$ & 315 & 3 & 2.12 & 67 & 69 \\
\hline Bulgaria & 2006 & $\mathrm{~EB}^{*}$ & $\mathrm{Y}$ & 292 & 10 & 2.12 & 65 & 72 \\
\hline Bulgaria & 2011 & $\mathrm{~EB}$ & $\mathrm{Y}$ & 274 & 7 & 2.03 & 73 & 79 \\
\hline Croatia & 1996 & WVS & $\mathrm{Y}$ & 432 & 4 & 2.67 & 44 & 46 \\
\hline Croatia & 2006 & EB* & $\mathrm{Y}$ & 322 & 8 & 2.31 & 58 & 63 \\
\hline Cyprus & 2006 & EB & $\mathrm{N}^{2}$ & 147 & 2 & 2.86 & 25 & 26 \\
\hline Cyprus & 2011 & EB & $\mathrm{N}^{2}$ & 168 & 2 & 2.36 & 56 & 58 \\
\hline Czech Republic & 1990 & WVS & $\mathrm{Y}$ & 289 & 0 & 2.18 & 76 & 76 \\
\hline Czech Republic & 1991 & EVS & $\mathrm{Y}$ & 670 & 1 & 2.20 & 74 & 75 \\
\hline Czech Republic & 1994 & ISSP & $\mathrm{Y}$ & 359 & 0 & 2.14 & 69 & 69 \\
\hline Czech Republic & 1998 & WVS & $\mathrm{Y}$ & 327 & 2 & 2.07 & 74 & 76 \\
\hline Czech Republic & 2006 & EB & $\mathrm{Y}$ & 348 & 9 & 2.06 & 67 & 73 \\
\hline Czech Republic & 2011 & EB & $\mathrm{Y}$ & 363 & 8 & 1.93 & 63 & 68 \\
\hline
\end{tabular}




\begin{tabular}{|c|c|c|c|c|c|c|c|c|}
\hline Country & Year & Survey & Selected & $\begin{array}{l}N(F \\
\text { aged } \\
15-49) \\
\end{array}$ & $\begin{array}{l}\text { \% miss., } \\
\text { DKN, } \\
\text { other }\end{array}$ & $\begin{array}{l}\text { Mean } \\
\text { ideal FS }\end{array}$ & $\begin{array}{l}\% \text { with } 2- \\
\text { child } \\
\text { ideal }\end{array}$ & $\begin{array}{l}\% \text { 2-child } \\
\text { ideal } \\
\text { (adjusted) }\end{array}$ \\
\hline Denmark & 1979 & $\mathrm{~EB}^{+}$ & $\mathrm{Y}$ & 371 & 8 & 2.34 & 61 & 67 \\
\hline Denmark & 1981 & EVS & $\mathrm{N}^{1}$ & 398 & 20 & 2.43 & 46 & 57 \\
\hline Denmark & 1990 & EVS & $\mathrm{Y}$ & 310 & 4 & 2.57 & 52 & 54 \\
\hline Denmark & 2001 & EB & $\mathrm{Y}$ & 281 & 12 & 2.36 & 53 & 60 \\
\hline Denmark & 2006 & EB & $\mathrm{N}^{1}$ & 250 & 21 & 2.52 & 43 & 55 \\
\hline Denmark & 2011 & EB & Y & 204 & 12 & 2.50 & 45 & 51 \\
\hline Estonia & 1990 & EVS & $\mathrm{Y}$ & 381 & 2 & 2.51 & 43 & 44 \\
\hline Estonia & 1996 & WVS & $\mathrm{Y}$ & 356 & 1 & 2.43 & 50 & 51 \\
\hline Estonia & 2006 & EB & $\mathrm{Y}$ & 308 & 8 & 2.53 & 44 & 47 \\
\hline Estonia & 2011 & EB & $\mathrm{Y}$ & 256 & 4 & 2.53 & 45 & 47 \\
\hline Finland & 1990 & EVS & $\mathrm{Y}$ & 217 & 12 & 2.66 & 37 & 42 \\
\hline Finland & 1996 & WVS & $\mathrm{Y}$ & 339 & 6 & 2.57 & 45 & 48 \\
\hline Finland & 2001 & EB & $\mathrm{N}^{1}$ & 301 & 19 & 2.48 & 40 & 49 \\
\hline Finland & 2006 & $\mathrm{~EB}$ & $\mathrm{Y}$ & 251 & 7 & 2.72 & 39 & 42 \\
\hline Finland & 2011 & EB & $\mathrm{Y}$ & 241 & 7 & 2.52 & 43 & 46 \\
\hline France & 1955 & Conj. & $\mathrm{Y}$ & 777 & 6 & 2.79 & 28 & 30 \\
\hline France & 1967 & Conj. & $\mathrm{Y}$ & 407 & 4 & 2.65 & 37 & 39 \\
\hline France & 1976 & Conj. & Y & 716 & 6 & 2.60 & 40 & 43 \\
\hline France & 1979 & $\mathrm{~EB}^{+}$ & $\mathrm{Y}$ & 370 & 5 & 2.47 & 46 & 48 \\
\hline France & 1981 & EVS & $\mathrm{Y}$ & 453 & 5 & 2.65 & 44 & 46 \\
\hline France & 1982 & Conj. & $\mathrm{Y}$ & 816 & 2 & 2.61 & 40 & 41 \\
\hline France & 1987 & Conj. & $\mathrm{Y}$ & 762 & 1 & 2.62 & 42 & 43 \\
\hline France & 1990 & EVS & $\mathrm{Y}$ & 364 & 4 & 2.60 & 45 & 47 \\
\hline France & 1998 & Int. fec. & $\mathrm{Y}$ & 1391 & 2 & 2.57 & 51 & 51 \\
\hline France & 2001 & EB & Y & 339 & 12 & 2.51 & 43 & 49 \\
\hline France & 2006 & EB & $\mathrm{Y}$ & 309 & 7 & 2.51 & 49 & 53 \\
\hline France & 2010 & Fecond & Y & 2425 & 4 & 2.48 & 55 & 57 \\
\hline France & 2011 & EB & $\mathrm{Y}$ & 266 & 6 & 2.30 & 62 & 66 \\
\hline eastern Germany & 1990 & EVS & $\mathrm{Y}$ & 413 & 1 & 1.96 & 67 & 68 \\
\hline eastern Germany & 1994 & ISSP & $\mathrm{Y}$ & 289 & 1 & 1.94 & 77 & 78 \\
\hline eastern Germany & 1997 & WVS & Y & 341 & 6 & 2.01 & 69 & 73 \\
\hline eastern Germany & 2001 & EB & $\mathrm{Y}$ & 290 & 13 & 1.78 & 50 & 58 \\
\hline eastern Germany & 2006 & EB & $\mathrm{Y}$ & 119 & 8 & 2.11 & 67 & 73 \\
\hline eastern Germany & 2011 & $\mathrm{~EB}$ & Y & 163 & 13 & 1.98 & 57 & 66 \\
\hline
\end{tabular}




\begin{tabular}{|c|c|c|c|c|c|c|c|c|}
\hline Country & Year & Survey & Selected & $\begin{array}{l}N(F \\
\text { aged } \\
15-49) \\
\end{array}$ & $\begin{array}{l}\text { \% miss., } \\
\text { DKN, } \\
\text { other }\end{array}$ & $\begin{array}{l}\text { Mean } \\
\text { ideal FS }\end{array}$ & $\begin{array}{l}\% \text { with } 2- \\
\text { child } \\
\text { ideal }\end{array}$ & $\begin{array}{l}\% \text { 2-child } \\
\text { ideal } \\
\text { (adjusted) }\end{array}$ \\
\hline western Germany & 1979 & $\mathrm{~EB}^{+}$ & $\mathrm{Y}$ & 331 & 14 & 2.10 & 58 & 67 \\
\hline western Germany & 1981 & EVS & $\mathrm{Y}$ & 442 & 17 & 2.24 & 56 & 68 \\
\hline western Germany & 1988 & ISSP & $\mathrm{Y}$ & 954 & 4 & 2.13 & 64 & 67 \\
\hline western Germany & 1990 & EVS & $\mathrm{Y}$ & 595 & 10 & 2.10 & 55 & 61 \\
\hline western Germany & 1994 & ISSP & $\mathrm{Y}$ & 648 & 3 & 2.22 & 67 & 69 \\
\hline western Germany & 1997 & WVS & $\mathrm{Y}$ & 395 & 14 & 2.41 & 58 & 68 \\
\hline western Germany & 2001 & $\mathrm{~EB}$ & $\mathrm{~N}^{1}$ & 280 & 19 & 2.00 & 52 & 65 \\
\hline western Germany & 2006 & $\mathrm{~EB}$ & $\mathrm{Y}$ & 276 & 14 & 2.20 & 58 & 67 \\
\hline western Germany & 2011 & EB & $\mathrm{Y}$ & 258 & 14 & 2.10 & 58 & 67 \\
\hline Greece & 2001 & EB & $\mathrm{Y}$ & 289 & 2 & 2.56 & 46 & 47 \\
\hline Greece & 2006 & EB & $\mathrm{Y}$ & 298 & 4 & 2.40 & 49 & 51 \\
\hline Greece & 2011 & EB & $\mathrm{Y}$ & 288 & 8 & 2.29 & 56 & 60 \\
\hline Hungary & 1988 & ISSP & $\mathrm{Y}$ & 601 & 0 & 2.36 & 65 & 65 \\
\hline Hungary & 1991 & EVS & $\mathrm{Y}$ & 283 & 2 & 2.26 & 67 & 68 \\
\hline Hungary & 1994 & ISSP & $\mathrm{Y}$ & 421 & 3 & 2.26 & 59 & 61 \\
\hline Hungary & 1998 & WVS & $\mathrm{Y}$ & 191 & 5 & 2.36 & 56 & 59 \\
\hline Hungary & 2006 & $\mathrm{~EB}$ & $\mathrm{Y}$ & 285 & 4 & 2.22 & 62 & 65 \\
\hline Hungary & 2011 & $\mathrm{~EB}$ & $\mathrm{Y}$ & 276 & 5 & 2.14 & 61 & 65 \\
\hline Iceland & 1984 & EVS & $\mathrm{Y}$ & 345 & 1 & 2.90 & 27 & 28 \\
\hline Iceland & 1990 & EVS & $\mathrm{Y}$ & 253 & 4 & 2.95 & 21 & 22 \\
\hline Ireland & 1979 & $\mathrm{~EB}^{+}$ & $\mathrm{Y}$ & 310 & 7 & 3.48 & 21 & 22 \\
\hline Ireland & 1981 & EVS & Y & 453 & 10 & 3.88 & 17 & 19 \\
\hline Ireland & 1988 & ISSP & Y & 349 & 3 & 3.38 & 23 & 24 \\
\hline Ireland & 1990 & EVS & $\mathrm{Y}$ & 324 & 3 & 3.28 & 29 & 30 \\
\hline Ireland & 1994 & ISSP & $\mathrm{Y}$ & 301 & 6 & 2.97 & 34 & 36 \\
\hline Ireland & 2001 & EB & $\mathrm{N}^{1}$ & 359 & 30 & 2.66 & 28 & 40 \\
\hline Ireland & 2006 & EB & $\mathrm{N}^{1}$ & 331 & 26 & 2.81 & 28 & 37 \\
\hline Ireland & 2011 & EB & $\mathrm{N}^{1}$ & 351 & 23 & 2.70 & 32 & 42 \\
\hline Italy & 1979 & $\mathrm{~EB}^{+}$ & $\mathrm{Y}$ & 363 & 4 & 2.05 & 64 & 67 \\
\hline Italy & 1981 & EVS & $\mathrm{Y}$ & 471 & 4 & 2.27 & 61 & 64 \\
\hline Italy & 1988 & ISSP & $\mathrm{Y}$ & 341 & 0 & 2.37 & 58 & 58 \\
\hline Italy & 1990 & EVS & $\mathrm{Y}$ & 712 & 7 & 2.40 & 52 & 56 \\
\hline Italy & 1994 & ISSP & $\mathrm{Y}$ & 327 & 1 & 2.24 & 65 & 65 \\
\hline Italy & 2001 & EB & Y & 290 & 16 & 2.25 & 52 & 62 \\
\hline Italy & 2006 & EB & $\mathrm{Y}$ & 452 & 15 & 2.01 & 53 & 62 \\
\hline Italy & 2011 & $\mathrm{~EB}$ & $\mathrm{Y}$ & 354 & 14 & 1.95 & 52 & 60 \\
\hline
\end{tabular}




\begin{tabular}{|c|c|c|c|c|c|c|c|c|}
\hline Country & Year & Survey & Selected & $\begin{array}{l}N(F \\
\text { aged } \\
15-49)\end{array}$ & $\begin{array}{l}\text { \% miss., } \\
\text { DKN, } \\
\text { other }\end{array}$ & $\begin{array}{l}\text { Mean } \\
\text { ideal FS }\end{array}$ & $\begin{array}{l}\text { \% with } 2- \\
\text { child } \\
\text { ideal }\end{array}$ & $\begin{array}{l}\% \text { 2-child } \\
\text { ideal } \\
\text { (adjusted) }\end{array}$ \\
\hline Latvia & 1990 & EVS & Y & 412 & 9 & 2.57 & 40 & 44 \\
\hline Latvia & 1996 & WVS & $\mathrm{Y}$ & 437 & 1 & 2.41 & 52 & 53 \\
\hline Latvia & 2006 & EB & $\mathrm{Y}$ & 361 & 5 & 2.36 & 53 & 56 \\
\hline Latvia & 2011 & EB & $\mathrm{Y}$ & 355 & 3 & 2.40 & 51 & 52 \\
\hline Lithuania & 1990 & EVS & Y & 329 & 10 & 2.57 & 42 & 47 \\
\hline Lithuania & 1997 & WVS & $\mathrm{Y}$ & 313 & 5 & 2.39 & 53 & 56 \\
\hline Lithuania & 2006 & EB & $\mathrm{Y}$ & 312 & 2 & 2.23 & 62 & 63 \\
\hline Lithuania & 2011 & EB & $\mathrm{Y}$ & 314 & 6 & 2.22 & 59 & 63 \\
\hline Luxembourg & 1979 & $\mathrm{~EB}^{+}$ & $\mathrm{N}^{2,4}$ & 83 & 4 & 2.22 & 60 & 63 \\
\hline Luxembourg & 2001 & EB & $\mathrm{N}^{1,2}$ & 192 & 19 & 2.17 & 60 & 75 \\
\hline Luxembourg & 2006 & EB & $\mathrm{N}^{2}$ & 168 & 16 & 2.22 & 54 & 64 \\
\hline Luxembourg & 2011 & EB & $\mathrm{N}^{2}$ & 158 & 8 & 2.26 & 58 & 63 \\
\hline Macedonia & 1998 & WVS & $\mathrm{Y}$ & 376 & 6 & 2.33 & 58 & 62 \\
\hline Macedonia & 2001 & WVS & $\mathrm{Y}$ & 361 & 3 & 2.53 & 51 & 52 \\
\hline Malta & 1983 & EVS & $\mathrm{N}^{2}$ & 163 & 10 & 2.71 & 33 & 37 \\
\hline Malta & 1991 & EVS & $\mathrm{N}^{2}$ & 124 & 14 & 3.01 & 32 & 38 \\
\hline Malta & 2006 & EB & $\mathrm{N}^{2}$ & 146 & 7 & 2.05 & 65 & 69 \\
\hline Malta & 2011 & EB & $\mathrm{N}^{2}$ & 181 & 5 & 1.89 & 58 & 61 \\
\hline Moldova & 1996 & WVS & $\mathrm{Y}$ & 324 & 2 & 2.64 & 42 & 43 \\
\hline Moldova & 2002 & WVS & $\mathrm{Y}$ & 376 & 6 & 2.48 & 51 & 54 \\
\hline Montenegro & 1996 & WVS & $\mathrm{N}^{2,4}$ & 85 & 2 & 3.08 & 24 & 24 \\
\hline Montenegro & 2001 & WVS & $\mathrm{N}^{2}$ & 346 & 4 & 3.05 & 30 & 31 \\
\hline Netherlands & 1979 & $\mathrm{~EB}^{+}$ & Y & 369 & 6 & 2.29 & 67 & 71 \\
\hline Netherlands & 1981 & EVS & $\mathrm{Y}$ & 521 & 10 & 2.54 & 50 & 56 \\
\hline Netherlands & 1988 & ISSP & Y & 649 & 4 & 2.60 & 49 & 52 \\
\hline Netherlands & 1990 & EVS & Y & 400 & 13 & 2.52 & 42 & 48 \\
\hline Netherlands & 1994 & ISSP & $\mathrm{Y}$ & 742 & 0 & 2.61 & 51 & 51 \\
\hline Netherlands & 2001 & EB & $\mathrm{N}^{1}$ & 341 & 20 & 2.21 & 55 & 69 \\
\hline Netherlands & 2006 & EB & $\mathrm{N}^{1}$ & 345 & 25 & 2.37 & 47 & 63 \\
\hline Netherlands & 2011 & EB & $\mathrm{Y}$ & 271 & 16 & 2.25 & 58 & 69 \\
\hline Northern Ireland & 1979 & $\mathrm{~EB}+$ & $\mathrm{N}^{3,4}$ & 97 & 11 & 2.71 & 46 & 52 \\
\hline Northern Ireland & 1981 & EVS & $\mathrm{N}^{3}$ & 103 & 7 & 2.96 & 44 & 47 \\
\hline Northern Ireland & 1990 & EVS & $\mathrm{N}^{3}$ & 112 & 7 & 2.84 & 38 & 41 \\
\hline Northern Ireland & 1994 & ISSP & $\mathrm{N}^{3}$ & 194 & 5 & 2.79 & 44 & 46 \\
\hline Northern Ireland & 2001 & EB & $\mathrm{N}^{3}$ & 115 & 12 & 2.44 & 53 & 60 \\
\hline Northern Ireland & 2006 & EB & $\mathrm{N}^{1,3,4}$ & 94 & 24 & 2.54 & 42 & 56 \\
\hline Northern Ireland & 2011 & EB & $\mathrm{N}^{1,3,4}$ & 82 & 27 & 2.62 & 37 & 50 \\
\hline
\end{tabular}




\begin{tabular}{|c|c|c|c|c|c|c|c|c|}
\hline Country & Year & Survey & Selected & $\begin{array}{l}N(F \\
\text { aged } \\
15-49)\end{array}$ & $\begin{array}{l}\text { \% miss., } \\
\text { DKN, } \\
\text { other }\end{array}$ & $\begin{array}{l}\text { Mean } \\
\text { ideal FS }\end{array}$ & $\begin{array}{l}\text { \% with } 2- \\
\text { child } \\
\text { ideal }\end{array}$ & $\begin{array}{l}\% \text { 2-child } \\
\text { ideal } \\
\text { (adjusted) }\end{array}$ \\
\hline Norway & 1982 & EVS & Y & 291 & 11 & 2.62 & 45 & 51 \\
\hline Norway & 1990 & EVS & Y & 388 & 10 & 2.58 & 44 & 48 \\
\hline Norway & 1994 & ISSP & Y & 813 & 4 & 2.63 & 44 & 46 \\
\hline Norway & 1996 & WVS & Y & 372 & 10 & 2.65 & 38 & 42 \\
\hline Poland & 1990 & EVS & Y & 316 & 7 & 2.43 & 54 & 58 \\
\hline Poland & 1994 & ISSP & Y & 511 & 11 & 2.48 & 52 & 59 \\
\hline Poland & 1997 & WVS & Y & 347 & 9 & 2.47 & 48 & 52 \\
\hline Poland & 2006 & EB & Y & 292 & 5 & 2.22 & 60 & 63 \\
\hline Poland & 2011 & EB & $\mathrm{Y}$ & 308 & 15 & 2.15 & 51 & 60 \\
\hline Portugal & 1990 & EVS & Y & 383 & 1 & 2.37 & 59 & 60 \\
\hline Portugal & 2001 & EB & Y & 295 & 7 & 2.20 & 62 & 67 \\
\hline Portugal & 2006 & EB & Y & 232 & 7 & 2.23 & 62 & 66 \\
\hline Portugal & 2011 & EB & $\mathrm{Y}$ & 286 & 6 & 2.00 & 60 & 64 \\
\hline Romania & 1993 & EVS & Y & 345 & 0 & 2.19 & 66 & 67 \\
\hline Romania & 1998 & WVS & Y & 439 & 1 & 2.01 & 65 & 65 \\
\hline Romania & 2006 & $\mathrm{~EB}^{*}$ & Y & 312 & 11 & 1.93 & 65 & 73 \\
\hline Romania & 2011 & EB & $\mathrm{Y}$ & 323 & 11 & 1.97 & 63 & 71 \\
\hline Russia & 1990 & WVS & $\mathrm{Y}$ & 711 & 8 & 2.48 & 49 & 53 \\
\hline Russia & 1994 & ISSP & Y & 887 & 3 & 2.14 & 67 & 69 \\
\hline Russia & 1995 & WVS & Y & 664 & 2 & 2.15 & 67 & 69 \\
\hline Serbia & 1996 & WVS & Y & 381 & 2 & 2.45 & 52 & 53 \\
\hline Serbia & 2001 & WVS & Y & 350 & 3 & 2.58 & 45 & 47 \\
\hline Slovakia & 1990 & WVS & Y & 162 & 0 & 2.28 & 62 & 62 \\
\hline Slovakia & 1991 & EVS & Y & 388 & 2 & 2.39 & 61 & 62 \\
\hline Slovakia & 1998 & WVS & Y & 316 & 1 & 2.29 & 63 & 63 \\
\hline Slovakia & 2006 & EB & Y & 387 & 8 & 2.12 & 62 & 67 \\
\hline Slovakia & 2011 & EB & $\mathrm{Y}$ & 320 & 8 & 2.10 & 58 & 63 \\
\hline Slovenia & 1992 & EVS & Y & 332 & 6 & 2.31 & 60 & 64 \\
\hline Slovenia & 1994 & ISSP & $\mathrm{Y}$ & 340 & 1 & 2.29 & 60 & 61 \\
\hline Slovenia & 1995 & WVS & $\mathrm{Y}$ & 340 & 2 & 2.39 & 54 & 56 \\
\hline Slovenia & 2006 & EB & $\mathrm{Y}$ & 374 & 6 & 2.39 & 55 & 58 \\
\hline Slovenia & 2011 & EB & Y & 274 & 11 & 2.38 & 57 & 64 \\
\hline Spain & 1981 & EVS & $\mathrm{Y}$ & 739 & 8 & 2.88 & 35 & 38 \\
\hline Spain & 1990 & EVS & Y & 924 & 4 & 2.43 & 53 & 55 \\
\hline Spain & 1990 & WVS & Y & 504 & 5 & 2.33 & 59 & 62 \\
\hline Spain & 1994 & ISSP & Y & 754 & 5 & 2.33 & 58 & 61 \\
\hline Spain & 1995 & EVS & Y & 361 & 4 & 2.39 & 57 & 60 \\
\hline Spain & 2000 & WVS & Y & 348 & 3 & 2.20 & 59 & 61 \\
\hline Spain & 2001 & EB & $\mathrm{Y}$ & 319 & 10 & 2.19 & 58 & 65 \\
\hline
\end{tabular}




\begin{tabular}{|c|c|c|c|c|c|c|c|c|}
\hline Country & Year & Survey & Selected & $\begin{array}{l}N(F \\
\text { aged } \\
15-49) \\
\end{array}$ & $\begin{array}{l}\text { \% miss., } \\
\text { DKN, } \\
\text { other }\end{array}$ & $\begin{array}{l}\text { Mean } \\
\text { ideal FS } \\
\end{array}$ & $\begin{array}{l}\% \text { with 2- } \\
\text { child } \\
\text { ideal }\end{array}$ & $\begin{array}{l}\% \text { 2-child } \\
\text { ideal } \\
\text { (adjusted) }\end{array}$ \\
\hline Spain & 2006 & EB & $\mathrm{Y}$ & 307 & 10 & 2.15 & 62 & 69 \\
\hline Spain & 2011 & EB & $\mathrm{Y}$ & 305 & 7 & 2.07 & 64 & 68 \\
\hline Sweden & 1982 & EVS & $\mathrm{Y}$ & 269 & 7 & 2.38 & 60 & 65 \\
\hline Sweden & 1990 & EVS & $\mathrm{Y}$ & 302 & 12 & 2.64 & 46 & 52 \\
\hline Sweden & 1994 & ISSP & $\mathrm{Y}$ & 410 & 4 & 2.47 & 59 & 62 \\
\hline Sweden & 1996 & WVS & $\mathrm{Y}$ & 308 & 7 & 2.65 & 48 & 52 \\
\hline Sweden & 1999 & EVS & $\mathrm{Y}$ & 307 & 10 & 2.61 & 48 & 53 \\
\hline Sweden & 2001 & EB & $\mathrm{Y}$ & 277 & 16 & 2.42 & 50 & 60 \\
\hline Sweden & 2006 & EB & $\mathrm{Y}$ & 255 & 15 & 2.52 & 46 & 54 \\
\hline Sweden & 2011 & EB & $\mathrm{Y}$ & 266 & 10 & 2.39 & 51 & 57 \\
\hline Switzerland & 1989 & WVS & $\mathrm{Y}$ & 440 & 9 & 2.63 & 53 & 58 \\
\hline Switzerland & 1996 & WVS & $\mathrm{Y}$ & 378 & 8 & 2.37 & 61 & 67 \\
\hline Switzerland & 2002 & $\mathrm{SHP}^{5}$ & $\mathrm{Y}$ & 1089 & 8 & 2.28 & 66 & 72 \\
\hline Switzerland & 2005 & $\mathrm{SHP}^{5}$ & $\mathrm{Y}$ & 2038 & 8 & 2.18 & 67 & 73 \\
\hline Ukraine & 1996 & WVS & $\mathrm{Y}$ & 1003 & 5 & 2.14 & 64 & 68 \\
\hline Ukraine & 2007 & DHS & $\mathrm{Y}$ & 6841 & 4 & 1.97 & 61 & 63 \\
\hline United Kingdom & 1979 & $\mathrm{~EB}^{+}$ & $\mathrm{Y}$ & 330 & 8 & 2.25 & 66 & 72 \\
\hline United Kingdom & 1981 & EVS & $\mathrm{Y}$ & 390 & 7 & 2.34 & 64 & 69 \\
\hline United Kingdom & 1988 & WVS & $\mathrm{Y}$ & 447 & 9 & 2.38 & 64 & 71 \\
\hline United Kingdom & 1990 & EVS & $\mathrm{Y}$ & 457 & 8 & 2.39 & 58 & 63 \\
\hline United Kingdom & 1994 & ISSP & $\mathrm{Y}$ & 307 & 7 & 2.32 & 66 & 72 \\
\hline United Kingdom & 1998 & WVS & $\mathrm{Y}$ & 355 & 6 & 2.32 & 62 & 66 \\
\hline United Kingdom & 2001 & EB & $\mathrm{Y}$ & 354 & 17 & 2.36 & 51 & 61 \\
\hline United Kingdom & 2006 & $\mathrm{~EB}$ & $\mathrm{~N}^{1}$ & 280 & 23 & 2.49 & 40 & 52 \\
\hline United Kingdom & 2011 & EB & $\mathrm{N}^{1}$ & 293 & 21 & 2.37 & 45 & 58 \\
\hline
\end{tabular}

Notes

In the original dataset nonresponse and non-numerical responses combined with the respondents stating an ideal of "no children"; data adjusted in the table assuming that no respondents expressed an ideal of having no children

* In the original dataset the responses were shifted by one child; data and computations corrected here

1 The share of non-response and non-numerical responses reached $19 \%$ or higher

2 Small countries with population below 1 million excluded from the analysis

3 Data for Northern Ireland excluded from the analysis

4 Surveys with fewer than 100 female respondents aged 15-49 excluded from the analysis

$5 \quad$ Data not weighted

Conj. Enquête conjoncture

Int. Fec. Enquête intentions de fécondité

Fecond Enquête Fecond 
Appendix 2: Ideal family size in European regions: Main results for selected time periods

\begin{tabular}{|c|c|c|c|c|c|c|c|c|c|c|c|c|c|c|c|}
\hline \multicolumn{3}{|c|}{ Western Europe } & \multirow{3}{*}{$\begin{array}{c}\text { 2-child ideal: } \\
\text { \# surveys } \\
\text { with }>50 \%\end{array}$} & \multirow[b]{3}{*}{$\begin{array}{c}\text { MIFS } \\
\text { (average) }\end{array}$} & \multirow[b]{3}{*}{$\begin{array}{c}\text { Min } \\
\text { MIFS }\end{array}$} & \multirow[b]{3}{*}{$\begin{array}{l}\text { Max } \\
\text { MIFS }\end{array}$} & \multirow[b]{3}{*}{$\begin{array}{l}\text { Median } \\
\text { IFS }\end{array}$} & \multirow[b]{3}{*}{ Stdev } & \multicolumn{7}{|c|}{$\begin{array}{l}\text { Average share of respondents with a given family size } \\
\text { ideal }\end{array}$} \\
\hline & & & & & & & & & \multicolumn{4}{|c|}{ Non-adjusted } & \multicolumn{3}{|c|}{ Adjusted } \\
\hline & $\begin{array}{c}\# \\
\text { surveys }\end{array}$ & $\begin{array}{c}\# \\
\text { countries }\end{array}$ & & & & & & & $\% 2$ & $\% 0+1$ & $\% 3+$ & $0+1$ vs. $3+$ & $\% 2$ & $\% 0+1$ & $\% 3+$ \\
\hline $1979-83$ & 12 & 7 & 7 & 2.44 & 2.25 & 2.65 & 2.41 & 0.14 & 54 & 3 & 35 & 0.10 & 59 & 4 & 38 \\
\hline 1987-94 & 15 & 8 & 6 & 2.54 & 2.32 & 2.66 & 2.58 & 0.10 & 50 & 3 & 40 & 0.08 & 54 & 3 & 43 \\
\hline 1995-2002 & 11 & 7 & 6 & 2.47 & 2.19 & 2.65 & 2.51 & 0.14 & 50 & 4 & 36 & 0.11 & 55 & 4 & 40 \\
\hline
\end{tabular}

German-speaking countries

\begin{tabular}{|c|c|c|c|c|c|c|c|c|c|c|c|c|c|c|c|}
\hline \multicolumn{9}{|c|}{ German-speaking countries } & \multicolumn{7}{|c|}{ in } \\
\hline & \multirow[b]{2}{*}{$\begin{array}{c}\# \\
\text { surveys } \\
\end{array}$} & \multirow[b]{2}{*}{$\begin{array}{c}\# \\
\text { countries }\end{array}$} & \multirow{2}{*}{$\begin{array}{c}\text { 2-child ideal: } \\
\text { \# surveys } \\
\text { with }>\mathbf{5 0 \%} \\
\end{array}$} & \multirow[b]{2}{*}{$\begin{array}{c}\text { MIFS } \\
\text { (average) }\end{array}$} & \multirow[b]{2}{*}{$\begin{array}{c}\text { Min } \\
\text { MIFS }\end{array}$} & \multirow[b]{2}{*}{$\begin{array}{c}\text { Max } \\
\text { MIFS } \\
\end{array}$} & \multirow[b]{2}{*}{$\begin{array}{c}\text { Median } \\
\text { IFS }\end{array}$} & \multirow[b]{2}{*}{ Stdev } & \multicolumn{4}{|c|}{ Non-adjusted } & \multicolumn{3}{|c|}{ Adjusted } \\
\hline & & & & & & & & & $\% 2$ & $\% 0+1$ & $\% 3+$ & $\begin{array}{c}0+1 \text { vs. } \\
3+\end{array}$ & $\% 2$ & $\% 0+1$ & $\% 3+$ \\
\hline 1987-94 & 8 & 4 & 8 & 2.18 & 1.94 & 2.63 & 2.12 & 0.22 & 65 & 10 & 21 & 0.47 & 67 & 10 & 22 \\
\hline 1995-2002 & 5 & 4 & 5 & 2.17 & 1.78 & 2.41 & 2.28 & 0.24 & 61 & 10 & 19 & 0.55 & 67 & 12 & 21 \\
\hline 2006-11 & 8 & 4 & 8 & 2.12 & 1.98 & 2.20 & 2.14 & 0.08 & 59 & 11 & 20 & 0.56 & 65 & 12 & 22 \\
\hline
\end{tabular}

\begin{tabular}{|c|c|c|c|c|c|c|c|c|c|c|c|c|c|c|c|}
\hline \multirow[t]{3}{*}{ Central Eu } & \multirow[b]{3}{*}{$\begin{array}{c}\# \\
\text { surveys }\end{array}$} & \multirow[b]{3}{*}{$\begin{array}{c}\# \\
\text { countries } \\
\end{array}$} & \multirow{3}{*}{$\begin{array}{c}\text { 2-child ideal: } \\
\text { \# surveys } \\
\text { with }>\mathbf{5 0 \%} \\
\end{array}$} & \multirow[b]{3}{*}{$\begin{array}{c}\text { MIFS } \\
\text { (average) }\end{array}$} & \multirow[b]{3}{*}{$\begin{array}{c}\text { Min } \\
\text { MIFS }\end{array}$} & \multirow[b]{3}{*}{$\begin{array}{c}\text { Max } \\
\text { MIFS }\end{array}$} & \multirow[b]{3}{*}{$\begin{array}{l}\text { Median } \\
\text { IFS }\end{array}$} & \multirow[b]{3}{*}{ Stdev } & \multicolumn{7}{|c|}{$\begin{array}{l}\text { Average share of respondents with a given family size } \\
\text { ideal }\end{array}$} \\
\hline & & & & & & & & & \multicolumn{4}{|c|}{ Non-adjusted } & \multicolumn{3}{|c|}{ Adjusted } \\
\hline & & & & & & & & & $\% 2$ & $\% 0+1$ & \%3+ & $\begin{array}{c}0+1 \text { vs. } \\
3+ \\
\end{array}$ & $\% 2$ & $\% 0+1$ & $\% 3+$ \\
\hline $1987-94$ & 15 & 8 & 12 & 2.35 & 2.14 & 2.57 & 2.31 & 0.13 & 59 & 5 & 33 & 0.14 & 61 & 5 & 34 \\
\hline $1995-2002$ & 9 & 9 & 7 & 2.39 & 2.07 & 2.67 & 2.39 & 0.15 & 55 & 5 & 36 & 0.15 & 57 & 5 & 38 \\
\hline 2006-11 & 17 & 9 & 15 & 2.25 & 1.93 & 2.53 & 2.22 & 0.16 & 57 & 8 & 28 & 0.29 & 61 & 9 & 30 \\
\hline
\end{tabular}




\begin{tabular}{|c|c|c|c|c|c|c|c|c|c|c|c|c|c|c|c|}
\hline \multicolumn{3}{|c|}{ Eastern and South-eastern Europe } & \multirow{3}{*}{$\begin{array}{c}\text { 2-child ideal: } \\
\text { \# surveys } \\
\text { with }>\mathbf{5 0 \%}\end{array}$} & \multirow[b]{3}{*}{$\begin{array}{c}\text { MIFS } \\
\text { (average) }\end{array}$} & \multirow[b]{3}{*}{$\begin{array}{c}\text { Min } \\
\text { MIFS }\end{array}$} & \multirow[b]{3}{*}{$\begin{array}{c}\text { Max } \\
\text { MIFS }\end{array}$} & \multirow[b]{3}{*}{$\begin{array}{c}\text { Median } \\
\text { IFS }\end{array}$} & \multirow[b]{3}{*}{ Stdev } & \multicolumn{7}{|c|}{$\begin{array}{l}\text { Average share of respondents with a given family size } \\
\text { ideal }\end{array}$} \\
\hline & & & & & & & & & \multicolumn{4}{|c|}{ Non-adjusted } & \multicolumn{3}{|c|}{ Adjusted } \\
\hline & $\begin{array}{c}\# \\
\text { surveys }\end{array}$ & $\begin{array}{c}\# \\
\text { countries }\end{array}$ & & & & & & & $\% 2$ & $\% 0+1$ & \%3+ & $\begin{array}{c}0+1 \text { vs. } \\
3+\end{array}$ & $\% 2$ & $\% 0+1$ & $\% 3+$ \\
\hline 1987-94 & 6 & 4 & 5 & 2.24 & 2.00 & 2.48 & 2.18 & 0.17 & 62 & 9 & 27 & 0.34 & 63 & 9 & 28 \\
\hline 1995-2002 & 13 & 9 & 10 & 2.35 & 2.01 & 2.64 & 2.36 & 0.21 & 56 & 8 & 33 & 0.24 & 58 & 8 & 34 \\
\hline 2006-11 & 6 & 4 & 5 & 2.09 & 1.93 & 2.54 & 2.00 & 0.21 & 62 & 13 & 18 & 0.72 & 68 & 14 & 19 \\
\hline
\end{tabular}

\begin{tabular}{|c|c|c|c|c|c|c|c|c|c|c|c|c|c|c|c|}
\hline \multicolumn{3}{|c|}{ Southern Europe } & \multirow{3}{*}{$\begin{array}{c}\text { 2-child ideal: } \\
\text { \# surveys } \\
\text { with }>\mathbf{5 0 \%}\end{array}$} & \multirow[b]{3}{*}{$\begin{array}{c}\text { MIFS } \\
\text { (average) }\end{array}$} & \multirow[b]{3}{*}{$\begin{array}{l}\text { Min } \\
\text { MIFS }\end{array}$} & \multirow[b]{3}{*}{$\begin{array}{c}\text { Max } \\
\text { MIFS }\end{array}$} & \multirow[b]{3}{*}{$\begin{array}{l}\text { Median } \\
\text { IFS }\end{array}$} & \multirow[b]{3}{*}{ Stdev } & \multicolumn{7}{|c|}{$\begin{array}{l}\text { Average share of respondents with a given family size } \\
\text { ideal }\end{array}$} \\
\hline & & & & & & & & & \multicolumn{4}{|c|}{ Non-adjusted } & \multicolumn{3}{|c|}{ Adjusted } \\
\hline & $\begin{array}{c}\# \\
\text { surveys }\end{array}$ & $\begin{array}{c}\# \\
\text { countries }\end{array}$ & & & & & & & $\% 2$ & $\% 0+1$ & $\% 3+$ & $\begin{array}{c}0+1 \text { vs. } \\
3+\end{array}$ & $\% 2$ & $\% 0+1$ & $\% 3+$ \\
\hline 1987-94 & 7 & 3 & 7 & 2.35 & 2.24 & 2.43 & 2.37 & 0.06 & 58 & 6 & 33 & 0.20 & 60 & 7 & 34 \\
\hline 1995-2002 & 6 & 4 & 5 & 2.30 & 1.95 & 2.56 & 2.23 & 0.14 & 56 & 7 & 30 & 0.25 & 60 & 8 & 32 \\
\hline $\begin{array}{l}2006-11 \\
\text { detail } 2006\end{array}$ & 8 & 4 & 7 & 2.14 & 1.95 & 2.40 & 2.11 & 0.15 & 57 & 12 & 22 & 0.57 & 63 & 14 & 24 \\
\hline 2006 & 4 & 4 & 3 & 2.20 & 2.01 & 2.40 & 2.19 & 0.14 & 57 & 10 & 25 & 0.40 & 62 & 11 & 27 \\
\hline 2011 & 4 & 4 & 4 & 2.08 & 1.95 & 2.29 & 2.03 & 0.13 & 58 & 15 & 19 & 0.78 & 63 & 16 & 21 \\
\hline
\end{tabular}




\section{VIENNA INSTITUTE OF DEMOGRAPHY}

\section{Working Papers}

Sander, Nikola, Guy J. Abel, Ramon Bauer and Johannes Schmidt, Visualising Migration Flow Data with Circular Plots, VID Working Paper 2/2014.

Barakat, Bilal, Revisiting the History of Fertility Concentration and its Measurement, VID Working Paper 1/2014.

Buber-Ennser, Isabella, Attrition in the Austrian Generations and Gender Survey, VID Working Paper 10/2013.

De Rose, Alessandra and Maria Rita Testa, Climate Change and Reproductive Intentions in Europe, VID Working Paper 09/2013.

Di Giulio, Paola, Thomas Fent, Dimiter Philipov, Jana Vobecká and Maria WinklerDworak, State of the Art: A Family-Related Foresight Approach, VID Working Paper 08/2013.

Sander, Nikola, Guy J. Abel and Fernando Riosmena, The Future of International Migration: Developing Expert-Based Assumptions for Global Population Projections, VID Working Paper 07/2013.

Caselli, Graziella, Sven Drefahl, Marc Luy and Christian Wegner-Siegmundt, Future Mortality in Low-Mortality Countries, VID Working Paper 06/2013.

Basten, Stuart, Tomáš Sobotka and Kryštof Zeman, Future Fertility in Low Fertility Countries, VID Working Paper 05/2013.

Sharygin, Ethan, The Carbon Cost of an Educated Future: A Consumer Lifestyle Approach, VID Working Paper 04/2013.

Winkler-Dworak, Maria and Heiner Kaden, The Longevity of Academicians: Evidence from the Saxonian Academy of Sciences and Humanities in Leipzig, VID Working Paper 03/2013.

Feichtinger, Gustav, Alexia Prskawetz, Andrea Seidl, Christa Simon and Stefan Wrzaczek, Do Egalitarian Societies Boost Fertility?, VID Working Paper 02/2013.

Muttarak, Raya, Is it (dis)Advantageous to Have Mixed Parentage? Exploring Education \& Work Characteristics of Children of Interethnic Unions in Britain?, VID Working Paper 01/2013.

Testa, Maria Rita and Stuart Basten, Have Lifetime Fertility Intentions Declined During the "Great Recession"?, VID Working Paper 09/2012.

The Vienna Institute of Demography Working Paper Series receives only limited review. Views or opinions expressed herein are entirely those of the authors. 


\begin{abstract}
How persistent and universal has the two child family ideal been in Europe during the last three decades? We analyse responses of women of reproductive age from 168 surveys conducted in 37 countries in 1979-2012. A two-child ideal has become nearly universal among women in all parts of Europe. Countries that used to display higher ideal family size have converged over time towards a two-child model. Six out of ten women in Europe consider two children as ideal and this proportion is very similar in different regions. The mean ideal family size has become relatively closely clustered around 2.2 in most countries. Gradual shifts can be documented towards more women expressing an ideal of having one child (and, quite rarely, having no children) and a parallel decline in an ideal of three or more children. An increasing number of European countries saw their mean ideal family size falling to relatively low level around 1.952.15. But with an exception of one survey for eastern Germany and a few additional surveys not included in our study due to high nonresponse, none of the analysed surveys suggests a decline of mean ideal family size to levels considerably below replacement, i.e., below 1.9 children per woman. Data for countries outside Europe suggest a global spread of two-child preferences, also in many countries where the fertility transition is still in progress.
\end{abstract}

\title{
Keywords
}

Fertility ideals, ideal family size, fertility preferences, below-replacement fertility, Europe.

\section{Authors}

Tomáš Sobotka, Wittgenstein Centre for Demography and Global Human Capital (IIASA, VID/ÖAW, WU), Vienna Institute of Demography/Austrian Academy of Sciences. Email: tomas.sobotka@,oeaw.ac.at

Éva Beaujouan, Wittgenstein Centre for Demography and Global Human Capital (IIASA, VID/ÖAW, WU), Vienna Institute of Demography/Austrian Academy of Sciences. Email: eva.beaujouan@,oeaw.ac.at

\section{Acknowledgements}

This research was funded by the European Research Council under the European Union's Seventh Framework Programme (FP7/2007-2013) / ERC Grant agreement n 284238 (EURREP project).

Data for Switzerland are calculated from the Swiss Household Panel (SHP), which is based at the Swiss Centre of Expertise in the Social Sciences FORS (project financed by the Swiss National Science Foundation). Many thanks to Kryštof Zeman who provided help with the analysis of the Swiss Household Panel Data (SHP) surveys. 


\title{
Two is Best? The Persistence of a Two-child Family Ideal in Europe
}

\author{
Tomáš Sobotka and Éva Beaujouan
}

\section{Introduction}

Completed fertility rates in most of the highly developed countries fell below two children per woman already among the women born in the 1960s (Frejka and Sobotka 2004; Myrskylä et al 2013), supporting the view that fertility transition does not abruptly come to an end when fertility reaches a replacement-level threshold (Demeny 1997). At the same time, surveys of ideal and intended family size conducted in the 1980s and 1990s in low-fertility countries suggested that family size ideals as well as intentions had surprisingly stabilised around the replacement-level and became firmly centred on having two children. Hagewen and Morgan's (2005: 510) analysis of data for the United States concluded that "there is a remarkably pervasive desire (and supporting norms) for a family size of two children". Repeated cross-sectional Eurobarometer surveys conducted in all the European Union countries also suggested that family size of two still clearly remains a dominant ideal (Testa 2007, 2012). As Coleman (1999) observed "the pervasive endorsement across so many societies of the unique value of being a parent is impressive, as is the durability of ideal family sizes over two children in almost all advanced societies." This stability has contributed to a general decline in demographers' interest in the concept of ideal family size and has prompted some researchers to question the usefulness of studying fertility ideals and preferences, especially when making inferences about the likely future changes in family size (Simons 1978, Demeny 2003).

Some studies suggest, however, that the dominance of a two-child family ideal may eventually erode. There seems to be no intrinsic reason why individuals deciding about their family size should embrace replacement-level ideal of having two children (Bongaarts 2002). An extended experience of very low fertility would thus be unlikely to persist indefinitely without being accompanied by a corresponding change in family size ideals (Coleman 1999; Testa and Grilli 2006; Goldstein, Lutz and Testa 2003). This mechanism is part of the 'Low Fertility Trap' hypothesis (Lutz, Skirbekk and Testa 2006), which suggests that declining fertility rates lead to a spiral of falling numbers of births, rapid population aging, diminishing economic opportunities for younger generations and, eventually, to fewer encounters with children and declining family size ideals. Cultural changes may also contribute to the eventual erosion of a two-child family ideal: As societal norms related to family, living arrangements and gender roles become more permissive over time and across cohorts (Inglehart 1990, Lesthaeghe 1995), women and men should feel free to express unusual family size ideals. For instance, Merz and Liefbroer (2012) found a close connection between approval of voluntary childlessness and country's advancement in characteristic family and fertility changes associated with the Second demographic transition (Lesthaeghe 1995). However, van de Kaa (2001) found that women with "postmaterialist" value orientation, who are at the forefront of this transition, express similar or even higher family size ideals than the more traditionally-oriented women with "materialist" values. While people may become more tolerant of non-traditional behaviour, the high value placed on experiencing parenthood and having children may not necessarily disappear. 
In this paper we revisit data on ideal family size in Europe and provide a systematic analysis of their trends since the late 1970s, especially focusing on the possible erosion of two-child family ideals. Specifically, we address the following questions:

- How persistent and universal has the two child family ideal been in Europe during the last three decades?

- Is there evidence of emerging preference for small family size (zero or one child) in European countries with long history of sub-replacement fertility?

To address these questions, we analyse surveys conducted in 1979-2012 in 37 European countries with population above 1 million (data for eastern and western Germany are analysed separately). ${ }^{1}$ We focus on the responses of women of reproductive age (15-49) regarding their ideal family size. First we discuss the motivation for studying trends in ideal family size in Europe, the recent literature, and available data. After analysing time trends in ideal family size across all surveys, we discuss regional developments and the evidence for selected countries, with a special focus on Austria, eastern Germany, western Germany, and Switzerland. We also explore whether observed declines in mean ideal family size tend to slow down or reverse when they reach a low level. In addition, we discuss whether the countries experiencing an early decline in fertility well below replacement levels or a fall in fertility to very low levels subsequently saw a fall in ideal family size to subreplacement levels. The concluding discussion focuses on the reasons why a two-child ideal continues dominating in all parts of Europe.

\section{The Motivation for Studying Fertility Ideals}

Questions on the ideal family size have been asked first in a 1936 Gallup poll in the United States (Blake 1966). Since then it has appeared in different forms in hundreds of surveys globally. But it has also repeatedly attracted criticism for its perceived shortcomings, including the bewildering variety of questions on ideal number of children and yet more possible interpretations of these questions, encompassing also the distinct concepts of personal/individual, societal, group-specific and situational ideals (see a discussion in Ware 1974 and Philipov and Bernardi 2011). In addition, the term "ideal family size" may not include the choice of childlessness in the minds of many respondents, inhibiting them from mentioning zero as an ideal number of children (Blake 1974). Some researchers have questioned the validity of the concept of reproductive ideals: Hauser (1967: 404) considers the question meaningless, suggesting that since fertility ideals are closely correlated with completed family size, the "ideal tends to be what has actually occurred." Ryder and Westoff (1969, quoted in Ware 1974: 7) concluded their comparison of intended, expected, desired and ideal family size in the United States with a clearly negative assessment for the ideal family size, seeing it as "the least profitable variable to explore further" and positing that it "lacks face validity, is relatively unreliable, and it has small variance." Early research has also repeatedly questioned the

\footnotetext{
${ }^{1}$ This separation of datasets for eastern and western Germany is based not only on the fact that they formed two separate countries until 1990, but especially on the evidence of the severity of eastern German fertility decline in the early 1990s, and the distinctiveness of family and fertility patterns in these two areas which has persisted after the reunification (Kreyenfeld 2003, Goldstein, Lutz and Testa 2003, Goldstein and Kreyenfeld 2011, Sobotka 2011).
} 
usefulness of asking numerical questions about ideals in the context of high-fertility societies with little contraceptive use and limited concept of fertility as a planned and purposeful behaviour (Ware 1974). Over time, studies have highlighted the failure of questions on ideal family size to predict actual fertility behaviour. In the European context of low fertility, attention has been repeatedly paid to the perceived "gap" between ideal and actual family size (e.g. Testa 2012), which suggests either that respondents might be unrealistic about their fertility preferences or that ideals are perhaps too abstract and removed from real decision-making. As Demeny (2003) eloquently claims, fertility preferences may turn out to resemble a title of Günter Grass' novel, Kopfgeburten - births that increasingly occur only in the minds of would-beparents.

Some of these criticisms are clearly valid. The concept of ideal family size remains rather ambiguous and open to a multitude of interpretations (Blake 1966); there is no consensus among demographers about the preferred way(s) of asking about fertility ideals (Philipov and Bernardi 2011). But some of these perceived shortcomings are either subjective and might even be interpreted as the strengths of the measure (low variance and stability of ideals over time), or are caused by an inappropriate use of ideals for purposes for which they are not suited. Ideals are clearly not well suited for predicting fertility levels and their interchangeable use with intentions or desires, found in some of the past research papers, is misleading (Trent 1980). Past research also shows that ideals may change rapidly in times of swift cultural changes and thus can give useful signals about shifting societal norms and images about "desirable" family size. Such a shift was well documented by Blake (1974) for the United States between the mid-1960s and 1972, when ideal family size fell especially among those below age 25 and a two-child ideal became most common.

Furthermore, ideals, preferences, desires and intentions are often considered as key determinants of reproductive decision-making process (Philipov and Bernardi 2011) and behaviour (Schoen et al. 1999). They also constitute a useful measure of fertility motivation (Miller 2011) and, in comparison to other covariates, short term intentions give reasonably good predictions of subsequent fertility (see review in Ní Bhrolcháin and Beaujouan, 2011). Ideals and intentions are relatively "soft" concepts as they are open to uncertainty, doubt and revisions (e.g. Quesnel-Vallée and Morgan 2003), but nevertheless form a basic layer in the chain leading to the decision to have a child. Ideals, differently from intentions, reflect well more general societal pronatalist or antinatalist norms (Trent 1980). Family size ideals, especially personal ones, can also be seen as reflecting the number of children people would like to have if they lived under "ideal conditions" and faced no constraints such as poor health, infertility, not having a suitable partner, demanding job, precarious economic situation or inefficient contraception (Philipov and Bernardi 2011). Under this assumption, change over time in ideals could be seen as reflecting the air $d u$ temps, in particular the changing attitudes towards family, childbearing and the value of children in society.

\section{Trends in Fertility Ideals: Shifting To Subreplacement Levels?}

While an extensive body of literature in the last two decades has been devoted to studying shortterm fertility intentions, their determinants and their realisation in low-fertility countries, there 
has been comparatively little attention paid to aggregate-level fertility preferences. In particular the research on fertility ideals has fallen out of fashion and the question has been removed from a number of recent international surveys (Philipov and Bernardi 2011). This is perhaps due to the widespread notion that family size ideals are stable and that they do not matter much for reproductive decisions. Consequently, little global evidence of the ongoing trends in fertility ideals has been collected.

Viewed from the "low fertility trap" perspective, tentative evidence suggests that ideal family size has fallen below the replacement level in several low-fertility settings. Goldstein, Lutz and Testa (2003) suggested that Austria and Germany might be the first countries experiencing such a shift. Their analysis of Eurobarometer data from 2001 indicated that the mean ideal family size in these two countries has dipped to 1.6-1.7 children per woman. They expect that a similar decline is likely to take place in other low-fertility countries as well. Testa and Grilli (2006) reported a close link between the actual family size among older generations (women aged 40-60) and ideal family size of younger women aged 20-39 in Europe. Outside Europe, a shift towards one-child preferences has been reported for younger and higher-educated women in urban China (Ding and Hesketh 2006), where the mean ideal family size fell well below two children (Merli and Morgan 2011, Basten and $\mathrm{Gu}$ Baochang 2013). It remains unclear, however, to what extent this might be due to an internalisation of the restrictive government policies promoting one-child families during the last three decades (Nie and Wyman 2005).

\section{Data}

We used data from several cross-sectional multicountry surveys conducted since the 1970s: The World Value Survey (WVS) ${ }^{2}$, the European Values Study (EVS) ${ }^{3}$, the International Social Survey (ISSP) ${ }^{4}$ and the Eurobarometer surveys ${ }^{5}$. We also analysed complementary datasets for selected countries, specifically, the tabulated data from the Demographic and Health Surveys (DHS) in Albania and Ukraine ${ }^{6}$, data from several family surveys conducted in France ${ }^{7}$, Swiss Household Panel Survey (SHP) ${ }^{8}$, and the Generations and Gender Project surveys in Austria. ${ }^{9}$ Additionally, a discussion of trends in ideal family size in non-European countries is based

\footnotetext{
${ }^{2}$ WORLD VALUES SURVEY 1981-2008 OFFICIAL AGGREGATE v.20090901, 2009. World Values Survey Association (www.worldvaluessurvey.org). Aggregate File Producer: ASEP/JDS, Madrid

${ }^{3}$ European Values Study 1981-2008, Longitudinal Data File ZA4804. Spanish data files ZA4451 and ZA4487. GESIS Data Archive, Cologne.

${ }^{4}$ ISSP Research Group, International Social Survey Programme (ISSP): 1988 ZA1700, 1994 ZA620. Distributor: GESIS Cologne Germany

${ }^{5}$ European Commission, Brussels: Eurobarometer 11, 56.2, 65.1; TNS OPINION \& SOCIAL, Brussels (Producer); GESIS, Cologne (Publisher): ZA1036, ZA3627, ZA4505.

${ }^{6}$ ICF International, 2012. MEASURE DHS STATcompiler - http://www.statcompiler.com - data downloaded April 172013.

${ }^{7}$ INED, Enquêtes conjoncture 1955, 1967, 1976, 1982, 1987; INED, Enquête intentions de fécondité 1998; INEDINSERM, Enquête Fecond 2010.

${ }^{8}$ Swiss Household Panel Surveys (SHP). waves 2002 and 2005.

${ }^{9}$ Austrian Generation and Gender surveys, wave 1 (2009) and wave 2 (2013), Statistics Austria, Vienna Institute of Demography.
} 
mainly on the DHS and RHS (Reproductive Health Survey) data, despite their question wording which differed considerably from the other surveys analysed here (see questions below and footnote 12).

To obtain a reasonable sample size we included all women of reproductive age, broadly defined as 15-49 years. We might have selected a younger and narrower group of respondents, but that would have limited the sample size in most surveys to uncomfortably small numbers. ${ }^{10}$

The question on ideal family size differed in each group of surveys. In the multi-country surveys analysed here the question was as follows: ${ }^{11}$

WVS and EVS: "What do you think is the ideal size of a family - how many children, if any?" ISSP: "All in all, what do you think is the ideal number of children for a family to have?"

Eurobarometer (1979): "In (country name) today, what do you think, is the ideal number of children for a family?"

Eurobarometer (1990): "In (your country) today, what do you think, the ideal number of children is, for a family like yours or the one you might have?"

Eurobarometer (2001, 2006, and 2011): "Generally speaking, what do you think is the ideal number of children for a family?"

DHS, RHS: (a) For childless women: "If you could choose exactly the number of children to have in your whole life, how many would that be?". 12

(b) For women with surviving children: "If you could go back to the time you did not have any children and could choose exactly the number of children to have in your whole life, how many would that be?"

In the questionnaires, the "Don't know" option was not explicitly included in the WVS, EVS and ISSP surveys, but it was added in the Eurobarometer surveys, which also included in 2001-11 the response option "There is no ideal number, it depends". The distinction between missing responses and "don't know" answers was often not available in the datasets. In the 1979 Eurobarometer survey, nonresponse in the questionnaires was coded " 0 ", the same way as an ideal of having no children. After investigating the subsequent surveys from the 1980s, we adjusted these data by considering all these responses as either missing or "do not know"

\footnotetext{
${ }^{10}$ It might be argued that by selecting a wide age range for our analyses we would miss the opportunity to detect shifts in ideal family size among young adults, who could be the early adopters of low family size ideals. However, the available literature does not suggest any important shift among the young respondents. A detailed analysis of the data from the 2011 Eurobarometer survey by Testa (2012) actually shows that mean general ideal family size is higher in the age group 15-24 than in age groups 25-39 and 40-54 in a large majority of countries, which is also illustrated by the results for all the EU countries combined (mean ideal family size of 2.27, 2.11 and 2.13 in these respective age groups) (Table A2.1 in Testa 2012).

${ }^{11}$ Exact question wording in individual-country surveys for Austria, France and Switzerland is available from the authors upon request.

12 The question does not closely match the questions asked in other surveys, although it is consistently interpreted as "ideal family size" in DHS reports as well as online tabulations provided by MeasureDHS Statcompiler. In our study we refer in broader term to "fertility preferences" when analysing DHS and RHS data. In the European comparisons we use the DHS only for one survey in two countries (Albania and Ukraine), and the results are closely aligned with the results of the other surveys. The DHS has an advantage of a large sample size in comparison with the other surveys available. We also use this survey in a discussion of non-European countries alongside with WVS and ISSP surveys for Australia, Canada, Japan, and South Korea.
} 
answers, i.e. assuming that no respondents were choosing a zero-child ideal family size. Indeed in the 1980s, the share of respondents in different surveys choosing an ideal family size of zero was negligible, reaching highest values as low as $1.1-1.3 \%$ in Austria, Belgium and the Netherlands in 1988 (ISSP survey).

In all the surveys and for each country, we checked the proportion of respondents who did not give a numerical answer to the question on ideals or whose responses were missing (see overview table in Appendix 1). This number was surprisingly high (up to 30\%) in a number of surveys, especially in some of the Eurobarometer surveys 2001, 2006 and 2011. After looking at the general proportion of unspecified values in all the surveys, we chose a threshold of $18 \%$, above which the survey was not included for further analysis. ${ }^{13}$

Indeed, for any given country the surveys with a high proportion of missing or nonnumerical responses often showed values of ideals deviating most from the other surveys. Furthermore, the sample size in the analysed WVS, EVS, ISSP and EB surveys was already small, typically between 200 and 500 women of reproductive age (fewer in smaller countries). Nonresponse and missing values further diminished the sample usable for our computations. To obtain comparable results relatively little affected by the differences in the share of respondents giving non-numerical answers, we computed two alternative sets of indicators of ideal family size; 1) as reported in each survey, and 2) adjusted for non-response and non-numerical responses, i.e., providing a distribution of ideal family size only among the respondents specifying their ideal number of children (excluding the range responses). Most of our analyses present these adjusted results.

Finally, we excluded available datasets for countries with population below 1 million (Cyprus, Iceland, Luxembourg, Malta and Montenegro) and Northern Ireland as only a few surveys were available, and each was based on small number of female respondents aged 15-49 ranging from 82 to 194 except for the two surveys available for Iceland and the 2001 Montenegro WVS survey. Altogether 168 surveys for 37 countries and regions, out of the total 203 datasets considered, met our selection criteria and were selected for our analyses of changes from 1979 to 2012 (see the list of all considered, included and excluded surveys in Appendix 1).

The analysis of time series of reproductive ideals constituted a good check of the accuracy of results for different countries, which were typically based on small samples. Partly in order to compensate for the small sample size in most surveys, we conducted additional regional analyses, grouping the data for broader geographical regions that also reflect major differences in fertility patterns across Europe (Sobotka 2013). This helped us eliminating fluctuations in the data that might have been caused by a small sample size or changes in non-response. We used the following regional groupings:

\footnotetext{
${ }^{13}$ The high share of respondents choosing the answer "There is no ideal number" in some of the Eurobarometer surveys provides a signal about the possible erosion of a notion that there might be a common ideal family size. This issue is worth analysing deeper, but as it is not captured in the other surveys, we do not analyse these responses and treat them merely as "statistical noise" that may affect the aggregate results. Moreover, in many countries there is little consistency between the share of missing and non-numerical responses across different Eurobarometer surveys (see Appendix 1), which makes it difficult to pursue a substantive interpretation in terms of uncertainty being systematically higher or lower in specific countries.
} 
- Western and Northern Europe: Belgium, Denmark, Finland, France, Netherlands, Norway, Sweden, United Kingdom. ${ }^{14}$

- Southern Europe: Greece, Italy, Portugal, and Spain.

- "German-speaking countries": Austria, eastern and western-Germany, Switzerland.

- Central Europe: Croatia, Czech Republic, Estonia, Hungary, Latvia, Lithuania, Poland, Slovakia, Slovenia.

- Eastern and South-eastern Europe: Albania, Belarus, Bulgaria, Macedonia, Moldova, Romania, Russian Federation, Serbia, and Ukraine.

\section{Results}

\subsection{Changes in Ideal Family Size in Europe since 1979: All Surveys Combined}

We first inspect changes in ideal family size and the share of women expressing a two-child ideal across Europe, computing selected key indicators for the pool of all analysed surveys combined in the period 1979-2012. Potentially, this analysis can be biased by the changing composition of countries and surveys analysed in different periods, including multiple surveys analysed in one period for some countries (see overview of all surveys by country in Appendix 1). To improve comparability of data over time and obtain a reasonable number of surveys for each period we grouped the surveys into six periods that do not cover equal time intervals, but are rather centred on the years of the important multicountry surveys analysed here.

Despite uneven country and survey coverage Table 1 gives a concise picture of the changes over time. First, it shows a gradual decline in the average value of mean ideal family size (MIFS) by about 0.1 in a decade: The average ideal family size in the analysed surveys dropped from 2.53 in $1979-83$ to 2.21 in $2008-11$. The median of ideal family size across all surveys declined slower and from a lower initial value of 2.38 in 1979-83 to 2.19 in 2008-11. At the same time, the orientation towards a two-child family ideal has slightly strengthened. In the surveys conducted since 1993 , around $60 \%$ of respondents expressed a two-child ideal when the data were adjusted for nonresponse and non-numerical answers, up from $55 \%$ in the 1980 s. More important, the share of surveys where a majority of respondents express a two-child ideal has climbed over time, from $58 \%$ in $1979-83$ to three quarters in the 1990 s and the early $2000 \mathrm{~s}$ and to $85 \%$ in 2008-11. Only in two out of 109 surveys conducted since 1993 the most frequent ideal differed from two: In Norway in 1996 (WVS survey) and in Finland in 2006 (EB survey) the share of women stating a three-child ideal slightly surpassed that with the two-child ideal. While a two-child ideal firmly prevails today all over Europe, the gradual decline in mean ideal family size was fuelled by a declining share of women with an ideal of three or more children, accompanied by a slower increase in the share of women expressing a sub-replacement ideal of

\footnotetext{
${ }^{14}$ We did not include data for Ireland in this regional comparison. The surveys consistently displayed considerably higher fertility ideals in Ireland than in the other countries in this region but were only available for the earlier period until 1994. This affected the regional comparison of trends after 1994 when no survey was available for Ireland (the EB 2001-11 surveys for Ireland showed a high share of non-numerical responses between 23 and $30 \%$ and, in accordance with our selection rule, were not included in the analyses).
} 
zero or one child only. Across all surveys, this share has more than doubled from 5\% in 1979-83 to $11 \%$ in $2008-11$ when adjusting for non-response.

Table 1: Summary results for European countries; all selected surveys combined, by period, women aged 15-49

\begin{tabular}{|c|c|c|c|c|c|c|c|c|c|c|}
\hline \multirow[b]{2}{*}{ Period } & \multirow[b]{2}{*}{$\begin{array}{c}\# \\
\text { surveys }\end{array}$} & \multirow[b]{2}{*}{$\begin{array}{c}\# \\
\text { countries } \\
\end{array}$} & \multirow[b]{2}{*}{$\begin{array}{l}\text { Average } \\
\text { MIFS }\end{array}$} & \multirow[b]{2}{*}{$\begin{array}{c}\text { Median } \\
\text { MIFS }\end{array}$} & \multirow[b]{2}{*}{$\begin{array}{l}\text { Std. dev. } \\
\text { MIFS }\end{array}$} & \multirow[b]{2}{*}{$\begin{array}{c}\text { Surveys } \\
\text { with }> \\
50 \% \\
\text { stating 2- } \\
\text { child } \\
\text { ideal (\%) }\end{array}$} & \multirow[b]{2}{*}{$\begin{array}{c}\text { Mean } \\
\text { share } \\
\text { with 2- } \\
\text { child } \\
\text { ideal (\%) }\end{array}$} & \multicolumn{3}{|c|}{ Adjusted for non-response } \\
\hline & & & & & & & & $\begin{array}{c}\text { Mean } \\
\text { share } \\
\text { with ideal } \\
0+1(\%)\end{array}$ & $\begin{array}{c}\text { Mean } \\
\text { share } \\
\text { with ideal } \\
2(\%)\end{array}$ & $\begin{array}{c}\text { Mean } \\
\text { share } \\
\text { with ideal } \\
3+(\%)\end{array}$ \\
\hline $1979-83$ & 19 & 11 & 2.53 & 2.38 & 0.44 & 58 & 51 & 5 & 55 & 40 \\
\hline $1987-91$ & 38 & 27 & 2.45 & 2.42 & 0.26 & 63 & 54 & 5 & 56 & 38 \\
\hline 1993-97 & 36 & 27 & 2.35 & 2.38 & 0.23 & 78 & 58 & 7 & 60 & 33 \\
\hline 1998-2002 & 25 & 19 & 2.34 & 2.36 & 0.20 & 76 & 55 & 7 & 59 & 33 \\
\hline 2005-07 & 23 & 23 & 2.25 & 2.22 & 0.19 & 78 & 57 & 9 & 62 & 29 \\
\hline $2008-11$ & 27 & 24 & 2.21 & 2.19 & 0.19 & 85 & 56 & 11 & 61 & 28 \\
\hline
\end{tabular}

Figures 1 and 2 allow a more detailed look at the variation of changes in ideal family size. The decline in the variance of mean ideal family size in different surveys and countries (Table 1) has been driven especially by a diminishing number of countries with high ideal family size. This is also illustrated by the rapidly declining level of the highest-reported MIFS in each analysed period, from 3.88 in 1979-83 (Ireland in EVS in 1981) to 2.54 in 2008-11 (Albania in DHS, 2008-9). ${ }^{15}$ By contrast, the minimum reported MIFS almost suggests that there is a lowerfloor to the decline in ideal family size, as it was remarkably stable and close to 2.0 in all the analysed surveys and periods except in 1998-2002 (Figure 1). Since the mid-1990s a majority of surveys shows a MIFS in the range of 2.0-2.5, with a slightly declining tendency.

There was a clear trend towards more uniformity in a two-child ideal (2CI) across different surveys, as illustrated also by a strong rise in the minimum share of respondents with a two-child ideal from $17 \%$ in the earliest period (Ireland in 1981) to $43 \%$ in the latest period (Finland in 2011). A majority of the surveys conducted in 2008-11 fall into the narrow range of 50 to $60 \%$ of respondents expressing a two-child ideal (Figure 2), suggesting a remarkable convergence across Europe.

\footnotetext{
15 The contrast between the earlier and later period is partly affected by excluding the 2001-11 Eurobarometer surveys for Ireland from our analyses due to the high share of non-response and non-numerical responses. If we included these data, the maximum MIFS value would remain somewhat higher and would decline to 2.70 in 2008 11.
} 
Figure 1: Mean ideal family size in Europe, summary results for all selected surveys by period, women aged 15-49

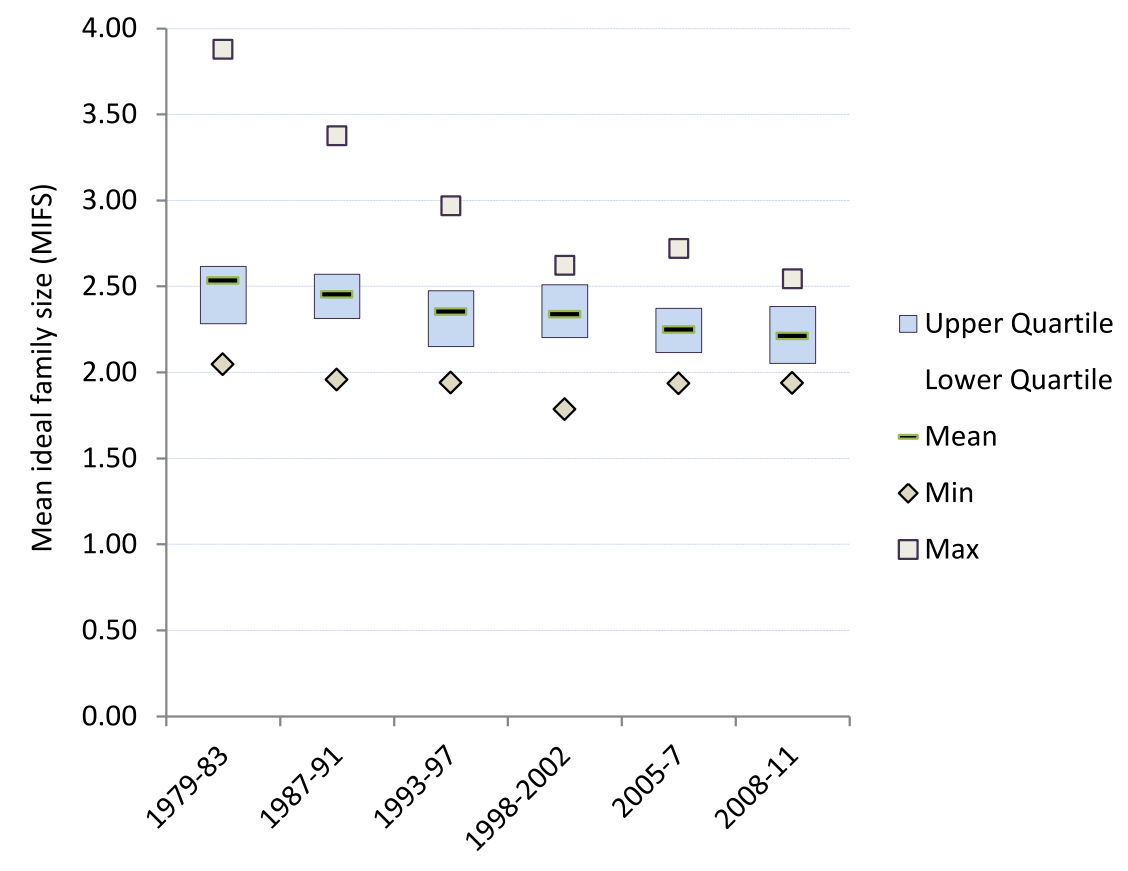

Figure 2: Percent respondents with an ideal of two children, summary results for all selected surveys in Europe by period, women aged 15-49

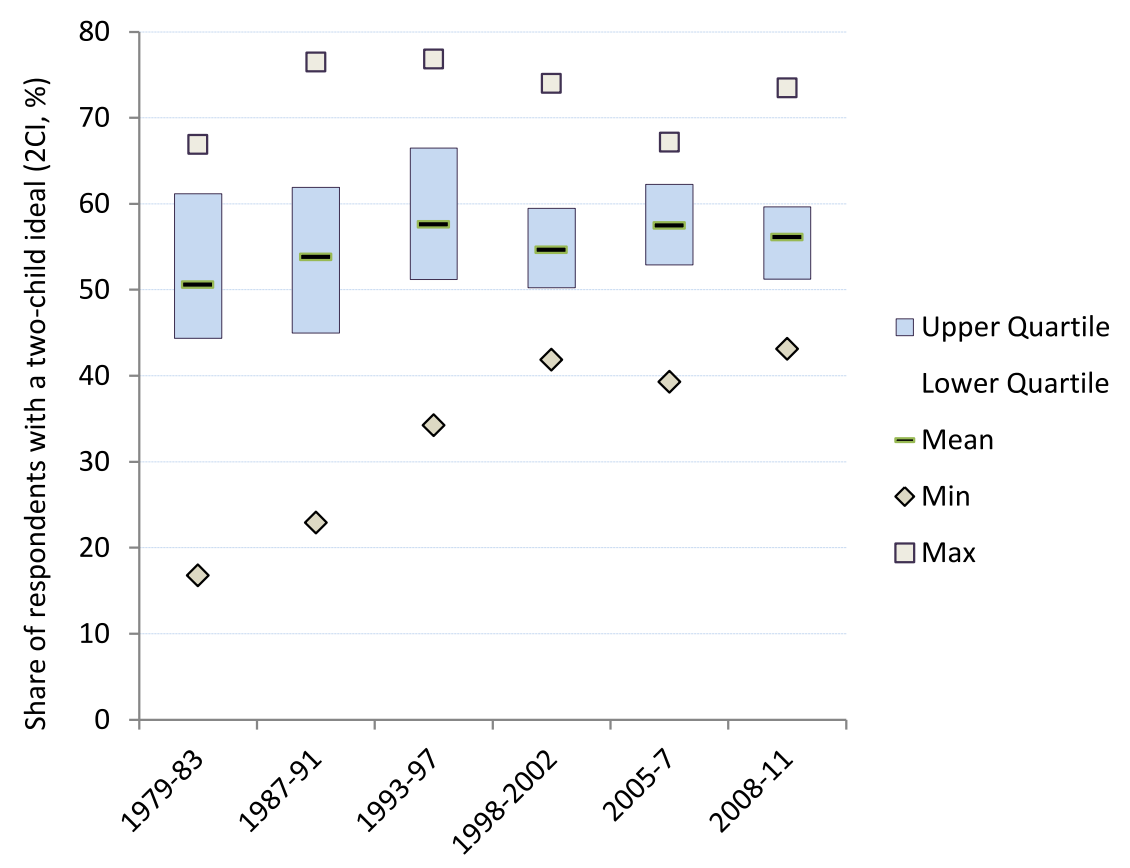




\subsection{Comparison of Major Regions}

Did the trends in ideal family size, evidenced in the analysis of all surveys combined, progress in different parts of Europe in a similar fashion? Our analysis in Figures 3 and 4, complemented by Appendix 2, focuses on broad time periods since the late 1980s - except for Western \& Northern Europe - in order to increase the number of surveys in each region and make the regional data more comparable over time. The data depict remarkable similarities between regions, especially regarding the ideal of having two children. By the late 1980s, and most probably earlier, this had become a clearly dominant family ideal in all the broad regions studied, with as many as two thirds of respondents in the German-speaking countries in favour of two-child families. None of the regions studied shows any sign of an erosion of the two child ideal between the late 1980s and 2006-11; in fact only minor changes can be seen over time. In the most recent period, the adjusted average share of respondents embracing a two-child ideal surpasses 6 out of 10 in all parts of Europe except Western \& Northern Europe, where the share has been slightly lower during the whole analysed period.

In contrast with this stability in two-child ideal, subtle shifts and regional differences can be seen in trends in mean ideal family size as well as in the ideals of larger family size (three or more children) and smaller family size (none or one child). Gradual declines in the MIFS can be observed in Central, Southern, South-eastern and Eastern Europe, with only Western \& Northern Europe and German-speaking countries showing general stability. The average value for Eastern Europe in 2006-11 reaches a low of 2.0, followed by Southern Europe and German-speaking countries with the average of 2.1 .

Recently, the spread of one-child ideal has been rather pronounced in Southern, Eastern and South-eastern Europe, where it may soon surpass the ideal of having three or more children, unless they both stabilise at a similar level. Data for Southern Europe allow a finer distinction of trends after 2001. A faster shift towards a stronger preference of very small family size began already in 2001-6, although the rise of one-child ideal accelerated between 2006 and 2011, when its preference jumped from 10 to $15 \%$ (see also the next section). At the same time, even in this region a two-child ideal remains dominant and four times as frequent as an ideal of having zero or one child only. 
Figure 3: Changes in ideal family size (mean and distribution) in broader European regions (average values across all surveys in a given period; data adjusted for non-response and for nonnumerical responses)
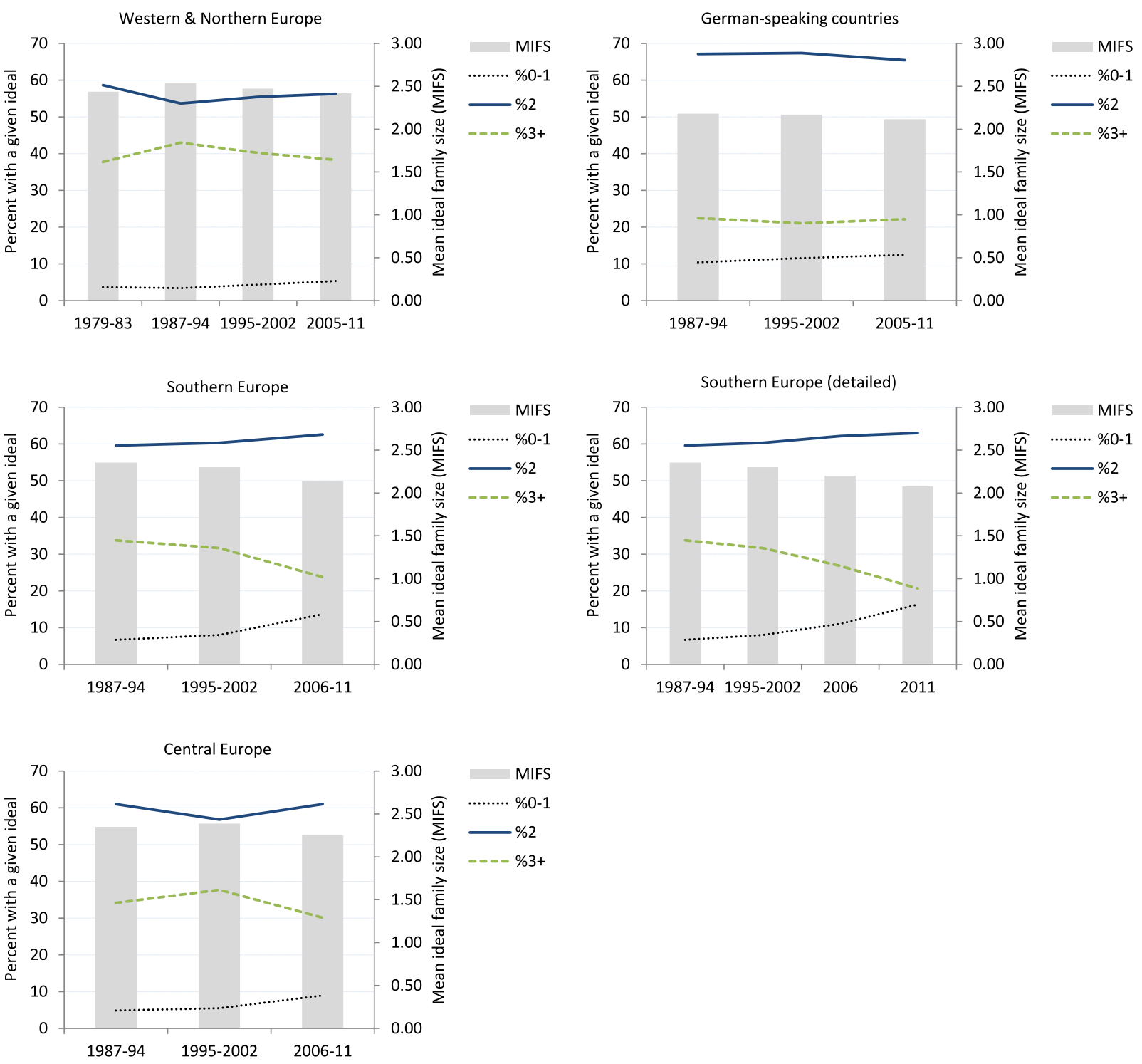
Figure 4: Mean ideal family size and the share of women with a two-child ideal in broader European regions (average values across all surveys in a given period; data adjusted for nonresponse and for non-numerical responses)
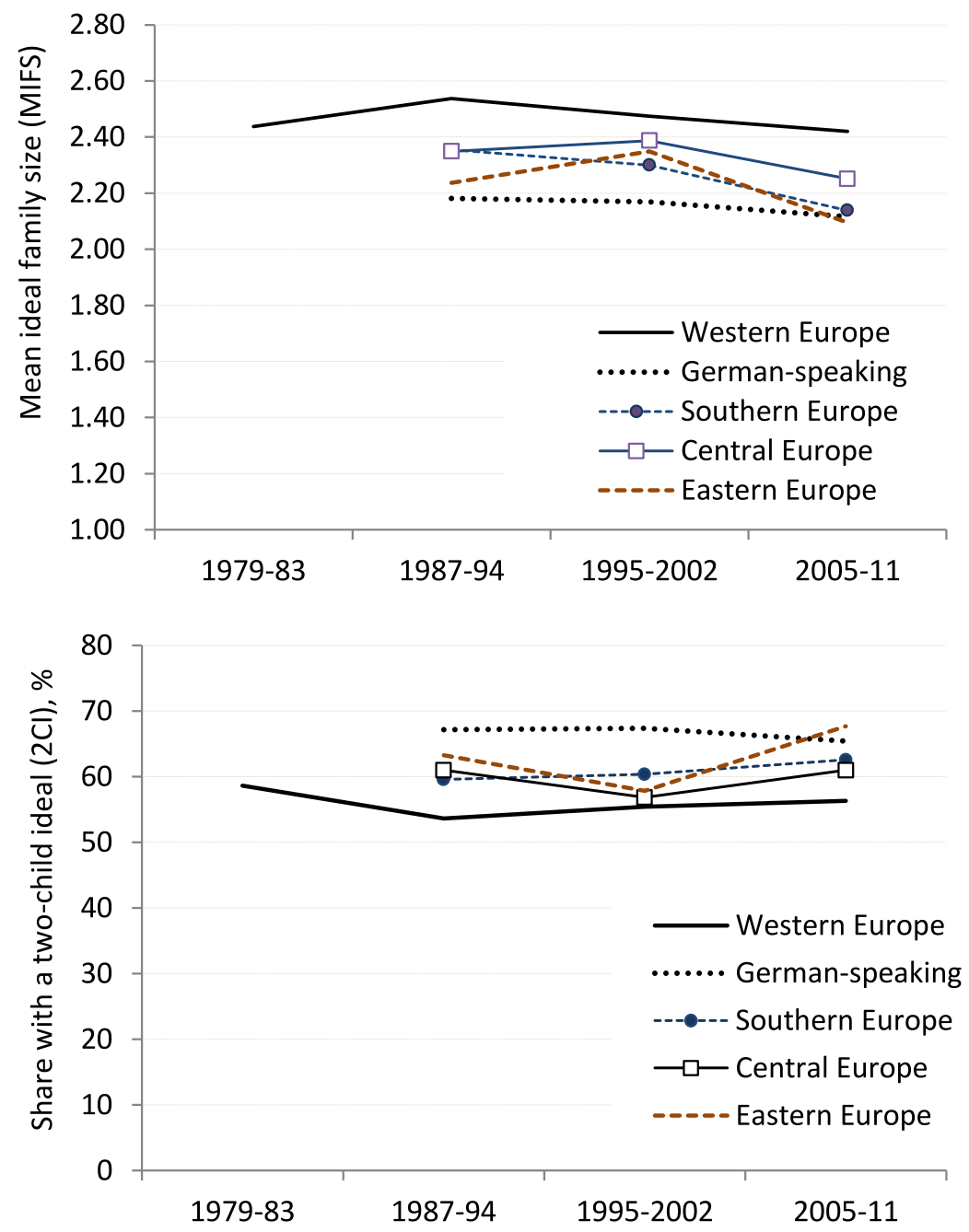

\subsection{Trends in Selected Countries}

To gain deeper understanding of regional trends in reproductive ideals, we illustrate changes in ideal family size in selected countries with a longer time series of available data (Figure 5). We focus especially on the largest European countries and on providing contrasting examples for each region. Data for the three German-speaking countries are discussed separately in the next section. We do not discuss trends in the countries in Eastern and South-eastern Europe, for which we lack longer time series of comparable data.

France and Sweden are two countries representing well the higher end of the European range of ideal family sizes. These countries have a stable model of "two or three" family size preference: The slightly predominant ideal of two children coexists with the high share of women expressing an ideal of three children, whereas the ideal of one or no child remains rare. 
Corresponding to that, the mean ideal family size approaches 2.5 . In France, where we have compiled a longer time series spanning from 1955, the two-child ideal started prevailing continuously over the "three or more" option only in the 1990s. In Belgium, the ideal of two dominates more strongly and a slight increase in the share of women with an ideal of zero or one can be observed.

The Southern European countries share a trend towards a low MIFS around 2.0, a fast decline in the share of women with a larger family ideal and a concurrent rise in the preference for a small family size. In Portugal and Italy, the share of women with a zero or one-child ideal has already surpassed that with the preference for a family of three or larger. The rather sharp decline in family size ideals between 2006 and 2011 in Portugal and Greece (not shown here) is suggestive of the possible negative influence of the long-standing economic recession (Testa 2012), similar to the evidence on the likely negative effect of the recession on fertility intentions in Greece (Testa and Basten 2013). However, only the next survey can confirm our speculations.

In Central Europe, Czech Republic had a very strong orientation towards a two-child ideal already in 1990, with only one in five women at that time having an ideal of three or more children. By 2011, this has further eroded and the one-child ideal has become more prevalent, with the adjusted share of $19 \%$, pushing the MIFS to the lowest level in Europe (1.93). In Hungary, a gradual shift towards more women with a small family ideal is also observed, but not (yet) depicting a cross-over with the share of women expressing a larger ideal. Slovenia, despite having similarly low fertility as the Czech Republic and Hungary, shows yet another pattern, characterised by stable distribution of ideal family size and a very low share of women with an ideal of zero or one, which does not increase over time.

Figure 5: Changes in ideal family size in selected European countries, women aged 15-49 (data adjusted for non-response)
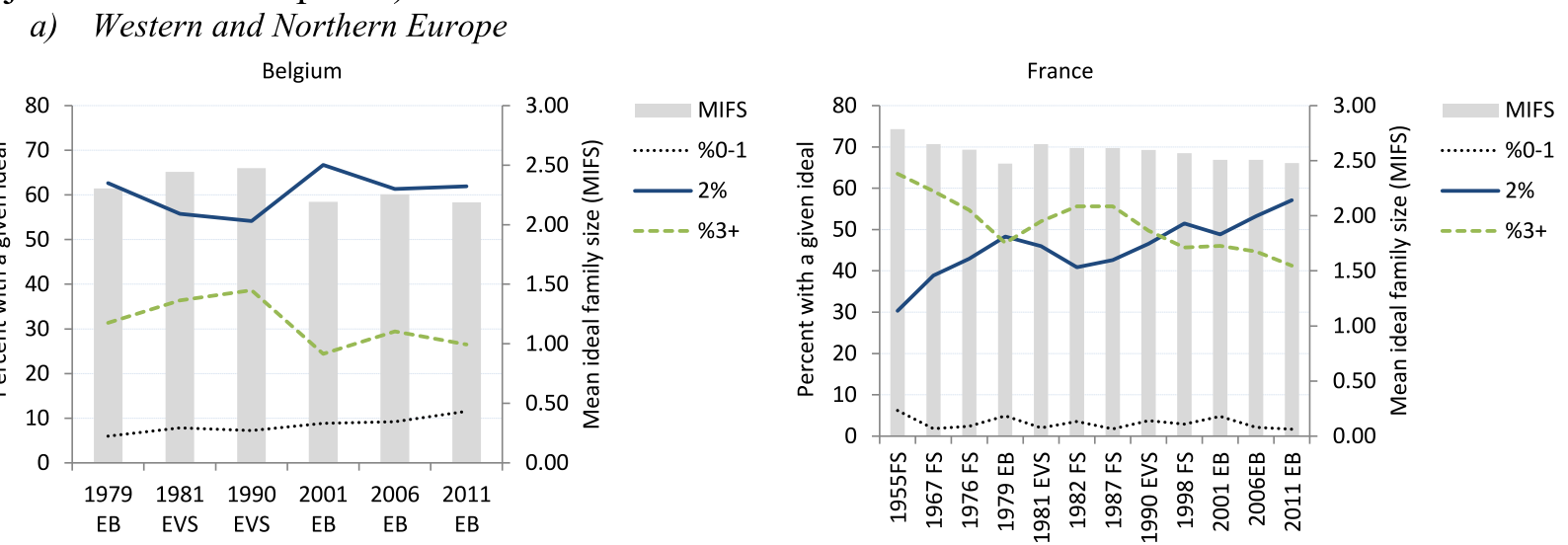


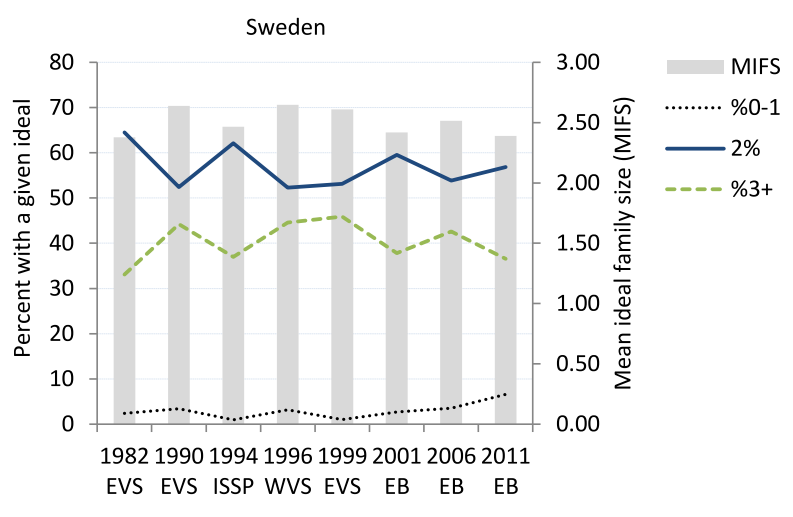

\section{b) Southern Europe}
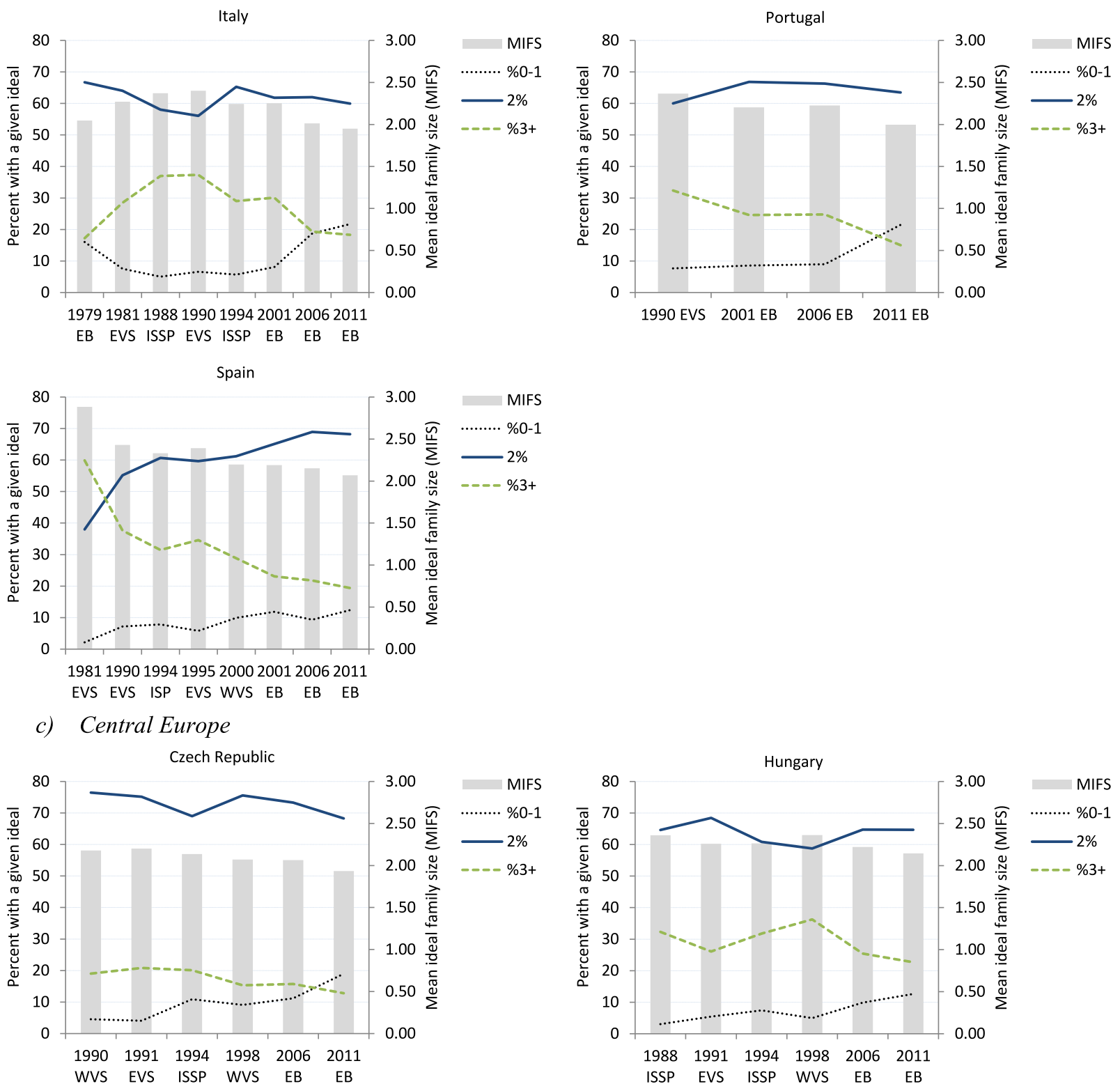


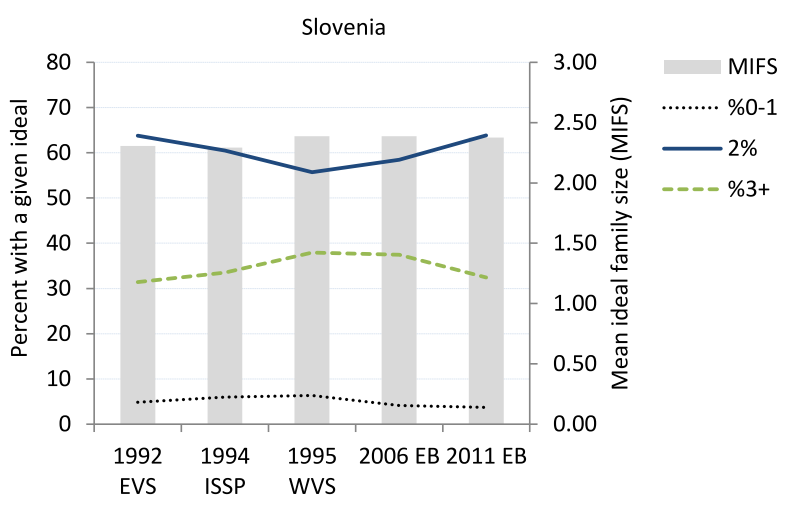

\subsection{Ideal Family Size in Austria, Germany, and Switzerland}

We were able to reconstruct trends in family size ideals in all the three predominantly Germanspeaking countries of Europe, looking separately at eastern and western Germany. These countries share a long history of low fertility (Sobotka 2011). With the exception of two surveys that do not align well with longer-time trends, the Austrian 1994 ISSP survey and the 2001 EB survey in eastern Germany, the time series for Austria and Germany show remarkable stability in fertility ideals, especially in western Germany (Figure 6). This is best illustrated by comparing the earliest and the latest survey conducted in 1979 and 2011. Both surveys show identical MIFS for western Germany of 2.10 and an identical share of respondents with a two-child ideal of 67 $\%$ when adjusted for non-response and non-numerical responses. There are no noticeable shifts in the distribution of larger- or small-family size ideals. The available literature indicates that women and men in western Germany have fully embraced a two-child family ideal at least two decades earlier: A 1957 survey of married women and men aged 15-45 showed that $45 \%$ had an ideal of two children, with the MIFS reaching $2.58^{16}$ (Freedman et al. 1959, Table 2). Also a comparison of eastern German 1990 EVS data with the 2011 EB data reveals striking continuity, with the MIFS "changing" from 1.96 to 1.98. The data for Austria suggest a decline in MIFS (2.30 in the 1998 ISSP survey vs. 1.98 in the 2011 Eurobarometer survey and 2.20 in the 2012 GGP survey) going hand in hand with a gradual increase in the share of women having an ideal of one or no children. In Switzerland we observe a gradual shift to a lower family size ideal, with a notable decline in the ideal of having three or more children, contributing to the rising popularity of a two-child ideal. Unlike in Austria and Germany, the ideal of having one or no children remains marginal in Switzerland.

Our results do not lend support to the earlier widely discussed findings of Goldstein, Lutz and Testa (2003) that younger cohorts of women in Austria and Germany have, after experiencing decades of low fertility, started expressing fertility ideals well below the replacement threshold. What is the main reason for the lack of supporting evidence in our study? First, we analyse general ideal family size, whereas Goldstein, Lutz and Testa looked at personal ideals, which have been in Austria slightly lower than the general ideals. Second, we excluded the 2001 EB surveys for Austria and western Germany which did not conform to our selection

\footnotetext{
${ }^{16}$ If the survey included also unmarried men and women - as has become a common practice a few decades laterthe mean ideal family size would probably be lower as some of those who were unmarried arguably formed a select group with a lower family size ideals.
} 
criteria due to the high share of non-response and of respondents that stated that "there is no ideal family size," altogether $19 \%$ in western Germany and $23 \%$ in Austria. These surveys reported very low ideals (see Appendix 1) that were not replicated in subsequent surveys in these countries, as shown in our analyses as well as in additional surveys analysed by Philipov and Bernardi (2011: 503, Table 1). One of the surveys analysed by the authors, the $2001 \mathrm{~EB}$ in eastern Germany, is included in Figure 6, but it constitutes an interruption in otherwise relatively stable time series. In our whole dataset, this survey showed the lowest value of MIFS at 1.78, way below the next lowest value of 1.93 reached in Romania in 2006 and in the Czech Republic in 2011, which adds to our suspicion that the 2001 EB survey in eastern Germany might suffer methodological problems, such as having a sample selection not well representative of east German population. ${ }^{17}$

Figure 6: Changes in ideal family size in Austria, eastern and western Germany and Switzerland, women aged 15-49 (data adjusted for non-response)
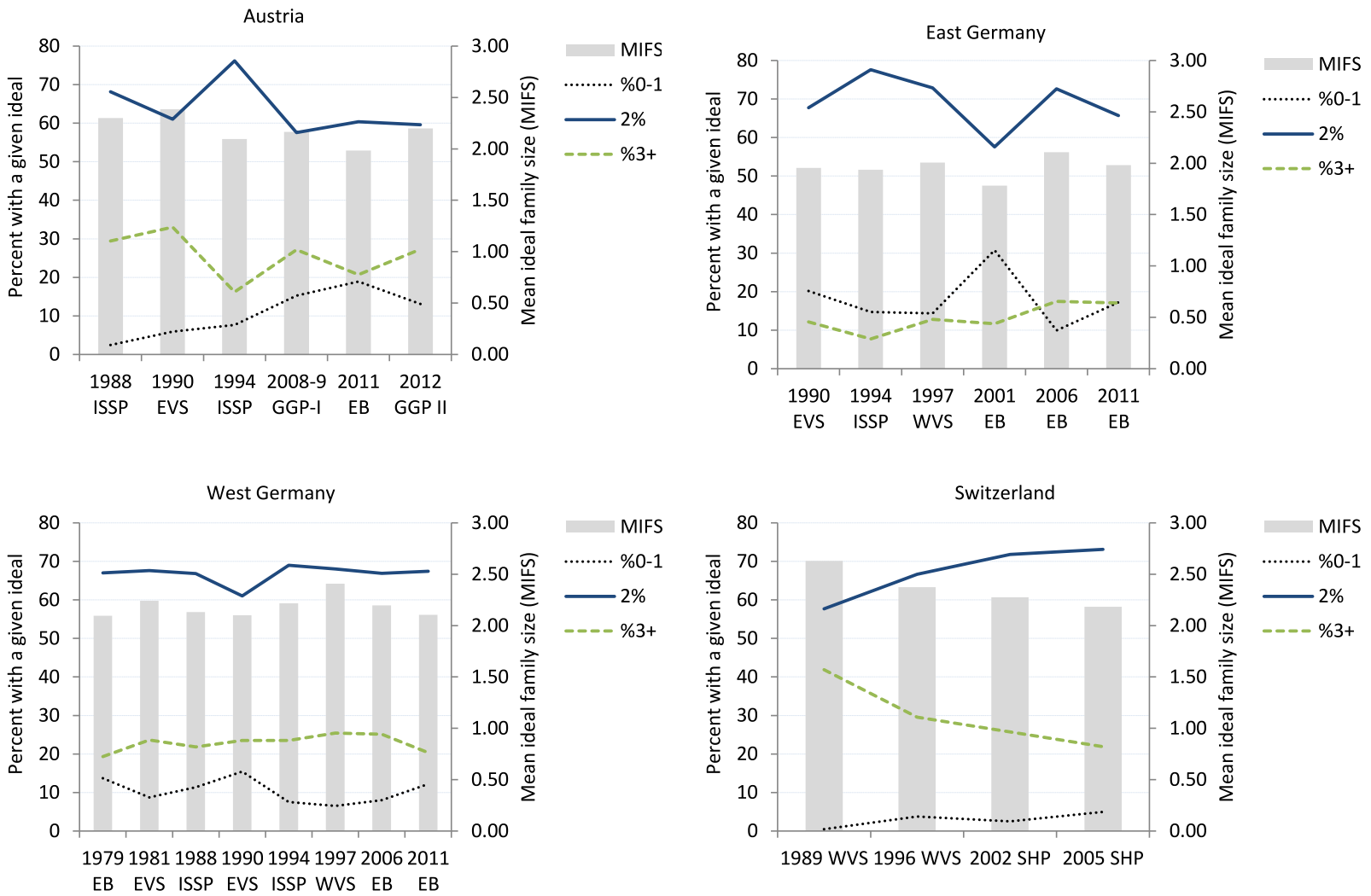

\subsection{Does a Decline in Mean Ideal Family Size Slow down when it reaches Low Levels?}

Our analyses suggest that the mean ideal family size around two constitutes a low threshold which, so far, has not been consistently crossed in Europe-except for a few one-off surveys and

\footnotetext{
${ }^{17}$ The study by Philipov and Bernardi (2011: 503, Table 2) compared additional datasets for eastern Germany and reported a similarly low mean family size ideal of 1.70 in another survey, the 1992 FFS.
} 
some variation around this value. This is remarkable both because the long history of very low fertility in a number of countries suggests that ideals could eventually follow the fertility trends observed earlier (Lutz, Skirbekk and Testa 2006) and because there is no pertinent reason to believe that ideals should follow the homeostatic logic of the "replacement level of fertility" model and stop falling when reaching the levels around replacement.

To investigate this in a more systematic fashion, we analysed changes in mean ideal family size depending on the initial MIFS level. Specifically, we selected for each country all pairs of consecutive surveys that took place within a period of up to ten years and analysed the changes in MIFS from one survey to the next. To standardise the results, we computed the annual change in MIFS between the year of the initial survey and the subsequent one. The results displayed in Figure $7 \mathrm{a}$ are by definition affected by the fact that we combined different surveys with not fully comparable questions, sample sizes, non-response options and other features. This should increase the noise in our time series as well as instability in the analysed results. This concern aside, our analysis suggests indeed that there is a relationship between the initial MIFS level and its subsequent change: The lower the initial MIFS level, the weaker its subsequent decline. A crossover even occurs when the MIFS falls below 2.3 children: When a survey shows a MIFS below this threshold, it is more likely to increase rather than decline in the next period. This effect is not very strong, but nevertheless suggests a frequent broad stabilisation of mean ideal family size once it reaches a low level close to the replacement. We also found a similar relationship for the two-child family ideal with the stabilising level at around $60 \%$. Above that level, the share of respondents with a two-child ideal is more likely to fall than to rise in the next survey (Figure $7 b$ ).

Figure 7a: Average annual change in the mean ideal family size (MIFS) between two consecutive surveys, conditional on the initial MIFS value; 127 pairs of surveys in Europe, 19792011

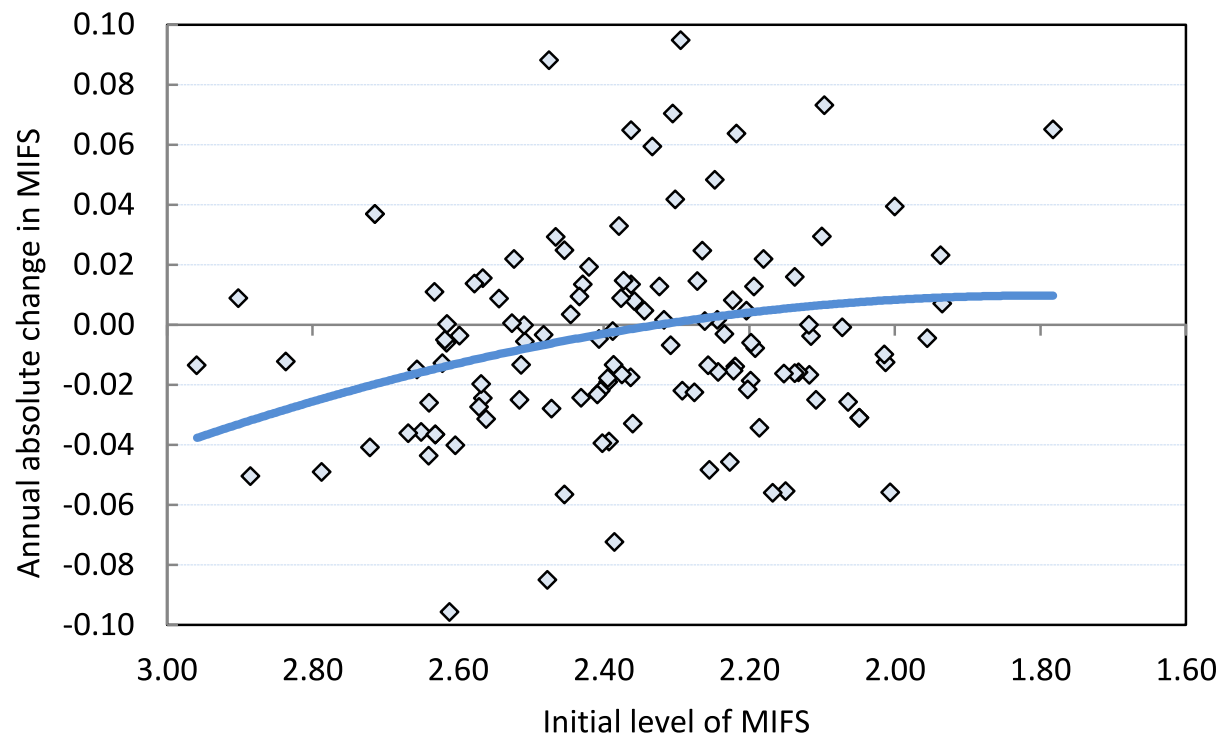


Figure 7b: Average annual change in the share of women aged 15-49 reporting a two-child family ideal (2CI) between two consecutive surveys, conditional on the initial 2CI value; 131 pairs of surveys in Europe, 1979-2011

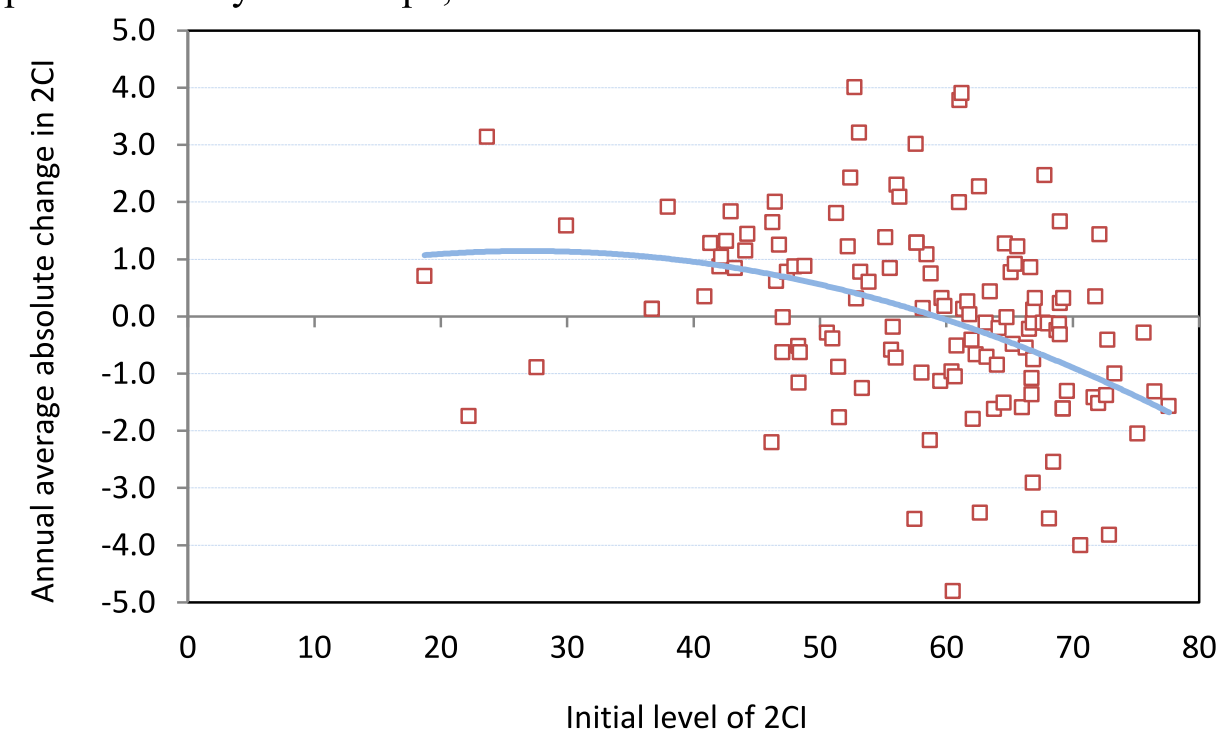

Notes: For the initial MIFS level only the data with an initial MIFS at or below 3.0 were selected (this resulted in the withdrawal of four data pairs). The level of $2 \mathrm{CI}$ is adjusted for non-response and non-numerical responses. The trendline in both graphs is a second-order polynomial curve supplied by MS Excel package.

\subsection{The Links between Subreplacement Fertility and Ideal Family Size}

If the changes in ideal family size tend to follow, at least partly, the changes in fertility behaviour as hypothesised by Lutz, Skirbekk and Testa (2006), two predictions related to its possible decline to levels significantly below replacement can be made:

- 1) The earlier a country experiences a decline in fertility to very low levels, the more likely it is to see a shift to MIFS below replacement;

- 2) The deeper fertility falls in a country, the more likely this country is to experience a shift to MIFS below replacement.

We address these predictions by ranking European countries by the timing and intensity of their fertility declines to low levels and analysing their most recent MIFS levels. To avoid tempo and parity composition distortions present in the most conventional measure of fertility, the period total fertility rate, we use completed cohort fertility rate (CFR). Table 2 looks at the European countries that experienced an early decline of CFR below 1.8 children per woman, selecting all countries experiencing such declines by the 1963 cohort. There appears to be no systematic relation between the early spread of low fertility and recent ideal family size. Three countries with earliest spread of low cohort fertility, western Germany, Austria, and Switzerland, retain comparatively higher MIFS at 2.1-2.3 than many countries with later cohort fertility declines, including Italy, eastern Germany and Spain.

However, when we rank countries with lowest fertility levels, as measured by their estimated cohort fertility rate among the women born in mid-1970s, a tentative link emerges between the 
magnitude of cohort fertility decline and MIFS level (Table 3). Specifically, all countries except Greece with a CFR below 1.6 children per woman share a low MIFS in the narrow range 1.952.11 . $^{18}$ However, even in these countries ideal family size still remains very close to the replacement threshold.

Table 2: European countries which experienced an early decline of completed fertility below 1.8 by cohort when fertility fell below this level and most recent MIFS level

\begin{tabular}{l|c|cc}
\hline & $\begin{array}{c}\text { First cohort with } \\
\text { a CFR }<1.8\end{array}$ & Year & Value \\
\hline Western Germany & 1944 & 2011 & 2.10 \\
Switzerland & 1950 & 2005 & 2.18 \\
Austria & 1954 & 2012 & 2.20 \\
Italy & 1956 & 2011 & 1.95 \\
Eastern Germany & 1960 & 2011 & 1.98 \\
Spain & 1960 & 2011 & 2.07 \\
Russia & 1961 & 1995 & 2.15 \\
Belarus & 1962 & 1996 & 2.11 \\
Ukraine & 1962 & 2007 & 1.97 \\
Lithuania & 1962 & 2011 & 2.22 \\
Slovenia & 1963 & 2011 & 2.38 \\
\hline
\end{tabular}

Notes: Data not shown for Luxembourg, where the CFR fell below 1.8 already in the 1947 cohort, but later rebounded above this threshold in the 1960s cohorts (the MIFS for Luxembourg was 2.26 in the 2011 EB survey).

Sources: MIFS data are based on the most recent surveys listed in Appendix 1. Data on completed fertility are based on Council of Europe (2006) yearbook.

\footnotetext{
${ }^{18}$ Despite finding some correspondence between fertility level and ideal family size among the countries with the lowest cohort fertility in Europe, relatively low MIFS levels are also found in some countries with a higher cohort fertility rate. For instance, the country with a lowest MIFS of 1.93 in the 2011 Eurobarometer survey, the Czech Republic, has comparatively high CFR estimated at 1.77-78 for the 1974-75 cohorts (Prioux and Barbieri 2013).
} 
Table 3: European countries with lowest completed cohort fertility among women born in 197475 and most recent MIFS level

\begin{tabular}{l|ccc}
\hline \multicolumn{1}{c}{} & \multicolumn{2}{c}{ Most recent MIFS } \\
& $\begin{array}{c}\text { CFR } \\
\text { (Cohort } \\
\text { Spl4-75) }\end{array}$ & Year & Value \\
\hline Spain & $1.37-1.41$ & 2011 & 2.07 \\
Italy & $1.42-45$ & 2011 & 1.95 \\
Ukraine & $1.51^{*}$ & 2007 & 1.97 \\
Eastern Germany & 1.55 & 2011 & 2.10 \\
Romania & 1.55 & 2011 & 1.97 \\
Bulgaria & 1.56 & 2011 & 2.03 \\
Western Germany & 1.57 & 2011 & 1.98 \\
Greece & $1.55-58$ & 2011 & 2.29 \\
Portugal & $1.57-58$ & 2011 & 2.00 \\
Belarus & $1.58^{*}$ & 1996 & 2.11 \\
Poland & $1.61-62$ & 2011 & 2.15 \\
Russia & 1.62 & 1995 & 2.15 \\
Austria & $1.63-64$ & 2012 & 2.20 \\
Switzerland & $1.63-65$ & 2005 & 2.18 \\
Slovenia & $1.66-67$ & 2011 & 2.38 \\
\hline
\end{tabular}

Notes: * Data pertain to the 1972 cohort;

Sources: MIFS data are based on the most recent surveys listed in Appendix 1. Data on completed cohort fertility are partly projected and for most countries based on the computations by Prioux and Barbieri 2013: 537, Table A7 for the 1974-75 cohort (trend projection), Data for Russia, eastern and western Germany are for the 1975 cohort and were computed by Myrskylä et al. 2013 (Table 2). Data for Belarus and Ukraine pertain to the 1972 cohort and are based on the forthcoming European Demographic Data Sheet 2014 (VID 2014; computations by Kryštof Zeman).

\subsection{How Prominent are Two-Child Ideals outside Europe?}

Is the ideal of having two children equally popular outside Europe? The evidence for nonEuropean countries with a long history of low fertility is indeed similar to that for Europe: Having two children has become a dominant ideal decades ago and it remains widely adhered to.

According to the series of Gallup polls dating back to 1936, the United States is close to the "two or three" children ideal, exhibited in Europe in France and in the Nordic countries. The two-child ideal rose quickly in prominence in the US during the socially turbulent times of the late 1960s-early 1970s: Between 1966 and 1973 the share of respondents saying that two children are ideal jumped from 18 to $46 \%$ (Livingston and Cohn 2010), and oscillated between 46 and $57 \%$ thereafter. Hagewen and Morgan's (2005) study, based on the considerably larger CPS and GSS surveys, shows similar results with close to a half of women of reproductive ages embracing a two-child ideal and with a mean ideal family around 2.4 in the 1990s and the early 2000s. 
Data for Australia and Canada from the ISSP and WVS surveys in 1995-2000 (our computations, data for countries outside Europe not listed in Appendix 1) show around a half of women aged 15-49 having an ideal of two children, with a MIFS at 2.4-2.6. Very similar values are found in the 2001 WVS survey for South Korea. In Japan, the WVS surveys in 1995-2005 show equal shares of women with two- and three-child ideal, around $40 \%$. The repeated waves of the Japanese National Fertility Survey indicate stable mean ideal family size among married women, dropping slightly from 2.6 in 1977 to 2.4 in 2010, while Japanese period total fertility rate has fallen to very low levels below 1.5 since the early 1990s (NIPSSR 2011a). ${ }^{19}$ In Taiwan, surveys of fertility preferences among married women indicate a continuous increase in the preference for having two children between 1970 and 2002, reaching $66 \%$ in the latest survey (Chang 2006: 13, Table 11).

We conducted additional analyses for countries in advanced stages of fertility transition, using the Demographic Health Survey (DHS) and Reproductive Health Survey (RHS) tabulations available in MeasureDHS Statcompiler (ICF International 2012). Specifically, we looked at the change in the preferred number of children among women of reproductive age in 18 countries of Latin America and the Caribbean, South Asia, South-east Asia, and in Turkey, Morocco and Namibia, where surveys were conducted both around 1990 and 2008 (for exact question wording see the Data section). ${ }^{20}$ Figure 8 shows a considerable shift towards a preference for two children; the average share of women desiring two children across the 18 countries jumped from 36 to $46 \%$, with an interquartile range of 40 to $53 \%$ in the latter period. The number of countries where more than $40 \%$ of women expressed a 2-child preference rose from 4 to 13 (Figure 9); in Bangladesh, Colombia, India, Nepal, Peru, and Turkey over half of women preferred two children. The mean desired family size declined in all analysed countries except Turkey and by around 2008 fell below 2.6 in 8 out of the 18 countries studied including Bangladesh, Bolivia, India, Nepal, and Peru.

\footnotetext{
${ }^{19}$ Never-married women were only asked about their desired number of children in case they planned to marry later in life. Among those aged 18-34 a two-child orientation clearly dominated, with a mean desired number of children showing a small decline from 2.3 to 2.1 between 1982 and 2010 (NIPSSR 2011b: p. 18, Table 3.2).

${ }^{20}$ Data for the following countries and surveys were analysed: Bangladesh DHS 1993-94 and 2007; Bolivia DHS 1989 and 1998; Colombia DHS 1990 and 2010; Dominican Republic DHS 1991 and 2007; Ecuador DHS 1987 and RHS 2004; Egypt DHS 1988 and 2008; Guatemala DHS 1987 and RHS 2008-9; Haiti DHS 1994-95 and 2005-6; India DHS 1992-3 and 2005-6; Indonesia DHS 1991 and 2007; Morocco DHS 1992 and 2003-4; Namibia DHS 1992 and 2006-7 ; Nepal DHS 1996 and 2011; Paraguay DHS 1990 and RHS 2008; Peru DHS 1991-2 and 2007-8; Philippines DHS 1993 and 2008; Sri Lanka DHS 1987 and 2006-7 (only ever-married women included in the latter survey); Turkey DHS 1993 and 2008 (only ever-married women included in the latter survey). We applied the same selection criteria as for European datasets, therefore did not include the data for Jordan and Pakistan, where a high share of women provided no or non-numerical responses (31 and $61 \%$, respectively) in the surveys that took place around 1990.
} 
Figure 8: Percentage of women aged 15-49 with a desired family size of two around 1990 and 2008; summary results from DHS and RHS surveys in 18 countries in advanced stage of fertility transition as compared with the ideal family size in European countries (data from Figure 2)

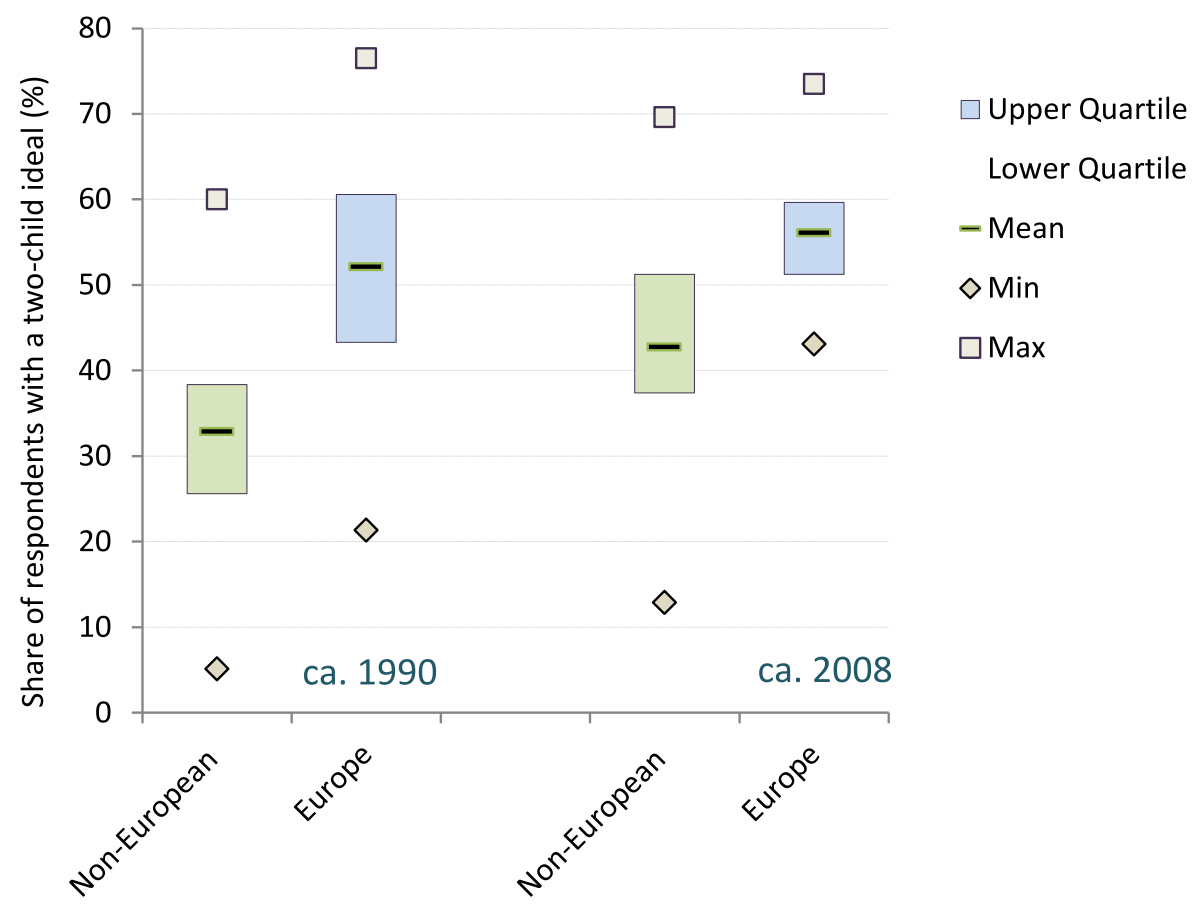

Figure 9: Share of women aged 15-49 desiring a two-child family around 1990 and 2008; summary results from DHS and RHS surveys in 18 countries in advanced stage of fertility transition

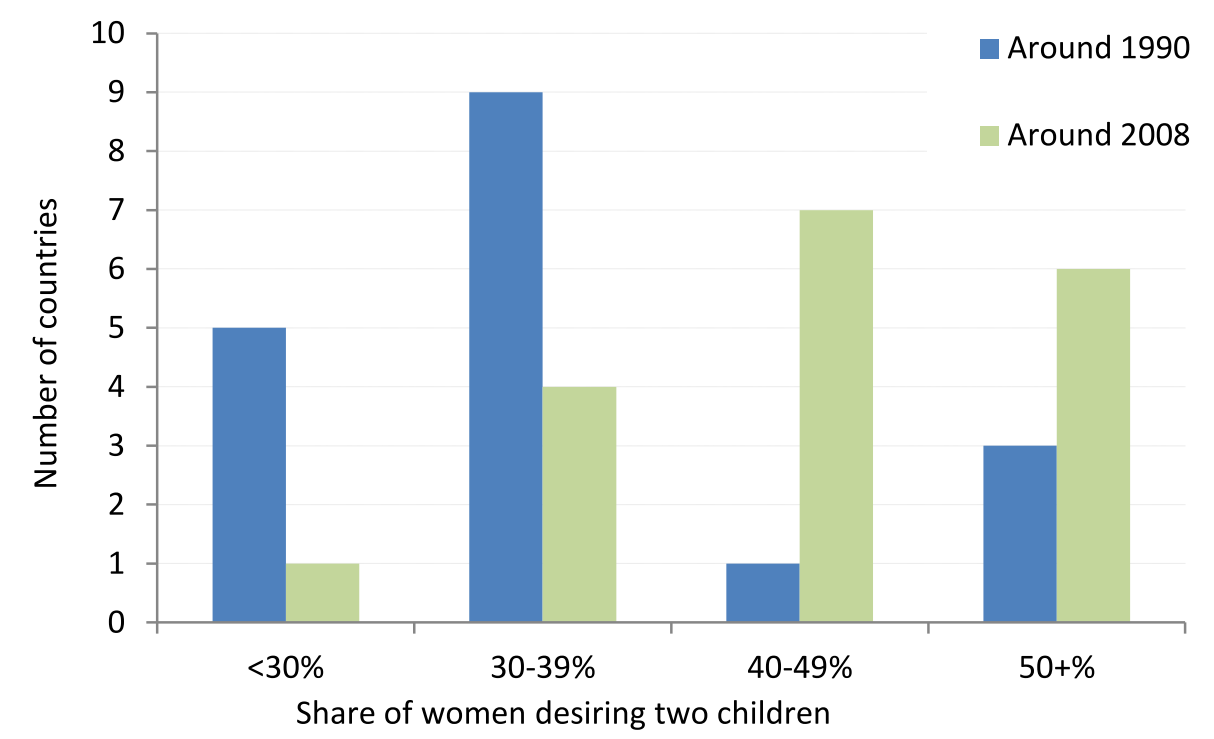




\section{Concluding Discussion}

\subsection{Main Findings}

In the last decades a two-child ideal has become nearly universal among women in Europe, as countries that used to display higher ideal family size have converged over time towards a twochild model. Six out of ten women in Europe consider two children as ideal and this proportion is very similar in different regions, irrespective of their fertility patterns and levels. Similarly, the mean ideal family size has become relatively closely clustered around 2.2 in most countries. Gradual shifts can be documented towards more women expressing an ideal of families with one child (and, quite rarely, no children), which goes hand in hand with the decline in an ideal of three or more children. These trends are regionally differentiated and have been more pronounced in Southern Europe (possibly in part due to the recent economic recession), Eastern and South-eastern Europe. However, there are no signs that women in any of the analysed European countries are moving away from a two-child ideal and embracing massively an ideal of having only one child, as has been evidenced in urban China (Basten and Gu Baochang 2013).

An increasing number of European countries - especially those which have reached a low level of completed fertility around 1.6 or lower - saw their mean ideal family size falling to relatively low level around 1.95-2.15. But with an exception of one survey for eastern Germany and a few additional surveys not included here due to high nonresponse, none of the analysed surveys suggests a decline of mean ideal family size to levels considerably below replacement, i.e., below 1.9 children per woman. Indeed, once a relatively low ideal family size below 2.3 is achieved, the next survey is more likely to show a slight increase rather than a further decline in MIFS. The evidence on the stability of reproductive ideals at around-replacement levels is most surprising for Austria, western Germany and Switzerland, which share an early fertility decline to levels well below replacement. Women in western Germany born in the mid-1950s reached a low completed fertility around 1.6, yet their daughters born in the 1980 s continue expressing considerably higher ideals averaging around the population replacement level of 2.1. This evidence is at odds with earlier reports on fertility ideals in Austria and Germany falling to the very low levels of 1.6-1.7 (Goldstein, Lutz and Testa 2003), which might have been partly affected by high non-response, low sample size or other data-related issues in the 2001 Eurobarometer survey (see also Philipov and Bernardi 2011: 502, fn 4).

We have not analysed fertility ideals for men, but available studies indicate that they come very close to those of women in most countries (see Testa 2012: 57, Table A.2.1 for the 2011 Eurobarometer survey ). Furthermore, the findings presented here align closely with our earlier analyses of intended family size of young women and men aged 25-29 in European countries participating in the Family and Fertility Surveys (FFS) in the 1990s and Generation and Gender Program (GGP) surveys in the 2000s. In both surveys, mean intended family size among young adults was closely clustered around 2.1 in most countries, with the minimum values around 1.9 (Beaujouan, Sobotka, Brzozowska and Neels 2013). Thus the findings on family size ideals presented here can be broadly extended to reproductive intentions at younger ages in Europe: The intention of having two children clearly dominates and there are not many signs yet of a systematic shift of intentions to levels considerably below replacement. Such a shift occurs partly only among women at later reproductive ages, when they are confronted with various 
obstacles and competing preferences that lead to downward revisions of their initially higher reproductive intentions (Iacovou and Tavares 2011, Gray et al. 2013).

The data for countries outside Europe, though often based on somewhat different measures of reproductive preferences in DHS and RHS surveys, suggest a remarkable global spread of two-child orientation also in many countries where the fertility transition is still in progress. A clear two-child preference is detected even in some countries with fertility level remaining well above replacement such as Bolivia (estimated period TFR of 3.2; PRB 2013), but also in countries with "ultra-low" fertility such as South Korea (period TFR hitting a low of 1.08 in 2005).

\subsection{Why an Ideal of Two?}

The spread and the subsequent persistence of a two-child family ideal in Europe are remarkable. Neither long-term experience of below-replacement fertility nor major social and economic upheavals or cultural and technological changes seem to have affected the widespread perception that having two children is ideal, both personally and for the society. The notion that fertility ideals and norms might not stay centred on two or more children forever has been around for long. Coleman (1999) argued that the basic question is "...whether there is any imaginable reason why the average should be two. (...) It is difficult to think of a mechanism, outside the realm of psychological 'instincts', or of biology, how such norms could be permanently protected." But childlessness is often viewed as an "extreme" choice. From the perspective of evolutionary biology and psychology, Foster (2000) argues that humans, and in particular women are biologically predisposed to nurturing behaviour and this "need to nurture" is strong enough to ensure that "women want to bear at least one child, despite the substantial costs of so doing." As parenthood is perceived by most people as a unique, valuable and desired experience, childless people may attain the status of parents and satisfy their "baby longing" by having just one offspring (Rotkirch et al, 2011).

There are many pertinent arguments why having one child might be best from an individual point of view. Parents can allocate more time and resources to interacting with their only child while minimising the negative impact children have on their leisure time, career progression and income. Their resources and attention can concentrate on one child, who does not have to experience conflict and competition with siblings (Mancillas 2006). From the perspective of parents, having one child is the "cheapest way to become a parent" (Jefferies 2001) and it minimalizes not only the economic costs, but also the potential negative impact children have on parents' leisure and employment. Wilson (2013: 1383) suggests that if the demographic transition "is hypothesised as a change from quantity to quality in children, then the logical endpoint is one child, not two." Striessnig and Lutz (2013: 411) argue that "at the individual level it is sufficient to have one child (under low child mortality conditions) if the primary goal is to pass on one's genes and continue to live on in the next generation". Blake (1981), reviewing the contemporary evidence on only children, found that despite widespread negative stereotypes they are intellectually superior, record better educational achievement, tend to count themselves as happy and suffer no obvious character or personality defects or disruptive behaviour when compared with children from larger families. A more recent review by Mancillas (2006) broadly corroborates these findings, citing high achievement and intelligence 
as "the most consistent and strongest advantages of only children" (pp. 270-71). Finally, the first child may substantially increase parents' happiness, while second child increases happiness only a little or not at all (Kohler, Behrman and Skytthe 2005, Myrskylä and Margolis 2012).

We have identified four broader factors that motivate people in contemporary lowfertility settings to view more than one child as an ideal. Besides the last one (fitting the social norm) they do not necessarily provide a rationale for preferring two children rather than, say, three or four, but they do provide a clear case for preferring more than one. Given that parents face high opportunity costs of having children, two children provide an "ideal strategy" to conform to the factors discussed below with the smallest possible effort.

Having one child of each sex provides a strong motivation for preferring two children. Interacting with a boy and with a girl may be perceived as qualitatively distinct experiences linked with different kinds of practical and psychological benefits, enjoyment, stimulation, communication, and play. Having two children is then a minimum needed-under ideal circumstances - to experience an interaction with one kid of each sex. Indeed, research on sex preferences and actual fertility behaviour documents considerable motivation of couples to have at least one child of each sex. This is most clearly illustrated in the studies of fertility behaviour among the parents of two or more children, where "a distinct and stable preference for at least one child of each sex can be observed as a common pattern (...) across many different social, economic and cultural contexts, whether they be located in developing countries or in highly industrialized nations" (Hank 2007).

Single child is viewed as spoiled and suffering. Even in contemporary low-fertility societies there are enduring negative stereotypes about only children who are often perceived as spoiled, self-centred, narcissist, domineering and quarrelsome (Mancillas 2006, Hagewen and Morgan 2005, Blake 1981, Almodovar 1973). Mancillas (2006: 268) traces these stereotypes to the psychologist G. Stanley Hall who claimed in his 1898 study that "being an only child is a disease in itself". The "onlies" are also expected to suffer from their status, experiencing loneliness, anxiety and deprivation. Although most of these stereotypes are unfounded (Blake 1981, Mancillas 2006), they create a negative perception of parents who have only one child as being selfish. Jefferies (2001: 4) cites British and Australian studies as well as a UK online forum that show that providing a companionship for the first child is an important reason why parents desire a second one.

Two children as an insurance strategy. In high-mortality societies individuals had a strong motivation to "produce" many offspring to achieve a high chance that at least one survives to adulthood and will be able to reproduce. This motivation for having more than one child has dramatically diminished as almost all children now survive to middle age. But more subtle "insurance strategy" to have more than one child may still be at work. If one child does not meet parental expectations because it is troublesome, difficult, hyperactive, or scoring badly at school, and, later in life, drops from school, experiences poor health, abuses drugs, turns violent, or moves far away and severs his or her ties with parents, having another child dramatically improves the chances that at least some of the parents' expectations and desires related to their children will be met. In many societies, children still serve as main providers of 
care for their ailing parents and having two children strongly increases the likelihood the parents will have someone to care about them when they get old.

Fitting the social norm. In Europe and many countries outside Europe, having two children has become a norm widely shared across generations and social groups. Since this norm is so widespread, most people know about it. Individuals uncertain about their preferences may state, for convenience, that their ideal family size is two - as they know this conforms to general expectations. Moreover, many people may receive cues from their parents, other relatives, friends, peers and colleagues, perpetuating the notion that two children are ideal. Recent comments posted by the readers of a blog entry "From one child to two" by Aimee Phan (2013) attest to that. Reader 479 writes: "As a parent of an only child, I get negative comments all the time", while DMV74 states "I must say I'm sick of the constant bash against only children (...) I've NEVER heard anyone say anything negative about couples having a second child. My baby is only 6 months old and all we get is when are we planning for the second one." In addition, people responding the question on "societal ideal" may also answer it having in mind a common sense (and broadly correct) perception that in order for the population to replace itself each couple needs to have (at least) two children.

Finally, some respondents expressing a two-child ideal may be influenced by their current family size and the size of their family of origin. An online survey focused on fertility ideals revealed that the respondents with children had difficulties stating their ideals "retrospectively" without being affected by their current family status (Hin et al. 2011: 147, fn 9). At younger ages, respondents may base their preferences on the size of their family of origin (Régnier-Loilier 2006, Hayford 2009), which now frequently means two children.

Clearly, these are pertinent explanations for the persistence of two-child ideals. But since these ideals are partly based on misconceptions (negative stereotypes about only children) or on perceived social norms that may eventually erode, the current remarkable and near-universal dominance of the two-child ideal in Europe may not prevail in all parts of the continent. The two-child norm may also erode via the changes in family forms, especially stepfamilies, which contribute to the spread of other living arrangements than the "stereotypical" married couple with two biological children. Although the earlier predictions of the imminent spread of subreplacement ideals have not yet materialised, subtle shifts towards a higher share of women with one child ideal are observed in many countries. They provide a signal about the potential for a future spread of one child ideals in Europe. Whether this will indeed take place is an open question. 


\section{References}

Almodovar, Jean-Pierre. 1973. "Existe-t-il un "syndrome de l'enfant unique "?". Enfance 26(3): 235-249.

Basten, Stuart and Baochang Gu. 2013. "National and regional trends in ideal family size in China". Paper presented at the IUSSP International Population Conference, Busan, Korea, 26-31 August 2013. Accessed in November 2013 at

$<$ http://www.iussp.org/sites/default/files/event_call_for_papers/GU $\% 20$ and $\% 20$ Basten $\% 2$ 0Long\%20Abstract.pdf $>$

Beaujouan, Éva, Tomáš Sobotka, Zuzanna Brzozowska and Karel Neels. 2013. "Education and sex differences in intended family size in Europe." Paper presented at the conference "Changing families and fertility choices," Oslo, 6-7 June 2013.

Blake, Judith. 1966. "Ideal family size among white Americans: A quarter of a century's evidence." Demography 3(1): 154-173.

Blake, Judith. 1974. "Can we believe recent data on birth expectations in the United States?". Demography 11(1): 25-44.

Blake, Judith. 1981. "The only child in America: Prejudice versus performance." Population and Development Review 7(1): 43-54.

Bongaarts, John. 2002. "The end of the fertility transition in the developed world". Population and Development Review 28 (3): 419-443.

Chang, Ming-Cheng. 2006. "Taiwan's transition from high fertility to lowest low levels." Asian Journal of Health and Information Sciences 1(1): 1-15.

Coleman, David A. 1999. "Reproduction and survival in an unknown world". NIDI Hofstee Lecture Series 5, NIDI, The Hague.

Demeny, Paul. 2003. "Population policy dilemmas in Europe at the dawn of the twenty-first century". Population and Development Review 29 (1): 1-28.

Ding, Qu Jian and Therese Hesketh. 2006. "Family size, fertility preferences, and sex ratio in China in the era of the one child family policy: results from national family planning and reproductive health survey." BMJ, 333(7564): 371-373.

Foster, Caroline. 2000. "The limits to low fertility: A biosocial approach". Population and Development Review 26 (2): 209-234.

Frejka, Tomas and Tomáš Sobotka. 2008. "Fertility in Europe: diverse, delayed, and below replacement." Demographic Research, Special collection 7, 19(3): 15-46.

Goldstein, Joshua R. and Michaela Kreyenfeld. 2011. "Has East Germany overtaken West Germany? Recent trends in order-specific fertility." Population and Development Review 37(3): 453-472.

Goldstein, Joshua R., Wolfgang Lutz, and Maria Rita Testa. 2003. "The emergence of subreplacement family size ideals in Europe". Population Research and Policy Review 22 (56): 479-496.

Gray, Edith, Ann Evans and Anna Reimondos. 2013. "Childbearing desires of childless men and women: When are goals adjusted?" Advances in Life Course Research 18(2): 141-149.

Hank, Karsten. 2007. "Parental gender preferences and reproductive behaviour: A review of the recent literature." Journal of Biosocial Science 39(5): 759-767.

Hagewen, Kellie J. and S. Philip Morgan. 2005. "Intended and ideal family size in the United States." Population and Development Review 31(3): 507-527. 
Hauser, Philip M. 1967. "Family planning and population programs." A book review article. Demography 4(1): 397-414.

Hayford, Sarah R. 2009. "The evolution of fertility expectations over the life course." Demography 46(4), 765-783.

Hin, Saskia, Anne Gauthier, Joshua R. Goldstein, and Christoph Bühler. 2011. "Fertility preferences: what measuring second choices teaches us." Vienna Yearbook of Population Research 2011 (9): 131-156.

Iacovou, Maria and Lara Patricio Tavares. 2011. "Yearning, learning and conceding: reasons men and women change their childbearing intentions." Population and Development Review 37(1): 89-123.

ICF International. 2012. MEASURE DHS STATcompiler. Accessed April 17, 2013 at http://www.statcompiler.com.

Inglehart, Ronald. 1990. Culture shift in advanced industrial society. Princeton University Press, Princeton, New Jersey.

Jefferies, Julie. 2001. "A reluctance to embrace the one-child family in Britain?" Paper presented at EURESCO conference "The Second Demographic Transition in Europe", Bad Herrenalb, Germany, 23-28 June 2001. Available at http://www.demogr.mpg.de/Papers/workshops/010623 paper05.pdf

Kohler, Hans-Peter, Jere R. Behrman, and Axel Skytthe. 2005. "Partner + Children = Happiness? The effects of partnerships and fertility on well-being." Population and Development Review 31(3): 407-445.

Kreyenfeld, Michaela. 2003. "Crisis or adaptation reconsidered: a comparison of East and West German fertility patterns in the first six years after the 'Wende'." European Journal of Population 19(3): 303-329.

Lesthaeghe, Ron. 1995. "The second demographic transition in Western countries: an interpretation". In.: K. O. Mason and A.-M. Jensen (eds.) Gender and family change in industrialized countries. Oxford, Clarendon Press, pp. 17-62.

Livingston, Gretchen and D'Vera Cohn. 2010. The New Demography of American Motherhood. Pew Research Centre, A Social \& Demographic Trends Report, Revised August 19, 2010.

Lutz, W., V. Skirbekk, and M. R. Testa. 2006. "The low fertility trap hypothesis. Forces that may lead to further postponement and fewer births in Europe." Vienna Yearbook of Population Research 2006: 167-192.

Mancillas, Adriean. 2006. "Challenging the stereotypes about only children: A review of the literature and implications for practice." Journal of Counseling \& Development 84(3): 268275.

Merli, M. Giovanna and S. Philip Morgan. 2011. "Below replacement fertility preferences in Shanghai." Population-E 66(3): 519-542.

Merz, Eva M., and Aart C. Liefbroer. 2012. "The attitude toward voluntary childlessness in Europe: Cultural and institutional explanations." Journal of Marriage and Family 74(3): 587-600. Miller 2011

Miller, Warren B. 2011. "Differences between fertility desires and intentions: implications for theory, research and policy." Vienna Yearbook of Population Research 2011 (Vol. 9): 7598.

Myrskylä, Mikko and Rachel Margolis. 2012. "Happiness: before and after the kids." MPIDR Working Paper WP-2012-013, Max Planck Institute for Demographic Research, Rostock. 
Myrskylä, Mikko, Joshua R. Goldstein, and Yen-Hsin Alice Cheng. 2013. "New cohort fertility forecasts for the developed world: rises, falls, and reversals." Population and Development Review 39(1): 31-56.

Ní Bhrolcháin, Máire and Éva Beaujouan. 2011. "Uncertainty in fertility intentions in Britain, 1979-2007." Vienna Yearbook of Population Research 2011(9): 99-129.

Nie, Yilin and Robert J. Wyman, 2005. "The one-child policy in Shanghai: Acceptance and internalization." Population and Development Review 31(2): 313-336.

NIPSSR. 2011a. The Fourteenth Japanese National Fertility Survey in 2010. Marriage Process and Fertility of Japanese Married Couples. National Institute of Population and Social Security Research, Tokyo.

NIPSSR. 2011b. The Fourteenth Japanese National Fertility Survey in 2010. Attitudes toward Marriage and Family among Japanese Singles. National Institute of Popyulation and Social Security Research, Tokyo.

Phan, Aimee. 2013. "From one child to two." Posted 13 October 2013 on The Motherlode blog; accessed 25 March 2014 at <http://parenting.blogs.nytimes.com/2013/10/13/from-onechild-to-two/? php $=$ true\&_type $=$ blogs \&_r $=0>$

Philipov, Dimiter and Laura Bernardi. 2011. "Reproductive decisions: concepts and measurement in Austria, Germany and Switzerland." Comparative Population Studies, 36(2-3): 495-530.

PRB. 2013. World Population data Sheet 2013. Population Reference Bureau, Washington. Accessed 8 April 2014 at http://www.prb.org/Publications/Datasheets/2013/2013-worldpopulation-data-sheet/data-sheet.aspx

Prioux, France and Magali Barbieri. 2013. "Recent demographic developments in France: Relatively low mortality at advanced ages.“ Population (English edition) 67(4): 493-550.

Quesnel-Vallée, Amélie and S. Philip Morgan. 2003. "Missing the target? Correspondence of fertility intentions and behavior in the U.S.". Population Research and Policy Review 22 (5-6): 497-525.

Régnier-Loilier, Arnaud. 2006. "Influence of own sibship size on the number of children desired at various times of life. The case of France." Population (English Edition) 61(3): 165-194.

Rotkirch, Anna, Stuart Basten, Heini Väisänen, and Markus Jokela. 2011. "Baby longing and men's reproductive motivation." Vienna Yearbook of Population Research 2011(9): 283306.

Ryder, Norman B. and Charles F. Westoff. 1969. "Relationships among intended expected desired and ideal family size: United States 1965." Population Research, March 1969.

Schoen, Robert, Nam Marie Astone, Young J. Kim, and Constance A. Nathanson. 1999. "Do fertility intentions affect fertility behaviour?" Journal of Marriage and the Family 61(3): 790-799.

Simons, John. 1978. "Illusions about attitudes." In: Population decline in Europe: Implications of a declining stationary population. Edward Arnold Publishers, Council of Europe, pp. 197-214.

Sobotka, Tomáš. 2011. "Fertility in Austria, Germany and Switzerland: is there a common pattern? " Comparative Population Studies 36(2-3): 263-304.

Sobotka, Tomáš. 2013. "Pathways to Low Fertility: European Perspectives", Expert Paper No. 2013/8, United Nations Department of Economic and Social Affairs, Population Division. URL: $\quad$ http://www.un.org/en/development/desa/population/publications/pdf/expert/20138_Sobotka_Expert-Paper.pdf 
Striessnig, Erich and Wolfgang Lutz. 2013. "Can below-replacement fertility be desirable?" Empirica 40(3): 409-425.

Testa, Maria Rita. 2007 "Childbearing preferences and family issues in Europe: evidence from the Eurobarometer 2006 survey." Vienna Yearbook of Population Research 2007(5): 357379.

Testa, Maria Rita. 2012. "Family sizes in Europe. Evidence from the 2011 Eurobarometer survey." European Demographic Research Papers 2012, No. 2. Vienna Institute of Demography, Austrian Academy of Sciences. URL: http://www.oeaw.ac.at/vid/download/edrp_2 2012.pdf

Testa, Maria Rita and Leonardo Grilli. 2006. "The influence of childbearing regional contexts on ideal family size in Europe." Population (English edition) 61(1): 99-127.

Testa, Maria Rita and Stuart Basten. 2013. "Fertility intentions and the 'Great Recession': evidence from the Eurobarometer surveys." Paper presented at Session 177 of the 2013 Annual Meeting of Population Association of America, New Orleans, 11-13 April 2013. Accessed in September 2013 at $<$ http://paa2013.princeton.edu/abstracts/132162>,

Trent, Roger B. 1980. "Evidence bearing on the construct validity of" ideal family size"." Population and Environment 3.3-4 (1980): 309-327."

Van de Kaa, Dirk J. 2001. "Postmodern fertility preferences: From changing value orientation to new behavior". In.: R. A. Bulatao, J. B. Casterline (eds.) Global fertility transition. Supplement to Population and Development Review 27, New York, Population Council, pp. 290-338.

VID. 2014. European Demographic Data Sheet. Vienna Institute of Demography and IIASA / Wittgenstein Centre for Demography and Global Human Capital. Forthcoming in June 2014 at http://www.oeaw.ac.at/vid/datasheet/index.html

Ware, Helen. 1974. "Ideal family size." World Fertility Survey, Occasional Papers No. 13 (October 1974), 28 p.

Wilson, Chris. "Thinking about post-transitional demographic regimes: A reflection." Demographic Research 28(46): 1373-1388. 


\section{Appendix 1: Overview of all European datasets considered for the analysis}

\begin{tabular}{|c|c|c|c|c|c|c|c|c|}
\hline Country & Year & Survey & Selected & $\begin{array}{l}N(F \\
\text { aged } \\
15-49)\end{array}$ & $\begin{array}{l}\text { \% miss., } \\
\text { DKN, } \\
\text { other }\end{array}$ & $\begin{array}{l}\text { Mean } \\
\text { ideal FS }\end{array}$ & $\begin{array}{l}\% \text { with } 2- \\
\text { child } \\
\text { ideal }\end{array}$ & $\begin{array}{l}\text { \% 2-child } \\
\text { ideal } \\
\text { (adjusted) }\end{array}$ \\
\hline Albania & 1998 & WVS & Y & 362 & 8 & 2.36 & 53 & 57 \\
\hline Albania & 2002 & WVS & Y & 363 & 3 & 2.62 & 42 & 43 \\
\hline Albania & $2008-9$ & DHS & $\mathrm{Y}$ & 7584 & 1 & 2.54 & 48 & 48 \\
\hline Austria & 1988 & ISSP & Y & 299 & 0 & 2.30 & 68 & 68 \\
\hline Austria & 1990 & EVS & Y & 496 & 2 & 2.38 & 60 & 61 \\
\hline Austria & 1994 & ISSP & $\mathrm{Y}$ & 299 & 3 & 2.10 & 74 & 76 \\
\hline Austria & 2001 & EB & $\mathrm{N}^{1}$ & 316 & 23 & 1.86 & 45 & 58 \\
\hline Austria & 2006 & EB & $\mathrm{N}^{1}$ & 324 & 32 & 1.73 & 40 & 59 \\
\hline Austria & $2008-9$ & GGP & Y & 3001 & 0 & 2.17 & 57 & 58 \\
\hline Austria & 2011 & EB & Y & 329 & 15 & 1.98 & 51 & 60 \\
\hline Austria & 2012 & GGP & $\mathrm{Y}$ & 2808 & 1 & 2.20 & 59 & 60 \\
\hline Belarus & 1990 & EVS & Y & 418 & 1 & 2.45 & 56 & 56 \\
\hline Belarus & 1996 & WVS & $\mathrm{Y}$ & 743 & 2 & 2.11 & 67 & 69 \\
\hline Belgium & 1979 & $\mathrm{~EB}^{+}$ & $\mathrm{Y}$ & 297 & 4 & 2.30 & 60 & 63 \\
\hline Belgium & 1981 & EVS & Y & 358 & 17 & 2.45 & 47 & 56 \\
\hline Belgium & 1990 & EVS & Y & 841 & 9 & 2.48 & 49 & 54 \\
\hline Belgium & 2001 & EB & Y & 298 & 15 & 2.19 & 57 & 67 \\
\hline Belgium & 2006 & EB & Y & 296 & 7 & 2.26 & 57 & 61 \\
\hline Belgium & 2011 & EB & $\mathrm{Y}$ & 272 & 6 & 2.19 & 59 & 62 \\
\hline Bulgaria & 1991 & EVS & Y & 367 & 2 & 2.17 & 68 & 70 \\
\hline Bulgaria & 1994 & ISSP & Y & 361 & 0 & 2.00 & 66 & 66 \\
\hline Bulgaria & 1997 & WVS & Y & 315 & 3 & 2.12 & 67 & 69 \\
\hline Bulgaria & 2006 & EB* & Y & 292 & 10 & 2.12 & 65 & 72 \\
\hline Bulgaria & 2011 & EB & $\mathrm{Y}$ & 274 & 7 & 2.03 & 73 & 79 \\
\hline Croatia & 1996 & WVS & $\mathrm{Y}$ & 432 & 4 & 2.67 & 44 & 46 \\
\hline Croatia & 2006 & $\mathrm{~EB}^{*}$ & $\mathrm{Y}$ & 322 & 8 & 2.31 & 58 & 63 \\
\hline Cyprus & 2006 & $\mathrm{~EB}$ & $\mathrm{~N}^{2}$ & 147 & 2 & 2.86 & 25 & 26 \\
\hline Cyprus & 2011 & EB & $\mathrm{N}^{2}$ & 168 & 2 & 2.36 & 56 & 58 \\
\hline Czech Republic & 1990 & WVS & $\mathrm{Y}$ & 289 & 0 & 2.18 & 76 & 76 \\
\hline Czech Republic & 1991 & EVS & $\mathrm{Y}$ & 670 & 1 & 2.20 & 74 & 75 \\
\hline Czech Republic & 1994 & ISSP & Y & 359 & 0 & 2.14 & 69 & 69 \\
\hline Czech Republic & 1998 & WVS & $\mathrm{Y}$ & 327 & 2 & 2.07 & 74 & 76 \\
\hline Czech Republic & 2006 & EB & $\mathrm{Y}$ & 348 & 9 & 2.06 & 67 & 73 \\
\hline Czech Republic & 2011 & $\mathrm{~EB}$ & $\mathrm{Y}$ & 363 & 8 & 1.93 & 63 & 68 \\
\hline
\end{tabular}




\begin{tabular}{|c|c|c|c|c|c|c|c|c|}
\hline Country & Year & Survey & Selected & $\begin{array}{l}N(F \\
\text { aged } \\
15-49)\end{array}$ & $\begin{array}{l}\text { \% miss., } \\
\text { DKN, } \\
\text { other }\end{array}$ & $\begin{array}{l}\text { Mean } \\
\text { ideal FS }\end{array}$ & $\begin{array}{l}\text { \% with 2- } \\
\text { child } \\
\text { ideal }\end{array}$ & $\begin{array}{l}\% \text { 2-child } \\
\text { ideal } \\
\text { (adjusted) }\end{array}$ \\
\hline Denmark & 1979 & $\mathrm{~EB}^{+}$ & $\mathrm{Y}$ & 371 & 8 & 2.34 & 61 & 67 \\
\hline Denmark & 1981 & EVS & $\mathrm{N}^{1}$ & 398 & 20 & 2.43 & 46 & 57 \\
\hline Denmark & 1990 & EVS & $\mathrm{Y}$ & 310 & 4 & 2.57 & 52 & 54 \\
\hline Denmark & 2001 & EB & $\mathrm{Y}$ & 281 & 12 & 2.36 & 53 & 60 \\
\hline Denmark & 2006 & $\mathrm{~EB}$ & $\mathrm{~N}^{1}$ & 250 & 21 & 2.52 & 43 & 55 \\
\hline Denmark & 2011 & EB & $\mathrm{Y}$ & 204 & 12 & 2.50 & 45 & 51 \\
\hline Estonia & 1990 & EVS & Y & 381 & 2 & 2.51 & 43 & 44 \\
\hline Estonia & 1996 & WVS & Y & 356 & 1 & 2.43 & 50 & 51 \\
\hline Estonia & 2006 & EB & Y & 308 & 8 & 2.53 & 44 & 47 \\
\hline Estonia & 2011 & EB & $\mathrm{Y}$ & 256 & 4 & 2.53 & 45 & 47 \\
\hline Finland & 1990 & EVS & Y & 217 & 12 & 2.66 & 37 & 42 \\
\hline Finland & 1996 & WVS & Y & 339 & 6 & 2.57 & 45 & 48 \\
\hline Finland & 2001 & EB & $\mathrm{N}^{1}$ & 301 & 19 & 2.48 & 40 & 49 \\
\hline Finland & 2006 & EB & Y & 251 & 7 & 2.72 & 39 & 42 \\
\hline Finland & 2011 & EB & $\mathrm{Y}$ & 241 & 7 & 2.52 & 43 & 46 \\
\hline France & 1955 & Conj. & $\mathrm{Y}$ & 777 & 6 & 2.79 & 28 & 30 \\
\hline France & 1967 & Conj. & Y & 407 & 4 & 2.65 & 37 & 39 \\
\hline France & 1976 & Conj. & Y & 716 & 6 & 2.60 & 40 & 43 \\
\hline France & 1979 & $\mathrm{~EB}^{+}$ & $\mathrm{Y}$ & 370 & 5 & 2.47 & 46 & 48 \\
\hline France & 1981 & EVS & $\mathrm{Y}$ & 453 & 5 & 2.65 & 44 & 46 \\
\hline France & 1982 & Conj. & Y & 816 & 2 & 2.61 & 40 & 41 \\
\hline France & 1987 & Conj. & Y & 762 & 1 & 2.62 & 42 & 43 \\
\hline France & 1990 & EVS & $\mathrm{Y}$ & 364 & 4 & 2.60 & 45 & 47 \\
\hline France & 1998 & Int. fec. & Y & 1391 & 2 & 2.57 & 51 & 51 \\
\hline France & 2001 & EB & $\mathrm{Y}$ & 339 & 12 & 2.51 & 43 & 49 \\
\hline France & 2006 & EB & $\mathrm{Y}$ & 309 & 7 & 2.51 & 49 & 53 \\
\hline France & 2010 & Fecond & Y & 2425 & 4 & 2.48 & 55 & 57 \\
\hline France & 2011 & $\mathrm{~EB}$ & $\mathrm{Y}$ & 266 & 6 & 2.30 & 62 & 66 \\
\hline eastern Germany & 1990 & EVS & Y & 413 & 1 & 1.96 & 67 & 68 \\
\hline eastern Germany & 1994 & ISSP & Y & 289 & 1 & 1.94 & 77 & 78 \\
\hline eastern Germany & 1997 & WVS & Y & 341 & 6 & 2.01 & 69 & 73 \\
\hline eastern Germany & 2001 & EB & $\mathrm{Y}$ & 290 & 13 & 1.78 & 50 & 58 \\
\hline eastern Germany & 2006 & EB & $\mathrm{Y}$ & 119 & 8 & 2.11 & 67 & 73 \\
\hline eastern Germany & 2011 & EB & $\mathrm{Y}$ & 163 & 13 & 1.98 & 57 & 66 \\
\hline
\end{tabular}




\begin{tabular}{|c|c|c|c|c|c|c|c|c|}
\hline Country & Year & Survey & Selected & $\begin{array}{l}N(F \\
\text { aged } \\
15-49)\end{array}$ & $\begin{array}{l}\text { \% miss., } \\
\text { DKN, } \\
\text { other }\end{array}$ & $\begin{array}{l}\text { Mean } \\
\text { ideal FS }\end{array}$ & $\begin{array}{l}\% \text { with } 2- \\
\text { child } \\
\text { ideal }\end{array}$ & $\begin{array}{l}\% \text { 2-child } \\
\text { ideal } \\
\text { (adjusted) }\end{array}$ \\
\hline western Germany & 1979 & $\mathrm{~EB}^{+}$ & $\mathrm{Y}$ & 331 & 14 & 2.10 & 58 & 67 \\
\hline western Germany & 1981 & EVS & $\mathrm{Y}$ & 442 & 17 & 2.24 & 56 & 68 \\
\hline western Germany & 1988 & ISSP & $\mathrm{Y}$ & 954 & 4 & 2.13 & 64 & 67 \\
\hline western Germany & 1990 & EVS & $\mathrm{Y}$ & 595 & 10 & 2.10 & 55 & 61 \\
\hline western Germany & 1994 & ISSP & $\mathrm{Y}$ & 648 & 3 & 2.22 & 67 & 69 \\
\hline western Germany & 1997 & WVS & Y & 395 & 14 & 2.41 & 58 & 68 \\
\hline western Germany & 2001 & $\mathrm{~EB}$ & $\mathrm{~N}^{1}$ & 280 & 19 & 2.00 & 52 & 65 \\
\hline western Germany & 2006 & EB & $\mathrm{Y}$ & 276 & 14 & 2.20 & 58 & 67 \\
\hline western Germany & 2011 & EB & $\mathrm{Y}$ & 258 & 14 & 2.10 & 58 & 67 \\
\hline Greece & 2001 & $\mathrm{~EB}$ & $\mathrm{Y}$ & 289 & 2 & 2.56 & 46 & 47 \\
\hline Greece & 2006 & EB & $\mathrm{Y}$ & 298 & 4 & 2.40 & 49 & 51 \\
\hline Greece & 2011 & $\mathrm{~EB}$ & $\mathrm{Y}$ & 288 & 8 & 2.29 & 56 & 60 \\
\hline Hungary & 1988 & ISSP & $\mathrm{Y}$ & 601 & 0 & 2.36 & 65 & 65 \\
\hline Hungary & 1991 & EVS & $\mathrm{Y}$ & 283 & 2 & 2.26 & 67 & 68 \\
\hline Hungary & 1994 & ISSP & $\mathrm{Y}$ & 421 & 3 & 2.26 & 59 & 61 \\
\hline Hungary & 1998 & WVS & $\mathrm{Y}$ & 191 & 5 & 2.36 & 56 & 59 \\
\hline Hungary & 2006 & EB & $\mathrm{Y}$ & 285 & 4 & 2.22 & 62 & 65 \\
\hline Hungary & 2011 & EB & $\mathrm{Y}$ & 276 & 5 & 2.14 & 61 & 65 \\
\hline Iceland & 1984 & EVS & $\mathrm{Y}$ & 345 & 1 & 2.90 & 27 & 28 \\
\hline Iceland & 1990 & EVS & $\mathrm{Y}$ & 253 & 4 & 2.95 & 21 & 22 \\
\hline Ireland & 1979 & $\mathrm{~EB}^{+}$ & $\mathrm{Y}$ & 310 & 7 & 3.48 & 21 & 22 \\
\hline Ireland & 1981 & EVS & $\mathrm{Y}$ & 453 & 10 & 3.88 & 17 & 19 \\
\hline Ireland & 1988 & ISSP & Y & 349 & 3 & 3.38 & 23 & 24 \\
\hline Ireland & 1990 & EVS & $\mathrm{Y}$ & 324 & 3 & 3.28 & 29 & 30 \\
\hline Ireland & 1994 & ISSP & Y & 301 & 6 & 2.97 & 34 & 36 \\
\hline Ireland & 2001 & EB & $\mathrm{N}^{1}$ & 359 & 30 & 2.66 & 28 & 40 \\
\hline Ireland & 2006 & EB & $\mathrm{N}^{1}$ & 331 & 26 & 2.81 & 28 & 37 \\
\hline Ireland & 2011 & EB & $\mathrm{N}^{1}$ & 351 & 23 & 2.70 & 32 & 42 \\
\hline Italy & 1979 & $\mathrm{~EB}^{+}$ & $\mathrm{Y}$ & 363 & 4 & 2.05 & 64 & 67 \\
\hline Italy & 1981 & EVS & Y & 471 & 4 & 2.27 & 61 & 64 \\
\hline Italy & 1988 & ISSP & $\mathrm{Y}$ & 341 & 0 & 2.37 & 58 & 58 \\
\hline Italy & 1990 & EVS & $\mathrm{Y}$ & 712 & 7 & 2.40 & 52 & 56 \\
\hline Italy & 1994 & ISSP & $\mathrm{Y}$ & 327 & 1 & 2.24 & 65 & 65 \\
\hline Italy & 2001 & $\mathrm{~EB}$ & $\mathrm{Y}$ & 290 & 16 & 2.25 & 52 & 62 \\
\hline Italy & 2006 & EB & Y & 452 & 15 & 2.01 & 53 & 62 \\
\hline Italy & 2011 & EB & $\mathrm{Y}$ & 354 & 14 & 1.95 & 52 & 60 \\
\hline
\end{tabular}




\begin{tabular}{|c|c|c|c|c|c|c|c|c|}
\hline Country & Year & Survey & Selected & $\begin{array}{l}N(F \\
\text { aged } \\
15-49)\end{array}$ & $\begin{array}{l}\text { \% miss., } \\
\text { DKN, } \\
\text { other }\end{array}$ & $\begin{array}{l}\text { Mean } \\
\text { ideal FS }\end{array}$ & $\begin{array}{l}\% \text { with } 2- \\
\text { child } \\
\text { ideal }\end{array}$ & $\begin{array}{l}\text { \% 2-child } \\
\text { ideal } \\
\text { (adjusted) }\end{array}$ \\
\hline Latvia & 1990 & EVS & Y & 412 & 9 & 2.57 & 40 & 44 \\
\hline Latvia & 1996 & WVS & Y & 437 & 1 & 2.41 & 52 & 53 \\
\hline Latvia & 2006 & EB & Y & 361 & 5 & 2.36 & 53 & 56 \\
\hline Latvia & 2011 & EB & $\mathrm{Y}$ & 355 & 3 & 2.40 & 51 & 52 \\
\hline Lithuania & 1990 & EVS & Y & 329 & 10 & 2.57 & 42 & 47 \\
\hline Lithuania & 1997 & WVS & Y & 313 & 5 & 2.39 & 53 & 56 \\
\hline Lithuania & 2006 & EB & $\mathrm{Y}$ & 312 & 2 & 2.23 & 62 & 63 \\
\hline Lithuania & 2011 & EB & $\mathrm{Y}$ & 314 & 6 & 2.22 & 59 & 63 \\
\hline Luxembourg & 1979 & $\mathrm{~EB}^{+}$ & $\mathrm{N}^{2,4}$ & 83 & 4 & 2.22 & 60 & 63 \\
\hline Luxembourg & 2001 & EB & $\mathrm{N}^{1,2}$ & 192 & 19 & 2.17 & 60 & 75 \\
\hline Luxembourg & 2006 & $\mathrm{~EB}$ & $\mathrm{~N}^{2}$ & 168 & 16 & 2.22 & 54 & 64 \\
\hline Luxembourg & 2011 & EB & $\mathrm{N}^{2}$ & 158 & 8 & 2.26 & 58 & 63 \\
\hline Macedonia & 1998 & WVS & $\mathrm{Y}$ & 376 & 6 & 2.33 & 58 & 62 \\
\hline Macedonia & 2001 & WVS & $\mathrm{Y}$ & 361 & 3 & 2.53 & 51 & 52 \\
\hline Malta & 1983 & EVS & $\mathrm{N}^{2}$ & 163 & 10 & 2.71 & 33 & 37 \\
\hline Malta & 1991 & EVS & $\mathrm{N}^{2}$ & 124 & 14 & 3.01 & 32 & 38 \\
\hline Malta & 2006 & EB & $\mathrm{N}^{2}$ & 146 & 7 & 2.05 & 65 & 69 \\
\hline Malta & 2011 & EB & $\mathrm{N}^{2}$ & 181 & 5 & 1.89 & 58 & 61 \\
\hline Moldova & 1996 & WVS & Y & 324 & 2 & 2.64 & 42 & 43 \\
\hline Moldova & 2002 & WVS & $\mathrm{Y}$ & 376 & 6 & 2.48 & 51 & 54 \\
\hline Montenegro & 1996 & WVS & $\mathrm{N}^{2,4}$ & 85 & 2 & 3.08 & 24 & 24 \\
\hline Montenegro & 2001 & WVS & $\mathrm{N}^{2}$ & 346 & 4 & 3.05 & 30 & 31 \\
\hline Netherlands & 1979 & $\mathrm{~EB}^{+}$ & $\mathrm{Y}$ & 369 & 6 & 2.29 & 67 & 71 \\
\hline Netherlands & 1981 & EVS & $\mathrm{Y}$ & 521 & 10 & 2.54 & 50 & 56 \\
\hline Netherlands & 1988 & ISSP & $\mathrm{Y}$ & 649 & 4 & 2.60 & 49 & 52 \\
\hline Netherlands & 1990 & EVS & $\mathrm{Y}$ & 400 & 13 & 2.52 & 42 & 48 \\
\hline Netherlands & 1994 & ISSP & $\mathrm{Y}$ & 742 & 0 & 2.61 & 51 & 51 \\
\hline Netherlands & 2001 & $\mathrm{~EB}$ & $\mathrm{~N}^{1}$ & 341 & 20 & 2.21 & 55 & 69 \\
\hline Netherlands & 2006 & $\mathrm{~EB}$ & $\mathrm{~N}^{1}$ & 345 & 25 & 2.37 & 47 & 63 \\
\hline Netherlands & 2011 & $\mathrm{~EB}$ & $\mathrm{Y}$ & 271 & 16 & 2.25 & 58 & 69 \\
\hline Northern Ireland & 1979 & $\mathrm{~EB}+$ & $\mathrm{N}^{3,4}$ & 97 & 11 & 2.71 & 46 & 52 \\
\hline Northern Ireland & 1981 & EVS & $\mathrm{N}^{3}$ & 103 & 7 & 2.96 & 44 & 47 \\
\hline Northern Ireland & 1990 & EVS & $\mathrm{N}^{3}$ & 112 & 7 & 2.84 & 38 & 41 \\
\hline Northern Ireland & 1994 & ISSP & $\mathrm{N}^{3}$ & 194 & 5 & 2.79 & 44 & 46 \\
\hline Northern Ireland & 2001 & EB & $\mathrm{N}^{3}$ & 115 & 12 & 2.44 & 53 & 60 \\
\hline Northern Ireland & 2006 & $\mathrm{~EB}$ & $\mathrm{~N}^{1,3,4}$ & 94 & 24 & 2.54 & 42 & 56 \\
\hline Northern Ireland & 2011 & EB & $\mathrm{N}^{1,3,4}$ & 82 & 27 & 2.62 & 37 & 50 \\
\hline
\end{tabular}




\begin{tabular}{|c|c|c|c|c|c|c|c|c|}
\hline Country & Year & Survey & Selected & $\begin{array}{l}N(F \\
\text { aged } \\
15-49)\end{array}$ & $\begin{array}{l}\text { \% miss., } \\
\text { DKN, } \\
\text { other }\end{array}$ & $\begin{array}{l}\text { Mean } \\
\text { ideal FS }\end{array}$ & $\begin{array}{l}\% \text { with } 2- \\
\text { child } \\
\text { ideal }\end{array}$ & $\begin{array}{l}\text { \% 2-child } \\
\text { ideal } \\
\text { (adjusted) }\end{array}$ \\
\hline Norway & 1982 & EVS & $\mathrm{Y}$ & 291 & 11 & 2.62 & 45 & 51 \\
\hline Norway & 1990 & EVS & Y & 388 & 10 & 2.58 & 44 & 48 \\
\hline Norway & 1994 & ISSP & $\mathrm{Y}$ & 813 & 4 & 2.63 & 44 & 46 \\
\hline Norway & 1996 & WVS & $\mathrm{Y}$ & 372 & 10 & 2.65 & 38 & 42 \\
\hline Poland & 1990 & EVS & $\mathrm{Y}$ & 316 & 7 & 2.43 & 54 & 58 \\
\hline Poland & 1994 & ISSP & Y & 511 & 11 & 2.48 & 52 & 59 \\
\hline Poland & 1997 & WVS & $\mathrm{Y}$ & 347 & 9 & 2.47 & 48 & 52 \\
\hline Poland & 2006 & $\mathrm{~EB}$ & Y & 292 & 5 & 2.22 & 60 & 63 \\
\hline Poland & 2011 & EB & $\mathrm{Y}$ & 308 & 15 & 2.15 & 51 & 60 \\
\hline Portugal & 1990 & EVS & $\mathrm{Y}$ & 383 & 1 & 2.37 & 59 & 60 \\
\hline Portugal & 2001 & EB & Y & 295 & 7 & 2.20 & 62 & 67 \\
\hline Portugal & 2006 & EB & Y & 232 & 7 & 2.23 & 62 & 66 \\
\hline Portugal & 2011 & EB & $\mathrm{Y}$ & 286 & 6 & 2.00 & 60 & 64 \\
\hline Romania & 1993 & EVS & $\mathrm{Y}$ & 345 & 0 & 2.19 & 66 & 67 \\
\hline Romania & 1998 & WVS & $\mathrm{Y}$ & 439 & 1 & 2.01 & 65 & 65 \\
\hline Romania & 2006 & $\mathrm{~EB}^{*}$ & Y & 312 & 11 & 1.93 & 65 & 73 \\
\hline Romania & 2011 & EB & $\mathrm{Y}$ & 323 & 11 & 1.97 & 63 & 71 \\
\hline Russia & 1990 & WVS & $\mathrm{Y}$ & 711 & 8 & 2.48 & 49 & 53 \\
\hline Russia & 1994 & ISSP & Y & 887 & 3 & 2.14 & 67 & 69 \\
\hline Russia & 1995 & WVS & $\mathrm{Y}$ & 664 & 2 & 2.15 & 67 & 69 \\
\hline Serbia & 1996 & WVS & $\mathrm{Y}$ & 381 & 2 & 2.45 & 52 & 53 \\
\hline Serbia & 2001 & WVS & $\mathrm{Y}$ & 350 & 3 & 2.58 & 45 & 47 \\
\hline Slovakia & 1990 & WVS & $\mathrm{Y}$ & 162 & 0 & 2.28 & 62 & 62 \\
\hline Slovakia & 1991 & EVS & Y & 388 & 2 & 2.39 & 61 & 62 \\
\hline Slovakia & 1998 & WVS & Y & 316 & 1 & 2.29 & 63 & 63 \\
\hline Slovakia & 2006 & EB & Y & 387 & 8 & 2.12 & 62 & 67 \\
\hline Slovakia & 2011 & EB & $\mathrm{Y}$ & 320 & 8 & 2.10 & 58 & 63 \\
\hline Slovenia & 1992 & EVS & $\mathrm{Y}$ & 332 & 6 & 2.31 & 60 & 64 \\
\hline Slovenia & 1994 & ISSP & Y & 340 & 1 & 2.29 & 60 & 61 \\
\hline Slovenia & 1995 & WVS & Y & 340 & 2 & 2.39 & 54 & 56 \\
\hline Slovenia & 2006 & EB & Y & 374 & 6 & 2.39 & 55 & 58 \\
\hline Slovenia & 2011 & EB & $\mathrm{Y}$ & 274 & 11 & 2.38 & 57 & 64 \\
\hline Spain & 1981 & EVS & $\mathrm{Y}$ & 739 & 8 & 2.88 & 35 & 38 \\
\hline Spain & 1990 & EVS & Y & 924 & 4 & 2.43 & 53 & 55 \\
\hline Spain & 1990 & WVS & $\mathrm{Y}$ & 504 & 5 & 2.33 & 59 & 62 \\
\hline Spain & 1994 & ISSP & $\mathrm{Y}$ & 754 & 5 & 2.33 & 58 & 61 \\
\hline Spain & 1995 & EVS & $\mathrm{Y}$ & 361 & 4 & 2.39 & 57 & 60 \\
\hline Spain & 2000 & WVS & $\mathrm{Y}$ & 348 & 3 & 2.20 & 59 & 61 \\
\hline Spain & 2001 & EB & $\mathrm{Y}$ & 319 & 10 & 2.19 & 58 & 65 \\
\hline
\end{tabular}




\begin{tabular}{|c|c|c|c|c|c|c|c|c|}
\hline Country & Year & Survey & Selected & $\begin{array}{l}N(F \\
\text { aged } \\
15-49)\end{array}$ & $\begin{array}{l}\text { \% miss., } \\
\text { DKN, } \\
\text { other }\end{array}$ & $\begin{array}{l}\text { Mean } \\
\text { ideal FS } \\
\end{array}$ & $\begin{array}{l}\text { \% with 2- } \\
\text { child } \\
\text { ideal }\end{array}$ & $\begin{array}{l}\% \text { 2-child } \\
\text { ideal } \\
\text { (adjusted) }\end{array}$ \\
\hline Spain & 2006 & $\mathrm{~EB}$ & $\mathrm{Y}$ & 307 & 10 & 2.15 & 62 & 69 \\
\hline Spain & 2011 & EB & $\mathrm{Y}$ & 305 & 7 & 2.07 & 64 & 68 \\
\hline Sweden & 1982 & EVS & $\mathrm{Y}$ & 269 & 7 & 2.38 & 60 & 65 \\
\hline Sweden & 1990 & EVS & $\mathrm{Y}$ & 302 & 12 & 2.64 & 46 & 52 \\
\hline Sweden & 1994 & ISSP & $\mathrm{Y}$ & 410 & 4 & 2.47 & 59 & 62 \\
\hline Sweden & 1996 & WVS & $\mathrm{Y}$ & 308 & 7 & 2.65 & 48 & 52 \\
\hline Sweden & 1999 & EVS & $\mathrm{Y}$ & 307 & 10 & 2.61 & 48 & 53 \\
\hline Sweden & 2001 & $\mathrm{~EB}$ & $\mathrm{Y}$ & 277 & 16 & 2.42 & 50 & 60 \\
\hline Sweden & 2006 & EB & $\mathrm{Y}$ & 255 & 15 & 2.52 & 46 & 54 \\
\hline Sweden & 2011 & EB & $\mathrm{Y}$ & 266 & 10 & 2.39 & 51 & 57 \\
\hline Switzerland & 1989 & WVS & $\mathrm{Y}$ & 440 & 9 & 2.63 & 53 & 58 \\
\hline Switzerland & 1996 & WVS & $\mathrm{Y}$ & 378 & 8 & 2.37 & 61 & 67 \\
\hline Switzerland & 2002 & SHP $^{5}$ & $\mathrm{Y}$ & 1089 & 8 & 2.28 & 66 & 72 \\
\hline Switzerland & 2005 & $\mathrm{SHP}^{5}$ & $\mathrm{Y}$ & 2038 & 8 & 2.18 & 67 & 73 \\
\hline Ukraine & 1996 & WVS & $\mathrm{Y}$ & 1003 & 5 & 2.14 & 64 & 68 \\
\hline Ukraine & 2007 & DHS & $\mathrm{Y}$ & 6841 & 4 & 1.97 & 61 & 63 \\
\hline United Kingdom & 1979 & $\mathrm{~EB}^{+}$ & $\mathrm{Y}$ & 330 & 8 & 2.25 & 66 & 72 \\
\hline United Kingdom & 1981 & EVS & $\mathrm{Y}$ & 390 & 7 & 2.34 & 64 & 69 \\
\hline United Kingdom & 1988 & WVS & $\mathrm{Y}$ & 447 & 9 & 2.38 & 64 & 71 \\
\hline United Kingdom & 1990 & EVS & $\mathrm{Y}$ & 457 & 8 & 2.39 & 58 & 63 \\
\hline United Kingdom & 1994 & ISSP & $\mathrm{Y}$ & 307 & 7 & 2.32 & 66 & 72 \\
\hline United Kingdom & 1998 & WVS & $\mathrm{Y}$ & 355 & 6 & 2.32 & 62 & 66 \\
\hline United Kingdom & 2001 & $\mathrm{~EB}$ & $\mathrm{Y}$ & 354 & 17 & 2.36 & 51 & 61 \\
\hline United Kingdom & 2006 & $\mathrm{~EB}$ & $\mathrm{~N}^{1}$ & 280 & 23 & 2.49 & 40 & 52 \\
\hline United Kingdom & 2011 & EB & $\mathrm{N}^{1}$ & 293 & 21 & 2.37 & 45 & 58 \\
\hline
\end{tabular}

\section{Notes}

$+\quad$ In the original dataset nonresponse and non-numerical responses combined with the respondents stating an ideal of "no children"; data adjusted in the table assuming that no respondents expressed an ideal of having no children

* In the original dataset the responses were shifted by one child; data and computations corrected here

1 The share of non-response and non-numerical responses reached $19 \%$ or higher

2 Small countries with population below 1 million excluded from the analysis

3 Data for Northern Ireland excluded from the analysis

4 Surveys with fewer than 100 female respondents aged 15-49 excluded from the analysis

$5 \quad$ Data not weighted

Conj. Enquête conjoncture

Int. Fec. Enquête intentions de fécondité

Fecond Enquête Fecond 
Appendix 2: Ideal family size in European regions: Main results for selected time periods

\begin{tabular}{|c|c|c|c|c|c|c|c|c|c|c|c|c|c|c|c|}
\hline \multicolumn{3}{|c|}{ Western Europe } & \multirow{3}{*}{$\begin{array}{c}\text { 2-child ideal: } \\
\text { \# surveys } \\
\text { with }>\mathbf{5 0 \%} \\
\end{array}$} & \multirow[b]{3}{*}{$\begin{array}{c}\text { MIFS } \\
\text { (average) }\end{array}$} & \multirow[b]{3}{*}{$\begin{array}{c}\text { Min } \\
\text { MIFS }\end{array}$} & \multirow[b]{3}{*}{$\begin{array}{c}\text { Max } \\
\text { MIFS } \\
\end{array}$} & \multirow[b]{3}{*}{$\begin{array}{c}\text { Median } \\
\text { IFS }\end{array}$} & \multirow[b]{3}{*}{ Stdev } & \multicolumn{7}{|c|}{$\begin{array}{l}\text { Average share of respondents with a given family size } \\
\text { ideal }\end{array}$} \\
\hline & & & & & & & & & \multicolumn{4}{|c|}{ Non-adjusted } & \multicolumn{3}{|c|}{ Adjusted } \\
\hline & $\begin{array}{c}\# \\
\text { surveys }\end{array}$ & $\begin{array}{c}\# \\
\text { countries }\end{array}$ & & & & & & & $\% 2$ & $\% 0+1$ & $\% 3+$ & $0+1$ vs. $3+$ & $\% 2$ & $\% 0+1$ & $\% 3+$ \\
\hline 1979-83 & 12 & 7 & 7 & 2.44 & 2.25 & 2.65 & 2.41 & 0.14 & 54 & 3 & 35 & 0.10 & 59 & 4 & 38 \\
\hline $1987-94$ & 15 & 8 & 6 & 2.54 & 2.32 & 2.66 & 2.58 & 0.10 & 50 & 3 & 40 & 0.08 & 54 & 3 & 43 \\
\hline 1995-2002 & 11 & 7 & 6 & 2.47 & 2.19 & 2.65 & 2.51 & 0.14 & 50 & 4 & 36 & 0.11 & 55 & 4 & 40 \\
\hline 2006-11 & 11 & 5 & 6 & 2.42 & 2.19 & 2.72 & 2.48 & 0.15 & 51 & 5 & 35 & 0.14 & 56 & 5 & 38 \\
\hline
\end{tabular}

\begin{tabular}{|c|c|c|c|c|c|c|c|c|c|c|c|c|c|c|c|}
\hline \multirow{2}{*}{\multicolumn{3}{|c|}{ German-speaking countries }} & \multirow{3}{*}{$\begin{array}{c}\text { 2-child ideal: } \\
\text { \# surveys } \\
\text { with }>\mathbf{5 0 \%} \\
\end{array}$} & \multirow[b]{3}{*}{$\begin{array}{c}\text { MIFS } \\
\text { (average) }\end{array}$} & \multirow[b]{3}{*}{$\begin{array}{c}\text { Min } \\
\text { MIFS }\end{array}$} & \multirow[b]{3}{*}{$\begin{array}{c}\text { Max } \\
\text { MIFS } \\
\end{array}$} & \multirow[b]{3}{*}{$\begin{array}{c}\text { Median } \\
\text { IFS } \\
\end{array}$} & \multirow[b]{3}{*}{ Stdev } & \multicolumn{7}{|c|}{$\begin{array}{l}\text { Average share of respondents with a given family size } \\
\text { ideal }\end{array}$} \\
\hline & & & & & & & & & \multicolumn{4}{|c|}{ Non-adjusted } & \multicolumn{3}{|c|}{ Adjusted } \\
\hline & $\begin{array}{c}\# \\
\text { surveys }\end{array}$ & $\begin{array}{c}\# \\
\text { countries }\end{array}$ & & & & & & & $\% 2$ & $\% 0+1$ & \%3+ & $\begin{array}{c}0+1 \text { vs. } \\
3+\end{array}$ & $\% 2$ & $\% 0+1$ & \%3+ \\
\hline $1987-94$ & 8 & 4 & 8 & 2.18 & 1.94 & 2.63 & 2.12 & 0.22 & 65 & 10 & 21 & 0.47 & 67 & 10 & 22 \\
\hline 1995-2002 & 5 & 4 & 5 & 2.17 & 1.78 & 2.41 & 2.28 & 0.24 & 61 & 10 & 19 & 0.55 & 67 & 12 & 21 \\
\hline 2006-11 & 8 & 4 & 8 & 2.12 & 1.98 & 2.20 & 2.14 & 0.08 & 59 & 11 & 20 & 0.56 & 65 & 12 & 22 \\
\hline
\end{tabular}

\begin{tabular}{|c|c|c|c|c|c|c|c|c|c|c|c|c|c|c|c|}
\hline \multirow[t]{3}{*}{ Central Eur } & \multirow[b]{3}{*}{$\begin{array}{c}\# \\
\text { surveys }\end{array}$} & \multirow[b]{3}{*}{$\begin{array}{c}\# \\
\text { countries }\end{array}$} & \multirow{3}{*}{$\begin{array}{c}\text { 2-child ideal: } \\
\text { \# surveys } \\
\text { with }>\mathbf{5 0 \%}\end{array}$} & \multirow[b]{3}{*}{$\begin{array}{c}\text { MIFS } \\
\text { (average) }\end{array}$} & \multirow[b]{3}{*}{$\begin{array}{c}\text { Min } \\
\text { MIFS }\end{array}$} & \multirow[b]{3}{*}{$\begin{array}{l}\text { Max } \\
\text { MIFS }\end{array}$} & \multirow[b]{3}{*}{$\begin{array}{l}\text { Median } \\
\text { IFS }\end{array}$} & \multirow[b]{3}{*}{ Stdev } & \multicolumn{7}{|c|}{$\begin{array}{l}\text { Average share of respondents with a given family size } \\
\text { ideal }\end{array}$} \\
\hline & & & & & & & & & \multicolumn{4}{|c|}{ Non-adjusted } & \multicolumn{3}{|c|}{ Adjusted } \\
\hline & & & & & & & & & $\% 2$ & $\% 0+1$ & \%3+ & $\begin{array}{c}0+1 \text { vs. } \\
3+\end{array}$ & $\% 2$ & $\% 0+1$ & \%3+ \\
\hline $1987-94$ & 15 & 8 & 12 & 2.35 & 2.14 & 2.57 & 2.31 & 0.13 & 59 & 5 & 33 & 0.14 & 61 & 5 & 34 \\
\hline 1995-2002 & 9 & 9 & 7 & 2.39 & 2.07 & 2.67 & 2.39 & 0.15 & 55 & 5 & 36 & 0.15 & 57 & 5 & 38 \\
\hline 2006-11 & 17 & 9 & 15 & 2.25 & 1.93 & 2.53 & 2.22 & 0.16 & 57 & 8 & 28 & 0.29 & 61 & 9 & 30 \\
\hline
\end{tabular}




\begin{tabular}{|c|c|c|c|c|c|c|c|c|c|c|c|c|c|c|c|}
\hline \multicolumn{3}{|c|}{ Eastern and South-eastern Europe } & \multirow{3}{*}{$\begin{array}{c}\text { 2-child ideal: } \\
\text { \# surveys } \\
\text { with }>\mathbf{5 0 \%} \\
\end{array}$} & \multirow[b]{3}{*}{$\begin{array}{c}\text { MIFS } \\
\text { (average) }\end{array}$} & \multirow[b]{3}{*}{$\begin{array}{c}\text { Min } \\
\text { MIFS }\end{array}$} & \multirow[b]{3}{*}{$\begin{array}{c}\text { Max } \\
\text { MIFS } \\
\end{array}$} & \multirow[b]{3}{*}{$\begin{array}{c}\text { Median } \\
\text { IFS }\end{array}$} & \multirow[b]{3}{*}{ Stdev } & \multicolumn{7}{|c|}{$\begin{array}{l}\text { Average share of respondents with a given family size } \\
\text { ideal }\end{array}$} \\
\hline & & & & & & & & & \multicolumn{4}{|c|}{ Non-adjusted } & \multicolumn{3}{|c|}{ Adjusted } \\
\hline & $\begin{array}{c}\# \\
\text { surveys } \\
\end{array}$ & $\begin{array}{c}\# \\
\text { countries } \\
\end{array}$ & & & & & & & $\% 2$ & $\% 0+1$ & $\% 3+$ & $\begin{array}{c}0+1 \text { vs. } \\
3+ \\
\end{array}$ & $\% 2$ & $\% 0+1$ & $\% 3+$ \\
\hline $1987-94$ & 6 & 4 & 5 & 2.24 & 2.00 & 2.48 & 2.18 & 0.17 & 62 & 9 & 27 & 0.34 & 63 & 9 & 28 \\
\hline 1995-2002 & 13 & 9 & 10 & 2.35 & 2.01 & 2.64 & 2.36 & 0.21 & 56 & 8 & 33 & 0.24 & 58 & 8 & 34 \\
\hline 2006-11 & 6 & 4 & 5 & 2.09 & 1.93 & 2.54 & 2.00 & 0.21 & 62 & 13 & 18 & 0.72 & 68 & 14 & 19 \\
\hline \multicolumn{3}{|c|}{ Southern Europe } & \multirow{3}{*}{$\begin{array}{c}\text { 2-child ideal: } \\
\text { \# surveys } \\
\text { with }>\mathbf{5 0 \%} \\
\end{array}$} & \multirow[b]{3}{*}{$\begin{array}{c}\text { MIFS } \\
\text { (average) }\end{array}$} & \multirow[b]{3}{*}{$\begin{array}{c}\text { Min } \\
\text { MIFS }\end{array}$} & \multirow[b]{3}{*}{$\begin{array}{c}\text { Max } \\
\text { MIFS } \\
\end{array}$} & \multirow[b]{3}{*}{$\begin{array}{c}\text { Median } \\
\text { IFS }\end{array}$} & & \multicolumn{7}{|c|}{$\begin{array}{l}\text { Average share of respondents with a given family size } \\
\text { ideal }\end{array}$} \\
\hline & & & & & & & & & \multicolumn{4}{|c|}{ Non-adjusted } & \multicolumn{3}{|c|}{ Adjusted } \\
\hline & $\begin{array}{c}\# \\
\text { surveys } \\
\end{array}$ & $\begin{array}{c}\# \\
\text { countries } \\
\end{array}$ & & & & & & Stdev & $\% 2$ & $\% 0+1$ & $\% 3+$ & $\begin{array}{c}0+1 \text { vs. } \\
3+ \\
\end{array}$ & $\% 2$ & $\% 0+1$ & $\% 3+$ \\
\hline $1987-94$ & 7 & 3 & 7 & 2.35 & 2.24 & 2.43 & 2.37 & 0.06 & 58 & 6 & 33 & 0.20 & 60 & 7 & 34 \\
\hline 1995-2002 & 6 & 4 & 5 & 2.30 & 1.95 & 2.56 & 2.23 & 0.14 & 56 & 7 & 30 & 0.25 & 60 & 8 & 32 \\
\hline \multicolumn{16}{|c|}{ detail $2006+11$} \\
\hline 2006 & 4 & 4 & 3 & 2.20 & 2.01 & 2.40 & 2.19 & 0.14 & 57 & 10 & 25 & 0.40 & 62 & 11 & 27 \\
\hline 2011 & 4 & 4 & 4 & 2.08 & 1.95 & 2.29 & 2.03 & 0.13 & 58 & 15 & 19 & 0.78 & 63 & 16 & 21 \\
\hline
\end{tabular}




\section{VIENNA INSTITUTE OF DEMOGRAPHY}

\section{Working Papers}

Sander, Nikola, Guy J. Abel, Ramon Bauer and Johannes Schmidt, Visualising Migration Flow Data with Circular Plots, VID Working Paper 2/2014.

Barakat, Bilal, Revisiting the History of Fertility Concentration and its Measurement, VID Working Paper 1/2014.

Buber-Ennser, Isabella, Attrition in the Austrian Generations and Gender Survey, VID Working Paper 10/2013.

De Rose, Alessandra and Maria Rita Testa, Climate Change and Reproductive Intentions in Europe, VID Working Paper 09/2013.

Di Giulio, Paola, Thomas Fent, Dimiter Philipov, Jana Vobecká and Maria WinklerDworak, State of the Art: A Family-Related Foresight Approach, VID Working Paper 08/2013.

Sander, Nikola, Guy J. Abel and Fernando Riosmena, The Future of International Migration: Developing Expert-Based Assumptions for Global Population Projections, VID Working Paper 07/2013.

Caselli, Graziella, Sven Drefahl, Marc Luy and Christian Wegner-Siegmundt, Future Mortality in Low-Mortality Countries, VID Working Paper 06/2013.

Basten, Stuart, Tomáš Sobotka and Kryštof Zeman, Future Fertility in Low Fertility Countries, VID Working Paper 05/2013.

Sharygin, Ethan, The Carbon Cost of an Educated Future: A Consumer Lifestyle Approach, VID Working Paper 04/2013.

Winkler-Dworak, Maria and Heiner Kaden, The Longevity of Academicians: Evidence from the Saxonian Academy of Sciences and Humanities in Leipzig, VID Working Paper 03/2013.

Feichtinger, Gustav, Alexia Prskawetz, Andrea Seidl, Christa Simon and Stefan Wrzaczek, Do Egalitarian Societies Boost Fertility?, VID Working Paper 02/2013.

Muttarak, Raya, Is it (dis)Advantageous to Have Mixed Parentage? Exploring Education \& Work Characteristics of Children of Interethnic Unions in Britain?, VID Working Paper 01/2013.

Testa, Maria Rita and Stuart Basten, Have Lifetime Fertility Intentions Declined During the "Great Recession"?, VID Working Paper 09/2012.

The Vienna Institute of Demography Working Paper Series receives only limited review. Views or opinions expressed herein are entirely those of the authors. 